This document has been digitised by the Bodleian Libraries, University of Oxford as part of the Oxford Digital Library for Forestry (ODLF) project.

Digitisation of this document has been made possible through the support of the Andrew W. Mellon Foundation.

The original contents of this document remain the copyright of the University of Oxford (http://www.ox.ac.uk/).

For enquiries please contact: enquiries.rsl@bodleian.ox.ac.uk 


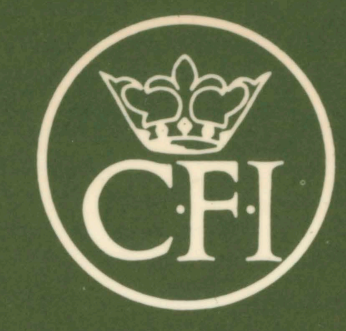

\section{C.F.I. OCCASIONAL PAPERS}

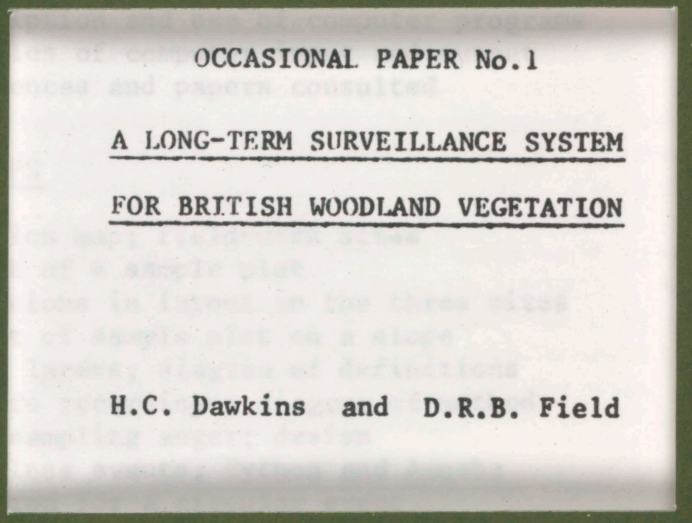

DEPARTMENT OF FORESTRY

COMMONWEALTH FORESTRY INSTITUTE

UNIVERSITY OF OXFORD 
2.4 The immediate stimulus for the present project was the realisation that most British forests were - or would shortly be - going through some drastic changes as a result of afforestation or changes of dominant species, and yet little or no statistically representative surveillance was in hand, or even planned. For instance, we found cases of being unable to trace or measure the onset and spread of quite obvious man-induced erosion, of damage by grey squirrel, invasion by turkey oak and sycamore, disappearance locally of English oak, and the spread (or retreat) of herbaceous flora and dependent wildlife into (or out of) pure conifers. Still less was it possible to make predictions of the future composition of polyspecific woodland in nature reserves or to detect the first signs of relatively longterm changes in a production-forest soil. In 1973 we knew of only one attempt to set up a comprehensive vegetation surveillance system in Britain (Bunce \& Shaw, 1973), and in our opinion this made insufficient provision for precise relocation of the observation points in future years. We cansidered these to be essential characteristics of a method designed to detect changes, when sampling error between occasions must be of the smallest possible, and must be unconfounded with the ordinary spatial sampling error of any scattered sample units.

2.5 The project was planned and financed under the following objective:

"To devise a system for permanent low-fraction sampling

of polyspecific woodland, capable of diagnosing and

predicting long-term changes in specific composition and

growth over large areas."

(This objective is critically defined in para. $\underline{8.15}$ )

Much of this objective went no further than what was already provided as a matter of routine by CFI systems elsewhere. However most CFI systems confine their observations to the traditional dimensions of timber production, namely tree numbers and volumes (stand, recruitment and mortality), health and growth-rate, often with some qualitative information on other flora and soil. The present project had a wider a im, namely to provide an early indication of the increase or decrease of any plant species or vegetative condition including the soil, particularly when likely to be of ecological or economic importance. Moreover it aimed to be diagnostic, correlating changes with each other so as to suggest causes, consequences or any other ecological

hypotheses. The predictive element was seen as following from modelling based on observations collected from the plots, but not until they had been re-observed on sufficient (at least two) future occasions. Several forest stand models have already been tested on uneven-aged stands as we 11 as on plantations, by other workers.

2.6 The stated objective raised an insoluble paradox; information had to be collected on the contemporary state of phenomena before they could be identified. Obviously this is only possible if there is correlation between ecological events, and particularly between some unknown change yet to come and a set of observations already made. The scheme described here depends heavily and hopefully on such correlation, and therefore selects for observation those phenomena believed to have indicative or correlative value. The project is indeed based on only one, though dual, hypothesis; that changes will occur and that posterity 
will want to know about them, especially their history, causes and consequences.

2.7 There seemed, in this surveillance system, to be three groups of problems;

.1 Statistical; how to achieve unbiassed representation and distribution, and what size and shape of sampling units to use.

.2 Ecological; what to record; the problem of unlimited phenomena of unpredictable importance.

.3 Temporal; how to ensure that the observations remain easily accessible and unambiguous.

2.8 The statistical problem and the response to it adopted for the present scheme was outlined in a previous paper (Dawkins, 1971). Briefly, sample units are systematically distributed for at least two reasons :

1 They are intended as the first stage of a long-term CFI system (Ware \& Cunia, 1962) using sampling with partial replacement ( $S P R$ ), or at least to allow interpolative supplementary sampling. Regular spacing forms an efficient grid within which to place future, possibly random sample units, temporary or permanent.

.2 The most likely alternative, stratified random sampling, cannot suit all purposes because the bases of stratification not only differ between purposes, but could seriously change with time. There only has to be some modification of the area sampled or of the area under different crops, or some new facts coming to light (e.g. on soils), and whatever statistical blocking was initially used could become inefficient or meaningless. No such effect can occur with systematic sampling.

It would be nice to give a third reason:

.3 Theoretical study; As a reason however it would be bogus. The field samples were laid out before the theoretical study was completed. The latter is reported in Appendix 1, and further discussion is given in paras. 3.10 and 3.11 .

2.9 Frequency, shape and size of sample units were decided mostly on arbitary or practical grounds, but in the light of considerable field experience; the details are described in $\underline{3.7}$ and $\underline{3.8}$.

Placement of sample units on intersections of the $100 \mathrm{~m}$ National Grid was one of many responses to the "temporal" problem described in $\underline{3.4}$ and $\underline{3.5}$.

2.10 The ecological problems seemed more intractable than the statistical, due to the unlimited nature of what may be observed, the limited nature of human effort, and the unpredictability of what may turn out to be useful. Seeking the correlates mentioned in 2.6, our scheme made the following assumptions: 
2.10.1 That most changes in performance and constituent species (animal or plant) of woodland are likely to be correlated with changes in the state of the larger or more frequent trees, which can be sufficiently quantitatively defined by species, stand basal-area, simple dimensions, growth-rate, and some estimate of competition and of cover;

.2 That certain features of ground flora and soil surface are likely to be indicative of conditions many years past as well as of the present;

.3 That any serious soil changes, such as loss or improvement of "fertility" (see 2.11), are likely to be detectable by observations within the top $30 \mathrm{~cm}$ of profile.

2.11 The most serious among the ecological problems was that fertility or site-quality has no single meaning. Traditional European site-class methods and modern CFI can detect a long-term decrease of growth or yield only if the same set of genotypes continues to be grown on a site over more than one rotation. This is rarely likely, either because of deliberate eugenics or even a change of species, or by the ordinary processes of succession. For the purposes of this project we considered that erosion, compaction or falling $\mathrm{pH}$ would constitute deterioration of a site, and so would falling species diversity (not simple to define), though not necessarily if such a trend was only local or cyclical.

2.12 Another problem of ecological observation was that of climate. Not only plant and animal but also soil characters fluctuate considerabiy from year to year and even by the week or day - let alone more obviously between seasons. Yet we wished to observe each plot only once or twice to minimise physical interference, and so in five months fieldwork in a particular area might have to record some plots at the end of May and others in early September. Hence it seemed futile to record, for example, fruiting agarics, illumination, soil moisture, or insect activity.

Some soil characters we rejected because in our very stony conditions their observation would have caused too much damage; they included 5 oil profile descriptions and measures of compaction or bulk density.

2.13 In the long run, by definition, it was the temporal problems that needed most attention. We accepted that perpetuation cannot be achieved by recommendation nor by administrative instruction. Our aims were:

1 That the information collected should be sufficiently useful and interesting to be worth looking at and to be positively sought by future researchers and managers of woodland;

.2 That the plots should be easily found for many years to come by those concerned with recurrent observation, though unnoticeable to all other forms of life;

.3 That the records also should be easily found, be intellectually as well as physically accessible, and be informative to any researcher or manager without any other source of knowledge of the project.

2.14 In summary, we wished to provide the information that future ecologists or managers would require when they ask the so-common question: "How has this feature changed over the past umpteen years and what might have been the causes of that change?" 
In tackling these three objectives we were acutely conscious of a paradox (worse perhaps than that of collecting information on unidentified phenomena)- namely this - that we aimed to set up a system of "permanent" surveillance knowing that it could never be so. Needs are sure to change and so are theories and techniques. Moreover few researchers and no administrators consider their predecessor's methods as good as their own - they would not be worth their pay if they did. Hence the parts of this work which matter are:

2.14.1 The 1973-75 inventory itself, as a base-line for future study of the three woods sampled;

.2 The presentation to ecologists of just one method of longterm surveillance of forest vegetative ecosystems.

Both are presented in the hopes that they will be used and will lead to something better. 


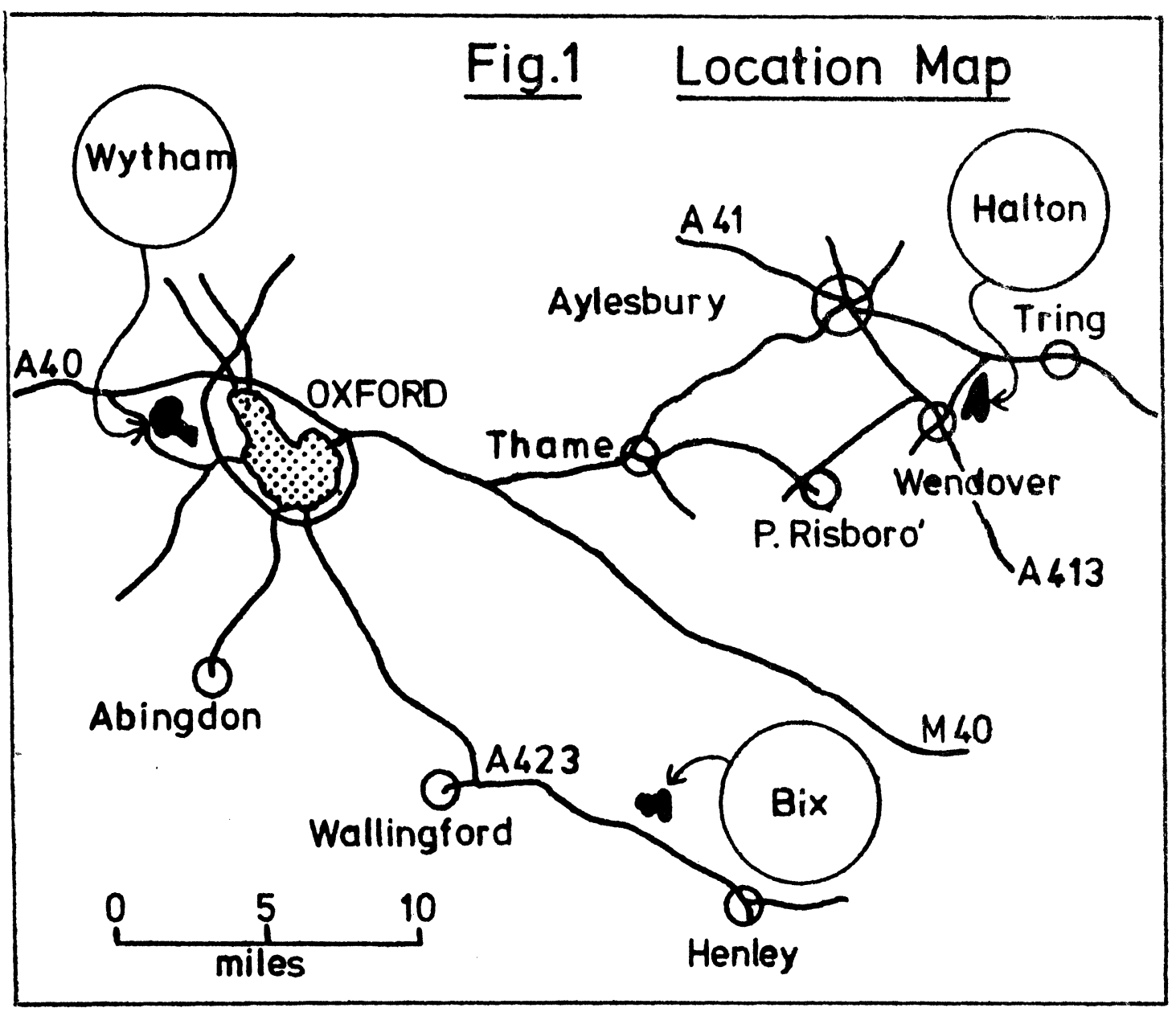


CHAPTER 3

THEORY AND DEVELOPMENT OF METHODS

3.1 Although we had clear ideas on at least some of the information which would be required in long-term ecosystem surveillance, we were even more aware of the practical difficulties. In this case the desirable was a record of the dimensions (situation, size, age etc.) of all organisms and of the changeable properties of the soil, but the practicable was constrained by the limited skills and time at our disposal. As usual, the compromises were decided subjectively, and in this chapter we describe the arguments behind them and the decisions taken.

\subsection{Selection of Sites. The features we sought were:}

.1 Woodland of mixed type, all the way from semi-natural to monoculture and from amenity to production. The greater the heterogeneity, with broadleaves and conifers, highforest and scrub, the more useful for our purpose.

.2 An assured future in corporate ownership, with a high likelihood of remaining as woodland.

.3 A measure of known history and precise cartography, with information on past use, and cover by 1:2500 ordnance maps marked with the National Grid.

.4 Areas over 100 ha. While extent is immaterial to the sampling method, a major use of the observations was to be comparison of sampling intensities with respect to both sampling error and efficiency of detection. Hence a minimum of 100 plots was considered important to allow a reasonable measure of subsampling. Plots were intended to be sited $100 \mathrm{~m}$ apart.

5 Proximity to 0xford. We originally intended to use part of the Dean and of the Ebworth woods; both were judged too far.

3.3 The Study Woods. Eventually three sites were selected for recording (Fig. 1). Two of them were in some sense nature reserves which meant that they were likely to retain so-called 'natural'

(i.e. polyspecific and uneven-aged) woodland for the foreseeable future.

1 1973: In the first year, a wooded Nature Reserve near Henley was selected. This site, of 100 hectares, is owned by the Berks, Bucks and Oxon Naturalists' Trust (BBONT), and is variously known as Bix Bottom, the Warburg Reserve and Page's Bottom. It is south of Maidensgrove, near Nettlebed, Oxfordshire, about $30 \mathrm{~km}$ (20 miles) $\mathrm{SE}$ of Oxford. There were 101 grid intersection points at which plots could be marked out.

Bix (as it will be called in this description) contains a great variety of forest types, including both hardwoods and conifers, some newly-planted areas and some old established woodland. 
The soil was mostly a rendzina over the Upper Chalk, and extremely flinty.

3.3.2 1974: An area of woodland owned by Oxford University was chosen. This, known as Wytham Wood or the Woods of Hazel. is about $8 \mathrm{~km}$ ( $5 \mathrm{miles}$ ) NW of Oxford. Like Bix, Wytham contains both conifers and hardwoods, and includes planted areas, old woodland, coppice and scrub. It varies more in soil type, including heavy clays, acid sandy loams, and some shallow soils over limestone. The area is about $320 \mathrm{hp}$ and was therefore less heavily sampled. Every $100 \mathrm{~m} \mathrm{grid}$ point was surveyed, but plots were laid out only at alternat. points, giving 163 plots.

Because many other workers in this Wood required conspiceou grid point markers for reference, the plots were sited at short distances from the associated grid points, so that they should not receive untypical wear and tear. (See Fig. '

.3 1975: For the third field recording, a Forestry Commissior Wood was selected. The nearest to Oxford that fitted the criteria was Halton Wood in Buckinghamshire, just north of Wendover, about $50 \mathrm{~km}$ ( $30 \mathrm{miles}$ ) E. of Oxford. This had the disadvantage of being for the most part on similar soils to those at Bix, although clay-with-flints was common here, but contained a wider variety of forest types, including productive Norway spruce.

National Grid maps were not available for the northernmost portion, which was omitted, but the remaining 250 hectares provided 123 plots sited at alternate $100 \mathrm{~m}$ grid points.

Halton Wood is open to the public, having two car parks within the wood; amenity is considered an important part of the management task.

3.4 Re-locatable plots. We required plots to be easily re-locatable by future investigators or management, but undetectable by random, irrelevant or mischievous encounter. There seemed in be two essentials:

1 That plot co-ordinates should be definable from precise features marked on maps unlikely to be lost;

.2 That plots should be precisely marked on the ground, the marks to be concealed and durable.

3.5 Map-siting. The first requirement cut out, as reference points, almost all artefacts on the ground, as well as some natural features such as streams whose courses or banks might easily be modified. In our somewhat vague relief it left only latitude/longitude or the National Grid. We used the latter and sited all plots at $100 \mathrm{~m} \mathrm{N.G.} \mathrm{intersection}$ or at constant distances and bearings from them. Obviously the principal constraint was our limited skill and time for survey, which in practice led to accuracies from $\pm 1 \mathrm{~m}$ on easy ground, to $\pm 3 \mathrm{~m}$ in the worst of thickets or on steep slopes.

3.6 Monumentation, to be concealed, had to be underground and 
therefore we presumed it must be metallic for ease of detection. For permanence we considered brass, copper or steel variously protected by galvanising, bitumen or plastic sleeve, or stainless. We also considered similarly protected magnetized rod (Wadsworth, 1970), but decided this would be beyond our budget in the quantities we required. In the end, for economy, we used discarded mild-steel electrical conduit, untreated but encasing a stainless steel tube of smaller diameter, both driven vertically into the ground. The mild steel should last at least three decades in these soils and is easily detectable; the stainless steel is less easily detectable but should be permanent. We counted on technical improvements to detection devices by the time the mild-steel disappears. Vertical tube was used rather than electronically superior horizontal plate because we suspected the latter would be more liable to shifting by deep-rutting tractor wheels or dragging logs.

3.7 Plot Shape. The choice was between strips (transects), square plots (quadrats) or circular plots (circlets).

Transects were not used because in woodland they are demonstrably (Dawkins, 1952) less economical than quadrats in terms of area of sample that must be observed for a given sampling error, and for a given efficiency of detection. The relative economy of access to transects low travel time per area observed - was not considered significant for the present study, conducted in small areas of well-roaded woods.

Circlets have the advantage in economy of monumentation, but were not used for the primary recording unit (but see 3.16 and 5.13 ) because their perimeter is laborious to locate precisely in continuouslyrecruiting woodland, their shape makes it difficult to subsample conformably, and their centre tends to be severely trampled during assessment.

Square quadrats were therefore used (Fig.2) and are always referred to as plots.

3.8 Plot Size. The primary requirement in this project was to observe long-term changes in the dominant vascular plants, especially the trees, rather than in their associates which were deemed largely dependent or correlated. Plots were therefore made 10 x 10 metres ( 0.01 ha or 1 are) to conform with the unit of area basic to European forest site-quality assessment. This is the area within which the helght of the tree of greatest diameter, provided it has not been overtopped, is indicative of productive quality of the site for that species. (UK reference, Hamilton \& Christie, 1971). Provision was made, however, for extending plots to $20 \times 20$ metres or any subdivision thereof it observations seemed to require larger plots, and as an insurance up to four actual or potential dominants ("leading trees", para. 5.2) were measured in each $10 \times 10 \mathrm{~m}$ plot.

We considered using Bunce \& Shaw's (1973) also Sykes \& Horrill's (1976) method of concentric plots, in which species extra to those in an initially small quadrat are recorded in expanding aureoles, but did not do 80 because we wanted all our information to relate to the whole plot area. We feared that correlations might be jeopardized if contemporary observations were not coincident in space as well as time.

3.9 Plot Frequency. Theoretical considerations suggested that at least 100 samples were needed for "validation" checks. Experience at 


\section{Fig.2 Sample plot layout (Halton)}

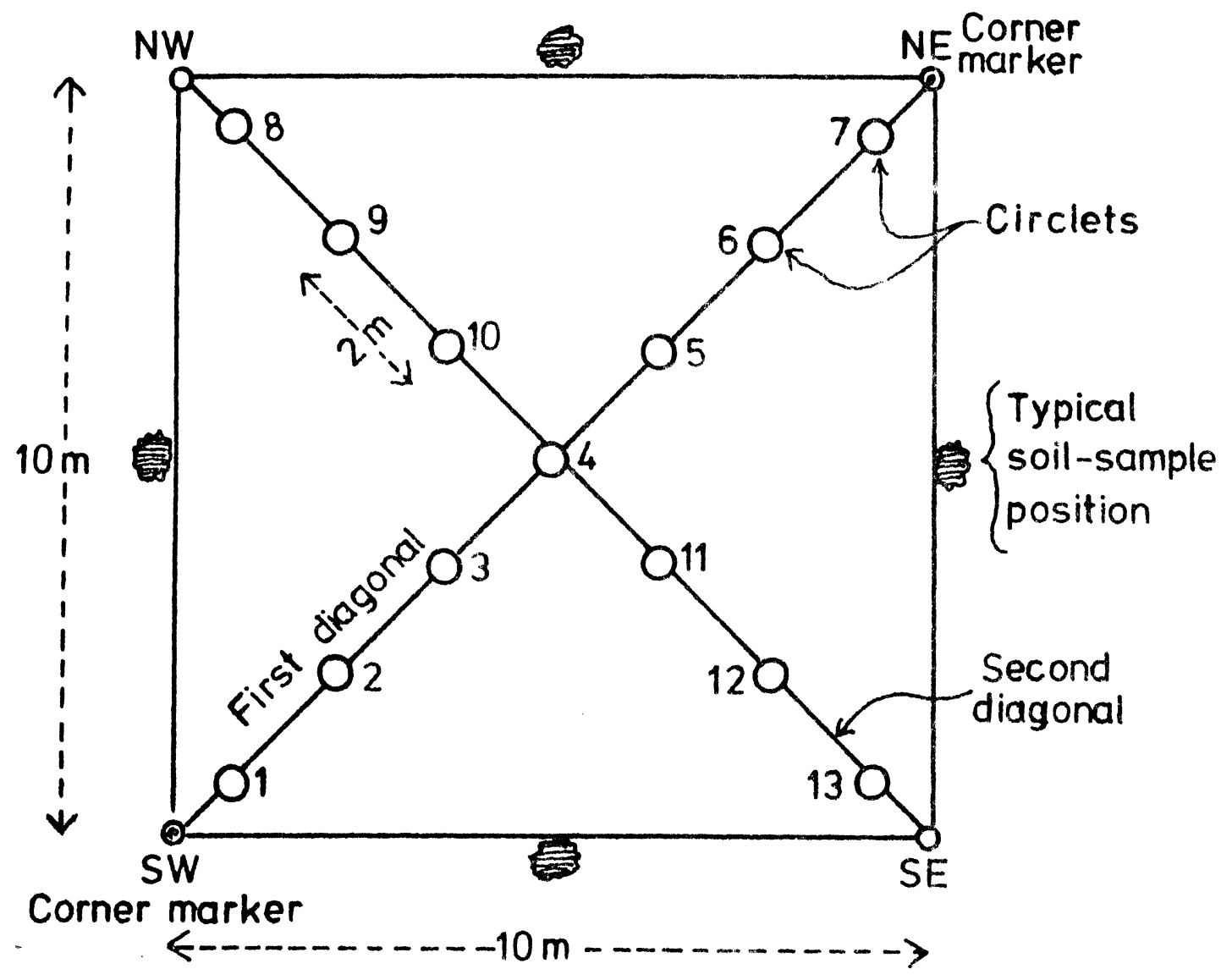


Bix suggested that something less than 200 plots could be recorded in one summer with the labour available.

At Bix, one plot was recorded at each $100 \mathrm{~m}$ grid intersection. At Wytham and Halton, plots were placed at alternate intersections which gave 163 and 123 plots respectively. We thought it better to sample a wider area at a lower fraction than to cover only part: of each site.

3.10 Systematic Sampling. The statistical reasons for using a systematic distribution of plots have already beon given ia para. 2.8, but there was also a spatial. one peculiar to our objectives. It seemed to us that a critical factor in a survei.llance system was the efficiency of detection of relatively rare phenomena or events, rather than the minimising of sampling errors. In the present sense an event could be a single plant or many scattered plants of one species, a community, a peculiarity of soi.l or relief, a patch of incipient erozion or disease - in fact any local perturbation or deviation from regularity or randomness. The probability of detecting such an event increases with its area, subject to shape, as will be discussed in Appendix 1. With random sampling, even if stratified, detection does not become a certainty until the area of the largest event exceeds the largest blank area between sample units, whereas with systematic sampling detection is certain when largest event area exceeds the mean sample spacing - which is of course the actual spacing between the sample units.

3.11 Spatial distribution of events. Some of the arguments for systematic sampling assumed spatially random distribution of the events which are to be recorded, at least on the scale of our sampling grid. However, clustering frequently occurs in nature and approximately reguln spacing is also possible ovex limited areas, so we felt it necessary to test the behaviour of both phenomena by computer-drawn mode $1 s$. The results are reported in Appendix. 1. In brief, it was found that randow positions turned out to be approximately "systematic", with respect to plots disposed on a sampling grid, more frequently than seemed likely, especially if only four to nine events occurred. Thus systematic sampling proved less efficient than random at detecting an event - a spatial phenomenon - with that number of replications. But in contrast. clustering of small events gave an effect similar to that of a single large event, at which of course syetematic sampling was more effictent than random. Hence on balance we were not disturbed by having decided to use a systematic sample layout.

\section{Subjects Recorded}

3.12 The Trees. It was explained in 2.10.1 why trees were reckoned the most important part of the observations. It is however impracticable to measure all trees, even for simple dimensions, in continuously recruiting woodland where there may be swarms of seedlings, sticks and small poles. Moreover, without knowledge of individual identities from one occasion to the next, it is also unprofitable to record all trees even by size-classes, because neither loss, recruitment nor growth can be inferred from such observations. For instance, a given number of stems in 1960 and the same number again in 1980 may mean anything from stagnation to complete turnover - the same individuals might have persisted or a partly or wholly different set might have replaced them. We therefore insisted that all tree measured must be individually traceable on future 
occasions, and therefore that some severe limit must be put on the number to be measured in a single plot.

3.13 The Leading Tree Method. We chose to use the LT method, originally devised for rain-forest in Malaya but much tested elsewhere over the past four decades. It is based on the fact that only a limited number of trees can be simultaneously dominant in a limited area, and on the assumption that the largest tree in a small plot is the most likely to be dominant - now, or in the near past, or in the foreseeable future. In the case of even-aged stands, the largest (in diameter) tree in a $100 \mathrm{~m}^{2}$ plot is also the one most representative of thepopulation from which dominant height and therefore site-quality is conventionally assessed by foresters. In fact, as a further safeguard, we measured the four largest trees, i.e. those having the four greatest diameters in the plot. It should be noted that there is no minimum or maximum size for this category; the leading tree could easily be a small seedling densely covered by low herbs, or a giant tree; both sizes and conditions would be recorded by our system.

By measuring and giving positional co-ordinates for only four trees, more time was left to record the silvicultural condition of each, including the position of its crown relative to adjacent canopy and a brief list of the species which seemed to be impeding it. This provides at least some of the information diagnostic of recent-past behaviour and predictive of the future.

We would have liked to have measured bole diameter at a precisely repeatable position on the bole. This cannot, however, be reliably done unless the bole is "permanently" marked, for example by paint-ring, or by an aluminium nail at some standard distance above or below the conventional breast-height. Paint-rings we considered too conspicuous and transient, nails too attractive to mischief (squirrels as well as juvenile humanity), and too transient on fast-growing trees. We therefore reluctantly measured only to an estimated (checked by tape) $1.3 \mathrm{~m}$ above ground level, and only to the nearest centimetre.

3.14 Other Tree Information. Our plots may be considered on the smal1 side for information on the mature trees of well-developed highforest. We therefore considered it necessary to record whole-stand composition in the vicinity of each plot as well as within it. The most convenient way of doing this, short of further survey, seemed to be by angle-gauge tally. We took two tallies, by Relaskop, from diagonally opposite corners of each plot. The practice should have prevented a plot, sited for instance in a small gap in oakwood from failing to record Quercus in quantity. Since the tally-factor used was 2, the sum of the two talies at a plot gives a direct estimate of stand and species basalarea in $\mathrm{m}^{2}$ per hectare in the vicinity of the plot, inclusive. (Ecologists unfamiliar with angle-gauge sampling will find a voluminous literature in forestry journals and textbooks, e.g. Loetsch (1973)).

3.15 Information on Cover. We were not the first to discover that canopy - as percentage cover or density - is extremely difficult to estimate even with instruments. In our case there was also the matter of season; plots recorded in late May would be difficult to make comparable with those recorded in late September without considerable precision as to exact point of judgment. This would of course have been possible using hemispherical photography - the fish-eye lens pointing upwards from the centre point of each plot. However we would still have had the problem of season. We judged it impracticable to visit every plot 
at a time of seasonal comparability, confined perhaps to the periods December - February or June - August. We therefore confined our estimate of canopy to what lay vertically over one of the diagonals of the plot, along which the observer had in any case to move in the course of recording circlets (para. 3.16). We also split the record into three levels: over $2.5 \mathrm{~m}, 2.5$ down to $0.5 \mathrm{~m}$ and under $0.5 \mathrm{~m}$ (Fig. 5). Only in the highest stratum did we find it feasible to allocate separate percentages to each species; below $2.5 \mathrm{~m}$ the picture was too confused and the foliage of any one species too diffuse and interlaced t.o make "cover" or "canopy" easily defined.

3.16 Other Vegetation. Just as with trees, we would have liked to record not only numbers but sizes of smaller forms, but found both to be quite impracticable. As suggested in 3.15, even relative or proportional cover provided by shrubby and herbaceous species seemed impossible to do with the precision we required. We therefore compromised with the following:

.1 Listing all vascular species found in the plot;

.2 Listing all vascular species found in a series of subsampling "circlets" to provide relative frequencies;

.3 Estimating proportional cover, over the whole plot, of a few designated species of known ecological significance - known to us as "ecosigs".

The circlets, each of $0.1 \mathrm{~m}^{2}$, were placed systematically along the plot diagonals (Fig. 2) and were therefore intended to be relocatable to within a few centimetres in future years. The "ecosigs" were selected in consultation with the late $\mathrm{Dr}$. P.S. Lloyd. Mosses were included in the circlet recording to a limited extent, the principal limit being our own lack of experience with bryophytes.

3.17 Ground Surface. As we were particularly concerned with site stability and biological richness, it seemed that temporal changes in litter and soil exposure must be made detectable. Three features were reasonably easily recorded; the presence of litter, of exposed soil, and of stones on the surface. The necessary quantitative element was obtained by recording all of these in the thirteen fixed circlets, so that each feature would appear with a score from zero to 13 in proportion to its frequency throughout the plot.

3.18 Other Above-Ground Features. During the survey a number of almost unclassifiable features were encountered, which seemed relevant to the biological condition or performance of the plot. They included artefacts such as paths, ditches, banks, pits, felling stumps, zoofacts such as burrows, molehills, nests, and recent violent events such as windfalls.

\section{Soil Observations}

3.19 Constraints. We wanted to record all changeable properties of soil which are related to fertility, defined somewhat vaguely as biological stability and diversity as well as site quality in the forester's sense. Obviously such properties should include erosion, $\mathrm{pH}$, compaction, permeability and water-retaining capacity, nutrient status, trace elements and heavy metal or other pollutants. There were however several serious constraints: 
3.19.1 We could not allow destructive sampling within the plots, certainly not to the degree inevitable in digging profileinspecting soil pits. Even with a soil auger, we quickly learned that excessive trampling resulted on all but the most favourable ground, a rare feature in these woods.

.2 Our samples had to be representative and spatially relatable to other observations made within the plots. There was therefore little point in sampling away from the plots where relevance would be less and spatial variation greater

.3 For long-term surveillance and therefore between-occasion sensitivity, we had to provide for precise re-location of every sampled site. Later collections would need to be very near to (but not coincident with) earlier ones, to avoid confounding spatial with temporal differences.

.4 Augering, without destruction of the profile and loss of accuracy in defining depth of sample, proved impossible over most of Halton and a few parts of Wytham, due to flints or limestone. Large soil-pits were no solution for the reasons given in the preceding three paragraphs.

.5 The ubiquity of tree roots, stones, or both, and many other irregularities such as animal burrows, made any form of sampling for compaction, permeability, bulk density etc. quite impracticable, at least when taken in combination with constraint 3.19 .2 above.

.6 The factor of seasonality, mentioned previously in connection with biological observations, made it meaningless to record soil moisture, water-table and the like, since our samples had to be collected at any time of year - though mostly in summer.

3.20 The Compromise. Our response to the constraints was to sample from four sites at each plot, tangent to but just outside its boundaries and therefore definable by geographical co-ordinates from the plot corners. A tubular auger (which some might call a "corer") was used in the softer ground, or a small hole to $30 \mathrm{~cm}$ depth where the auger failed, dug with crowbar, trowel or small spade according to need. Samples for analysis were taken from the auger or from the sides of the hole. Sufficient material was collected for dry storage as well as immediate study, to provide for analysis in future of durable materials not yet known to be important. Immediate analysis was confined to $\mathrm{pH}$ (on fresh samples), organic matter, and a few elements (total $\mathrm{N}$, "extractable" $\mathrm{P}, \mathrm{K}, \mathrm{Mg}, \mathrm{Ca}$ ), done for us by the Soil Laboratory of the Institute of Terrestrial Ecology, Merlewood, Cumbria.

\section{Subjective Siting of Plots}

3.21 It is arguable that our intentions could be served by subjectively sited permanent plots, supplemented by random or systematic temporary sample plots (or points) whenever quantitative or managerial information is required for an area as a whole. Had such subjective siting been used, plots would have been deliberately sited in places believed to be typical of particular ecological, silvicultural or pedological conditions, supposing of course that the area was already known well enough for these 
to be defined.

To allow evaluation of such a sampling system, we categorised each of our plots (at Halton) as typical or not. A "typical" plot was one which might have been deliberately placed as typically representative of a particular site or vegetation. To qualify as typical, the plot obviously had to be away from any boundary, 1:regularity or cline of vegetation or soil, and the community of which it was representative had to be one of considerable extent or interest. in the wood.

3.22 We also wished to know if the numerous but somewhat slaccato observations made in each plot, could be built up by computer search into a brief informative description such as a forester or ecologist might give. As a start in this direction, each plo: was given a descriptive heading, limited to a single line of un irmaliset, text, of the type: "beechwood with bramble floor" or "Ash oles ov blackthorn thicket" or "Spruce plantation, clean flocr". Th entry was thought of as the minimum comment that would be useful if 11 other information were $10 s t$. 
Fig. 3 Variations in plot layout

Angle-iron at,

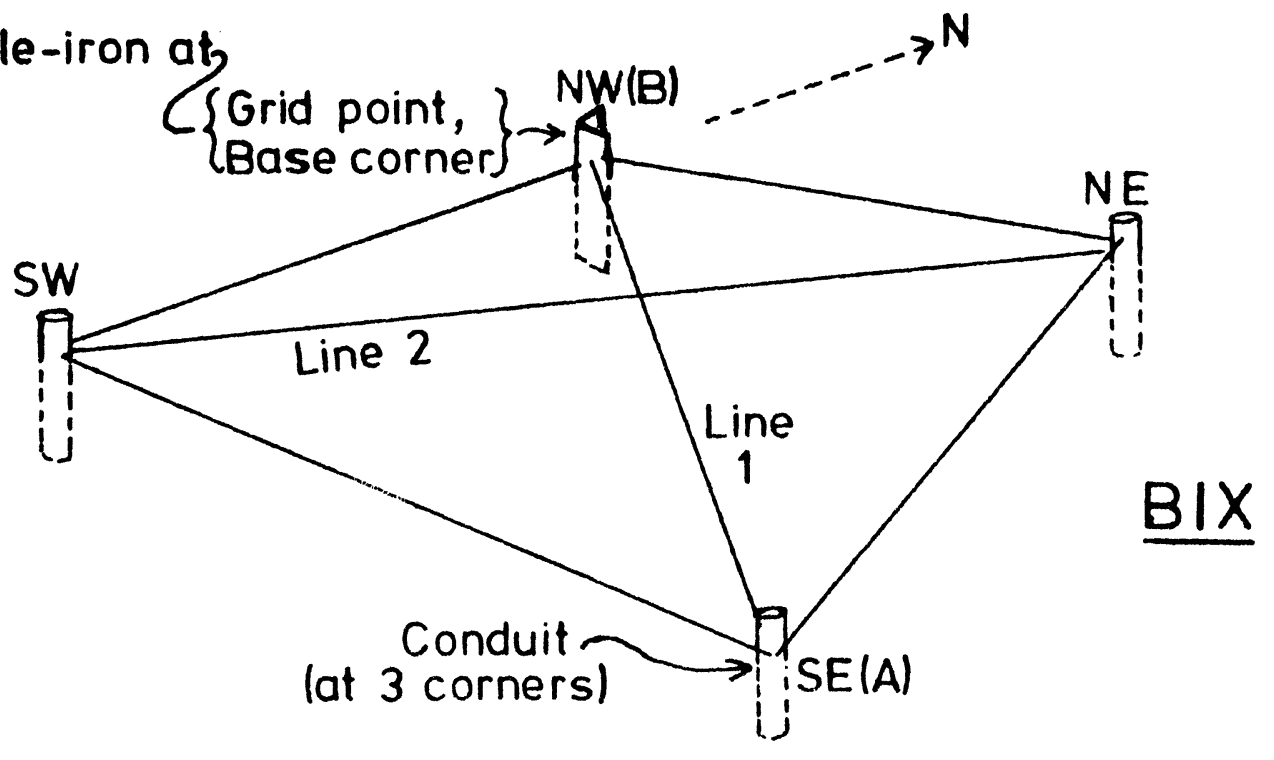

$14.14 \mathrm{~m}$ to SW $(A)$ Line 1

Grid point
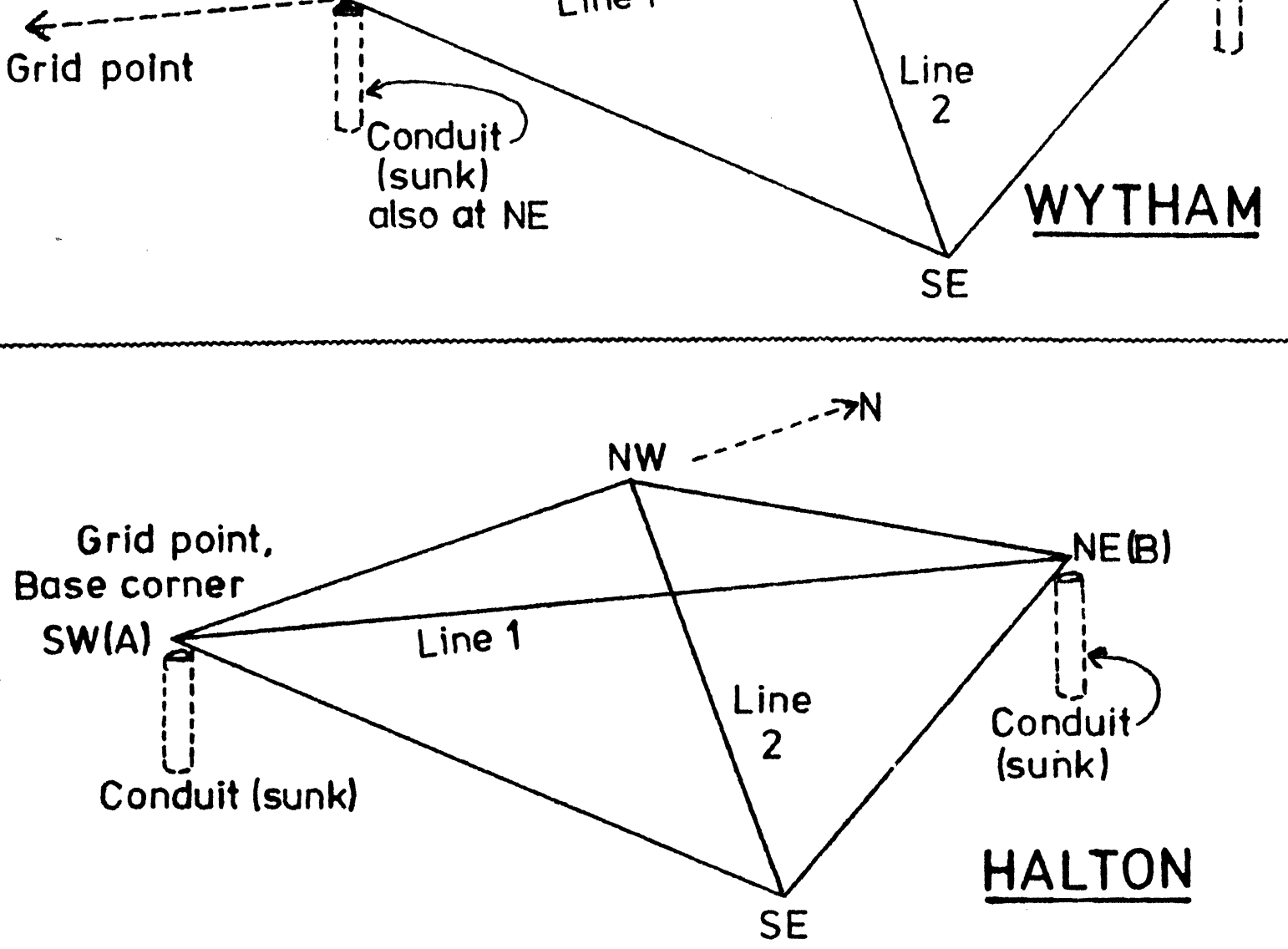


\section{CHAPTER 4}

\section{SURVEY AND PLOT MARRING}

4.1 There were two stages of field-work, firstly survey and marking the plots, then recording their contents. We found it necessary to do the first in winter, for the convenience of better visibility and so as to have all summer for the recording.

4.2 The particular ordnance maps that we used were:

\begin{tabular}{|c|c|c|c|c|c|c|c|c|}
\hline Bix: & SU & $7088-7188$ & $1965 / 6$ & Wytham: & SP 4407-4507 & Feb & 1970 & (b) \\
\hline & su & $7087-7187$ & $1964 / 65$ & & SP $4408-4508$ & Jan & 1970 & (b \\
\hline & su & $7287-7387$ & $1965 / 6$ & & SP $4409-4509$ & $"$ & " & $" 1$ \\
\hline & su & $7288-7388$ & $1964 / 5$ & & SP $4607-4707$ & " & " & \\
\hline & & & & & 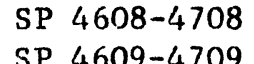 & $\begin{array}{c}\text { Dec } \\
" 1\end{array}$ & $\begin{array}{c}1969 \\
11\end{array}$ & $(t$ \\
\hline
\end{tabular}

Ha1ton: $\begin{array}{lll}\text { SP } 8607-8707 & \text { Sep } 1970 \\ \text { SP } 8807-8907 & \text { Jan } 1972 \\ & \text { SP } 8808-8908 & \text { Nov } 1970 \\ & \text { SP } 8809-8909 & \text { Oct } 1970\end{array}$

Also available for Wytham was a locally-drawn stock map giving a very simplified plan of the contents of each compartment.

For Halton, by courtesy of the Forestry Commission, we had a recent stock map.

For use in the field, it was found helpful to cut the maps into A4-sized sheets and carry these in a transparent plastic folder.

4.3 Bix Survey. At Bix, plot markers at 101 sites had already been put in by $\mathrm{W}$ : Rides before the start of the project.

Grid lines, which required a great deal of cutting, were laid out on the ground with compass and sighting poles. A $7.5^{\circ}$ deviation from magnetic north was used. Distances were measured with a "Topofil", (made by Topochaix Cie., 42 rue de Lagny, 75020 Paris, France) which pays out a thread and measures the distance covered with an accuracy of about $1 \%$. Each $100 \mathrm{~m}$ grid point was marked with a foot-long length of angle-iron driven into the ground so that about $5 \mathrm{~cm}$ projected. The top was painted blue, and an aluminium "Dymo" label tied to a hole in the iron with plastic-covered wire. The label carried the grid reference in hectometres as a six-figure group, e.g. 774/880. Such labels were expected to be weather-resistant, but proved attractive to animals, probably squirrels. The other three corners were marked with similar lengths of mild steel electrical conduit (circular in section, about $2 \mathrm{~cm}$ diameter), also driven vertically into the ground with 5-10 cm projecting. Where the ground sloped, true horizontal distance was marked out by "stepping" the tape or adjusting lengths using a secant table.

Each grid point formed the NW corner of the $10 \times 10 \mathrm{~m}$ sample plot, surveyed with an accuracy of about $0.05 \mathrm{~m}$, using "fibron" tapes. 
The layout of a plot is illustrated in Figs 2 and 3.

4.4 Wytham Survey. At Wytham, the survey was carried out by Adams, Field and Rides. The woodland boundaries and rides were surveyed between October and December 1973, the grid points and plots following until completion in May 1974.

.1 Location of Grid Points. The intersections of grid lines with the woodland boundaries were first marked with stakes. This was done by measuring distances froin accurately locatable points, such as angles in fences, to intersections of those fences with a grid line, first on the map, and then on the ground. Distances were measured by tape. Having located the start of each grid line entering the woodland area, the lines themselves were laid out, using a compass and sighting poles. A "Suunto" compass was used throughout, accurate when firmly held to about 0.25 degree. Magnesium alloy tree-heighting poles, painted in contrasting stripes of orange or yellow and white, made convenient sighting poles, being about $1.75 \mathrm{~m}$ tall. They could be set into each other to make taller poles if needed.

A magnetic deviation of $7.5^{\circ}$ was used to start with, derived from checking the angles of selected straight fences and roads. This was later modified to just under $8^{\circ}$.

To set up a grid line, either repeated bearings were taken from one pole to another as far away as could be seen, and the second pole adjusted, or - rather more accurate in most cases - two poles were lined up with a compass, the further poles put in to line up with these. The latter method normally results in a straighter line, making later correction more accurate.

Grid lines could usually be laid out right across the wood, usually in an $E-W$ direction because of terrain. Where vegetation made line-of-sight survey difficult, cutting was needed. This was kept to the minimum needed to improve vision along the line. Occasionally a line was offset one or two metres to circumvent obstacles such as dense blackthorn, and corrected again when the obstacle had been passed. Obstructing trees rarely interfered enough to warrant this.

Long-distance measurement was done with plastic-based electric fencing cable wound on to a reel with handle. Plastic tags were tied on to the cable at every ten metres, with each $100 \mathrm{~m}$ mark in a contrasting colour. The reel contained over $400 \mathrm{~m}$ of cable, but in practice we used only one or two hundred at a time. Slopes were allowed for by horizontal adjustment using slope tables; they were measured with a Sunto clinometer.

Stakes were put in at each grid point along the line, and then adjusted pro rata when the other end was reached - i.e. the other boundary mark. Closing errors less than $1 \mathrm{~m}$ were ignored. Example: a line $550 \mathrm{~m}$ long was started from the $\mathrm{N}$. boundary. On emerging at the $S$ boundary, the line was found to be $3 \mathrm{~m}$ too far east of the target stake. The grid points were therefore adjusted, going $\mathrm{N}$ again, by $3 \mathrm{~m} \mathrm{~W}, 2.5 \mathrm{~m}, 2 \mathrm{~m}$, 
$1.5 \mathrm{~m}, 1 \mathrm{~m} \mathrm{~W}$. If the line had been found to be too short or toolong, then the grid stakes would also have been adjusted in the $\mathrm{N}-\mathrm{S}$ direction.

The rides had been surveyed and provided with narker stakes before the grid lines were put in, but a number of rides failed to fit the map, and it was not clear which of them could be relied upon. Fit or otherwise of grid lines with ride markers was therefore given little weight. Checks were made by surveying lines in both directions, f.e. some $\mathrm{N}-\mathrm{S}$ lines were set up to check $\mathrm{E}-\mathrm{W}$ lines. In most cases a good fit was found. When discrepancies arose, errors were closed as in normal survey practice.

The grid points were intended to have an accuracy of $\pm 1 \mathrm{~m}$. In a few cases where checks were difficul:, the accuracy achieved was assessed as $\pm 3 \mathrm{~m}$. Something like 8 points a day were thus located by a team of two.

4.4.2 Marking of Grid Points with Grid Posts. Since a by-product of the survey to locate plots was the provision of a $1.00 \mathrm{~m}$ network of posts for reference by other scientific users of the wood, each grid point was marked with a large post, about $2 \mathrm{~m}$ high, $10 \mathrm{~cm}$ square in section, of untreated sweet chestnut. These were installed with a "Driveall", a heavy metal cylinder, open at one end, provided with handles. In rough areas a sledge hammer, rather lighter to transport, was used.

Including delivery of posts to points as near as possible to the grid points by Land-Rover, the daily quota averaged about 20 posts.

.3 Labelling of Posts. Each post, as well as having been made easy to see by being painted orange over the top half-metre, was also labelled with a stainless steel "Dymo" quarter-inch tape. This bore the easting and northing as a six-figure reference, e.g. 455/077, and was fixed to the top of the post with brass nails. A few posts had to be offset to avoid blocking rides. Their labels showed this, a typical reference being 455/07698. This would mean the 455/077 post had been placed $2 \mathrm{~m}$ south of the grid point.

.4 Marking out Plots, and Monumentation. There were 320 grid points in the wood, far too many for the number of plots we wished to - or could - record in a year. We therefore associated our plots with alternate grid points which left us with 163. To allow for a larger $20 \times 20$ metre plot to be set out later if required, also to ensure that no plot got excessive wear and tear from other observers using the grid posts, each plot was offset $14.14 \mathrm{~m}$ to the $\mathrm{NE}$ of the grid point, as follows:

from the grid point a tape was laid out along a bearing of $45^{\circ}$ (true, i.e. a little over $52.5^{\circ}$ on the compass). The base (SW) plot corner was marked with a temporary stake $14.14 \mathrm{~m}$ along this line, and the line extended to $28.28 \mathrm{~m}$ toreach the opposite (NE) corner, also marked with a stake. Some care was taken to minimise trampling along this line, as it was to be 
recorded botanically in the summer. Having established the SW and NE corners, the other two corners were sited by triangulation from these two, using a $20 \mathrm{~m}$ tape, and marked with stakes. Where vegetation made triangulation difficult, then the base corner was located as before, and the sides measured out with compass and tape unti 1 the whole plot had been circumnavigated. An optical square was tried in the early stages but proved less efficient than triangulation with tapes.

Slopes were allowed for by "stepping" the tape or adjusting with a secant table, so that the horizontal equivalent of the $10 \times 10 \mathrm{~m}$ square was marked out accurate to $0.05 \mathrm{~m}$ along any edge (Fig. 4). At a later date the base and opposite corners were marked with underground markers. Each of these consisted of a one-foot length $(30 \mathrm{~cm})$ of mild steel wiring conduit, about $2 \mathrm{~cm}$ o.d., acting as a sleeve for a shorter length of metric ( $15 \mathrm{~mm}$ o.d.) stainless steel tube, usually a tight fit. Each sleeve and tube was driven vertically into the ground with a mallet until the tip was just below soil leve1. These markers were intended to be permanent, cheap, and reasonably easy to locate by those seeking them without delimiting the plot in any visible manner. The choice of material was meant to avoid introducing undesirable pollutants to the site; a very localised column of subterranean rust was thought ecologically acceptable.

The layout and marking of a plot is shown in Figs. 2, 3 and 4. Each grid post which had an associated plot was also provided with an underground marker, usually of larger diameter conduit with the same stainless steel insert, driven into the ground adjacent to the grid post.

Throughout the measurement and demarcation of plots, care was taken to limit trampling within the plots. Similar care was taken during recording, so that most damage resulted along the plot edges; in some types of ground flora this was very noticeable.

4.5 Halton Survey. Since time was more limited, and rides were found to be accurately marked on the maps, grid points were not located by following grid lines across the wood, but instead were found by measuring distances along mid-lines of rides, using ride intersections or any other clearly mapped and angular features as reference points. The steep slopes found here would in any case have made the transect approach less accurate; the grid points were assessed as accurate to $\pm 2 \mathrm{~m}$. No visible reference grid was set out here, though forty "permanent" posts were put in by Forestry Commission staff at selected grid intersections (Fig. 19) to assist re-location of plots. Plots were sited with their SW corners at the grid points. Each plot was laid out and marked with temporary stakes and permanent underground markers as at Wytham. Shorter lengths of conduit were generally used, since the soils were mostly shallow.

A magnetic deviation of $8^{\circ}$ was used.

At Halton, unlike Bix and Wytham, plots were not established at all if their positions were not representative of the managed woodland, 


\section{Fig. 4 Layout on slope}



e.g. because of large areas of surfaced ride or, in two cases, on roadside spoil heaps still in an unstable condition.

4.6 Special Cases. Where a grid point lay close to the woodland boundary, a plot was marked out only if most of its area fell within the boundary. (At Halton, no plot was marked out if its area did not represent the managed wood). During the recording of such plots, some observations were "missing" since circlet or relaskop recordings were not made for points outside the woodland area. This is dealt with in more detail in Chapter 5. It would of course be possible to make provision for offsetting plots where their true positions would be irrelevant to the survey, using some pre-determined unbiassed ruling to shift them into relevant situations. We did not do so in this project, since we were not short of plots. It was mentioned in 4.4 .3 . that a few grid posts (but not plots) at wytham had to be offset, and were labelled accordingly.

Where plot corners occurred in rides, the temporary marker stakes put in were very short to allow vehicles to drive over them harmlessly. In a few cases, due perhaps to coincidence with a tree bole or metalled road, it was not possible to place in underground marker at the standard corners; in these cases it was placed at another corner ins tead. 
- 
5.0 The description in this chapter applies to the final system we evolved. At each site there were minor variations, which are detailed in Chapter 6.

The third site recorded, Halton Wood, differed little from the system as described here; the first, at Bix, quite a lot.

Before recording started at any plot, it was marked out in the following manner. Each corner was marked with a pole pushed into the ground, and edges were defined by laying graduated tapes round the perimeter, starting for convenience from the SW corner. Both diagonals were similarly marked out, starting at the western edge. An accuracy of $0.05 \mathrm{~m}$ was the aim. The sides of each plot ran along grid bearings, i.e. the SE corner lay on a bearing of $90^{\circ}$ true from the SW corner. In practice of course it is on a bearing of $(90+$ magnetic deviation $)^{\circ}$. Where the ground sloped, all measurements were adjusted to the horizontal, i.e. to conform with map measurements, and all co-ordinates were given as if the ground had been horizontal. For example, if a plot slopes to the east, the diagonals might measure $14.8 \mathrm{~m}$ along the ground (theoretically $14.14 \mathrm{~m}$ ). On the first diagonal, the plot positions, normally at each odd metre mark along the tapes, would be adjusted pro rata; i.e. the overall adjustment is $0.7 \mathrm{~m}$; there are 7 plot positions, each is therefore adjusted by $0.7 / 7 \mathrm{~m}=0.1 \mathrm{~m}$. The first will thus be at $1.1 . \mathrm{m}$, the second at $2.2 \ldots$ and the seventh at $13.7 \mathrm{~m}$. Tree and other co-ordinated observations based on the tapes would be similarly adjusted for slope. It will thus never occur that an item has co-ordinates of greater than $10 \mathrm{~m}$, even though the plot may measure more than this along the ground in either direction.

In the case of diagonals, and sometimes edges, we found it convenient to elevate the tapes horizontally so that the adjustments are automatically made (Fig. 4).

The following sections describe the process of recording as carried out by a team of two in the field, with the exception that Section 10 was usually done last, or by one operator while the other was burrowing or bagging soils.

Because field records were designed to be punched on to cards without (or with very little) doctoring, and because they and the program for reading, checking, sorting and storing the information still exist and are available for use, this account generally uses the present tense for the details of recording.

5.1 Section 1: Description of the Plot

Entries are made in the following sequence:

1 The National Grid reference of the associated grid point in hundreds of metres, e.g. "452 077" (easting before northing).

.2 The date of recording, in three integers, e.g. "25 7 1975". (The year may be shortened to two figures; day and year may be transposed without affecting input). 
.3 The number of people doing the recording, e.g. "3".

.4 Pairs of initials for the recorders, e.g. "HD/DF//". Each pair to be terminated as if it were a name, and the set terminated as if it were a list, i.e. with "//".

.5 A general description of the silvicultural/ecological appearance of the plot and its main tree components. This is limited to 79 characters, and must be presented as a separate line when the data is punched. The description may include the immediate area surrounding the plot as well as the plot itself, e.g. "GAP THICKET IN OLD BEECH. OCCASIONAL LARCH". Another example is: "MATURE ASH WITH EXTRACTION RACK. MERCIRY FLOOR. RIDE IN PLOT ${ }^{M}$.

.6 Planting dates - it is more convenient to add these afterwards, in the office. If the wood is not known to have been planted or its origin is uncertain, " 0 " (zero) is entered. If the planting date is not recorded, then a "-99" indicates this. plantings over more than one year may be entered either as a single negative number, e.g. " -1948 " or as both years, e.g. "1947 1948". A negative number indicates an approximate date. Up to three dates may be recorded. The programs will accept 2-digit numbers to mean "19..", e.g. "48" will be interpreted as "1948". "84" will be rejected, not having occurred yet this century.

.7 The observation of either "TYPICAL" or "ATYPICAL", depending on whether the plot would be chosen as representative of its area, if plots were being sited subjectively. This entry is abbreviable; only the first three characters are significant, e.g. "TYP". "-99" means "not recorded".

8 An entry to describe whether the plot has uniform slope or not. Level ground or uniform slope around the plot would mean no net lateral gain or loss of mobile nutrients or soil materials; a plot with concave slope would be gaining, and one with convex slope or at the top of a ridge would be losing. The codes for this classification of slope class are"0" for neutral. or indeterminable, " +1 " for gaining, and " 1 " for losing. These are scores, and one such code is entered, or, if no class is recorded, a "-9" or " $-9 "$ "

\subsection{Section 2. Leading Trees}

"Tree" is an arbitrarily defined category. Several species which might normally be regarded as trees are excluded for the purposes of recording "leading trees", "other trees dead" and "relaskop sweeps" (explained in Chapter 5). The distinction is based on growth habit of the species: those which do not normally form a single bole (i.e. they show basitonous growth) are excluded, e.g. hazel, hawthorn, elder, dogwood, viburnum, blackthorn, spindle, buckthorn. Species with acrotonous growth (tending to form single stems) such as holly, sallows, maples and crab apples are classed as trees.

The four largest-diameter trees within the plot are selected. A tree is classed as "in" if the centre of the bole at ground level falls within the plot. There is no lower limit to size, so that seedlings 
are included if they happen to be among the four largest trees. Where many small seedlings comprise the only trees in the plot, it is sufficient to select the four largest by eye; it would be pointless to measure a large number to ensure an exact choice. For each tree, the following is recorded:

5.2.1 The name, i.e. species name ( see Appendix 3).

.2 The diameter at breast height. This is estimated, not measured (but occasionally checked), $1.3 \mathrm{~m}$ from the ground, taken on the uphill side if the ground slopes. The diameter is recorded to the nearest centimetre, rounding either way, from measurement with a diameter tape. If the diameter is less than $5 \mathrm{~cm}$, the height of the tree is measured instead (see next subsection). If there is a swelling or other deformity at breast height, the diameter is measured at the narrowest point immediately below the swelling. (In our work any diameter of less than $5 \mathrm{~cm}$ was entered as " 0 ", but ith nor seems more useful to record the diameter in every casel.

If the tape cannot be placed round the tree (because of ivy or whiskers for example), then the centimetre graduations on the girthing side of the tape are used to provide an estimated diameter, which is entered as a negative integer, e.g. "-45". If the tree is multiple-stemmed, then the diameter of the largest-diameter stem only is
measured.

.3 If the tree is one of the two largest in diameter or its diameter is less than $5 \mathrm{~cm}$, the total height (not timber height) is measured. This is entered with an accuracy depending on the height itself, usually to the nearest metre, but to $0.5 \mathrm{~m}$ for trees of less than $5 \mathrm{~m}$, and to $0.1 \mathrm{~m}$ for trees of $1.5 \mathrm{~m}$ or less. Very small seedlings, of $0.5 \mathrm{~m}$ or less, may be measured to the nearest $0.05 \mathrm{~m}$.

Where heighting is found to be more than usually approximate, e.g. the apex is obscured, then the entry is made as a negative number, e.g. "-15" to show approximation.

For multi-stemmed trees, the height recorded is that of the stem of greatest diameter.

The apex of a broadleaved tree is defined as the tip of the shoot highest vertically above ground level, the latter taken at the foot of the tree. For computer handling reasons, an entry must be made for height of all four leading trees; for those without a height measurement, we suggest entering a "-99", although we used " 0 " In our field recording sheets.

.4 The co-ordinates of the centre of the bole at ground level (i.e. easting and northing in metres from the SW corner of the plot) are estimated from the periphery tapes, accurate to $0.1 \mathrm{~m}$. Negative entries to show approximation are not permitted, although it is allowable to omit the decimal part if zero, e.g. "1.0" entered as " 1 ". 
5.2.5 A score for the presence or absence of bole damage. The bole was defined as that part of a tree below the lowest living branch. Judgment was frequently required; "epicormics" did not count as branches, nor did very low or sma 11 minor shoots as with birches, sycamore, ash etc. Bole damage meant physical damage to the bark, usually by animal or human agency but possibly from falling branches, a lso bracket fungi. Recorded as " 1 " present or "0" (zero) absent. It was not found practicable to assign causes, nor to distinguish degrees of damage, though grey squirrel appeared to be responsible in most cases. Damage among the branches counted with the Crown. See 5.2.5.

.6 The crown class - what the forester might term a dominance score. The crown was defined as that part of a tree above the lowest living branch, but epicormics, very low or small minor shoots did not count as branches.

Crown class was an index of the position of a tree crown relative to its neighbours, using the Uganda-Malayan system (Dawkins 1958, Wyatt-Smith 1962) which considers mainly the freedom or otherwise of the "crown plan", i.e. the crown as seen from vertically above it. The class scores are assigned as follows:

(1) Crown plan fully exposed vertically

(i) Crown free from lateral competition at least within the $90^{\circ}$ inverted cone subtended by its base.

Score: 5

(ii) Having other crowns adjacent, of similar or greater height and within the $90^{\circ}$ cone.

Score: 4

(2) Crown plan partially vertically shaded and partially vertically exposed.

Score: 3

(3) Crown plan entirely vertically shaded

(i) Some direct side-light due to gap or edge of overhead canopy.

Score: 2

(ii) Laterally shaded all round, as well as vertically.

Score: 1

Note that a crown-class of 5 could apply to a seedling in short turf in a wide open gap, while crown-class 1 could apply to tall subdominant tree in a dense plantation, or to a likewise tall holly in closed oakwood.

.7 A score for crown damage, i.e. physical damage to the crown, especially bark chewed by animals or obvious recent windbreak, recorded as " 1 " if seen or " 0 " (zero) if not.

.8 Impeders. For trees of crown class 4 or less, up to three species may be named as those contributing most to shading, though a tree of class 4 itself may have no impeders. For trees of class 3 or less, at least one species must be named as an impeder. Where the tree is class 4 , its impedance must be assessed on the criterion of whether the subject tree requires silvicultural liberation - admittedly a subjective 
matter - and entry of names will depend on this. For small leading trees, it is quite possible for herb species to be named as impeders.

The list of impeding species must be terminated (para. 7.5). Here as elsewhere with names, some entry must be made; if there are no impeders, then " 0 " (zero) is entered.

5.2.9 "Comments" on form or condition of the tree may be entered, but here it is not necessary to make any entry on the form if no comment is to be recorded. Comment texts must be of eight or fewer significant characters. A list of characteristics that might call for comment follows, with standard comment texts:

\author{
Coppiced \\ Pollarded \\ Tree forked above breast height \\ Tree forked below breast height \\ Tree multiple-stemmed \\ Damage or loss of leading shoot \\ Tree leaning significantly \\ Tree unhealthy or moribund
}

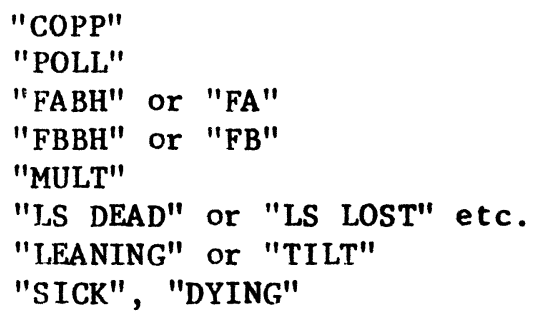

Note on punching data: if leading tree data is to be split over more than one line, it is necessary for items from 5.2.6 onwards to appear on the same line. One punched record per tree is a safe guide.

\subsection{Section 3. Other Trees Dead}

Any dead trees of species other than the leading trees are noted here. Although this is intended to provide evidence of previous cropping or dominance, it is permissable to record dead trees of the same species as the leaders if wished. Outstanding dead trees may also be recorded under section 9 which allows a note of their position. Dead trees may be either standing or fallen, but fellings clearly do not count.

A total number of dead trees is entered, e.g. "2", followed by up to 2 species names with diameters at breast height, e.g. "2 LARCH $17 \mathrm{ASH}$ 15". For trees that are leaning or fallen, the diameter is measured $1.3 \mathrm{~m}$ along the bole. Where there are no dead trees, a " $\mathrm{C}$ " (zero) is entered. The diameters are intended to give an idea of size; if there are several dead trees of the same species, only the two largest need be detailed, e.g. "3 ASH 25 ASH 21 ".

Should a dead tree be unidentifiable, the entry "NK" is available for this, e.g. "1 NK 15".

Punch this Section 3 on a new card if the last item punched was a leading tree comment.

\subsection{Section 4. Relaskop Sweep A.}

From a point at the SW corner of the plot, a relaskop sweep is made, using arc 2 of the instrument, and the total tally entered, 
followed, if the total is not zero, by subtallies for each tree species contributing. The latter parts constitute a list, and require a terminator. Example: if there are five trees tallying, two of which are ash and three larch, the entry would be: "5 2 ASH 3 IARCH//". It is allowable to omit the subtallies - in which case a "-99" is entered instead, but this is not informative and was never done intentionally.

If the total tally is thought approximate, e.g. because of a thick shrub layer, it may be entered as a negative number, e.g. " -5 ". The limit on the subtally list is ten different species. We never tallied more than eight, and the forms have eight spaces.

There was no special rule for dealing with trees that are borderline cases for tallying; we considered that a clear Yes or No must always be decided for every sighted tree.

\subsection{Section 5. Relaskop Sweep B}

A similar set of observations is made from the NE corner of the plot. For either relaskop sweep, each tree tallying indicates 2 square metres of basal area per hectare. The sum of the tallies for both positions therefore gives an estimate of mean basal area per hectare of the stand in and around the plot.

\subsection{Section 6. Cover Percentages; Upper Cover}

The cover estimates in this and the next two subsections apply to three imaginary layers over a line from the SW to the $\mathrm{NE}$ corner of the plot (the first diagona 1 ). The upper layer is that over $2.5 \mathrm{~m}$ from soil leve1, marked $U$ in Fig. 5. Any foliage or wood intersecting this plane counts toward upper cover, which is assessed by eye and entered as an integer percentage to the nearest $5 \%$, e.g. "95".

For this upper layer, the percentage cover from each contributing species is recorded as a list. Example: $60 \%$ of the line is covered, half of this is beech and half ash. The entry would be: "60 30 BEECH 30 ASH//". There may be overlap, in which case the component percentages may add up to more than the total, e.g. "75 60 LARCH 30 FRAXINUS EXCELSIOR//". (The full name used here is simply to remind the reader of the alternative forms of presenting tree species names). The component list may be omitted and replaced by "-99". Where the seasonal maximum has not been attained, it is estimated. This underlines the subjective nature of the estimated percentages. Where we recorded $100 \%$ upper cover, this does not mean that no daylight would appear in a photograph taken vertically upwards from the first diagonal; there would nearly always be "sunflecks".

\subsection{Section 7. Cover Percentages; Middle Cover}

A total percentage cover is entered, worked out on the same basis as above, but for the height layer 0.5 to $2.5 \mathrm{~m}$ above soil leve1 ( $M$ in Fig. 5).

This layer can be considered the shrub and tall herb layer; no species list is given. 
5.8 Section 8. Cover Percentages; Bottom Cover

A total percentage is entered, as for middle cover, but for the layer from ground leve 1 to $0.5 \mathrm{~m}$ above it ( $B$ in Fig. 5). This, the herb layer, includes living bryophyte as a contributor to cover.

\section{Fig. 5 Cover layers}

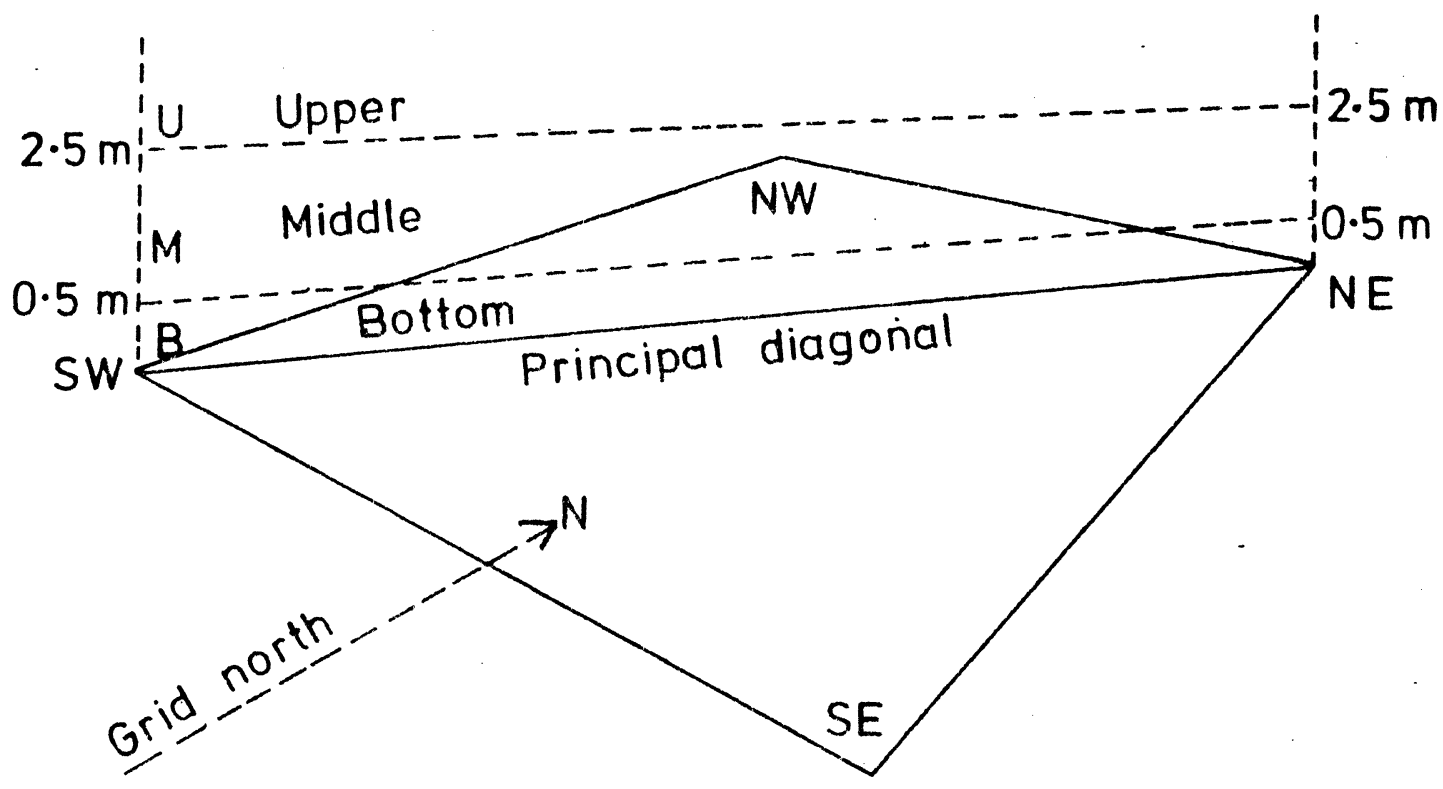

Note on Sections 6 to 8

Only living plants count as contribution toward cover at any level, although with a late recording, plants that were alive at mid-season obviously should count and were estimated as if at midseason. Estimates may have to differ from what is observed in the plot; for example, continuous low bracken in May may mean that midcover has to be estimated at $100 \%$, even though no plant has reached that height layer when the recording takes place.

It is permissable to use a percentage score of less than 5 to indicate "trace", e.g. "2", but negative entries to show approximation are not permitted. The negative entry "-99" is of course allowed to show omission of a whole section, and, as mentioned above, also to show omission of components of upper cover.

\subsection{Section 9. Other Features}

Any topographical, man- or animal-made event within the plot may be recorded in this section. Obvious candidates include ditches, gullies, streams, fences, rides, tracks, paths, badger setts, rabbit holes, etc., but any object of interest may be recorded. Up to three 
such events may be entered; should there be fewer than three, then the last or only entry should be "0" (zero).

Each feature is recorded as a descriptive text of up to 24 characters (among which the character "/" may not appear), terminated by "/", and followed by co-ordinates (as usual, eastings and northings based on the SW corner of the plot) to define the position of the feature. Two pairs of co-ordinates are entered; the second may be "0 0 " (zero zero), in which case the feature is considered to occupy a point defined by the first pair. Otherwise both pairs are significant, defining the ends of a line assumed straight unless otherwise defined. For example, take the path shown in Fig. 6. The entry under "features" would define it as a line, with co-ordinates where it intersects the plot margins. The entry thus might be: "PATH $1 \mathrm{M}$ WIDE / $3.0004 .0 "$ ". If the feature happens to be above ground level, e.g. a bird's nest or squirrel drey, then its height can only be included in the text, e.g. "SQUIRREL DREY $3 \mathrm{M}$ UP / 2.65 .700 ". It will be obvious that any feature actually starting at "O 0 ", i.e. the SW corner, must be entered with the "O 0 " first.

5.10 Section 10. Other Species in the Plot

This section, which needs to be filled in after all the other botanical recording, contains the names of any species (of living vascular plants) rooted within the plot but not entered elsewhere as within the plot. The section thus comprises a list of names, suitably terminated. Where there are no such names to enter, a "O" (zero) is recorded.

It is important to remember that names entered under parts of sections $1,2,4,5$, or 6 do not necessarily imply species within the plot (they can appear in the vicinity, or as impeders, in a relaskop sweep or as contributors to cover without being rooted in the plot) and so any such species names must be repeated here unless they appear in some other section that does indicate plants that were rooted within the plot.

It is not necessary to include here any of the "ecosigs" in the next section ( $\underline{5.11}$ ), as the program handling names adds the ecosig spectes to the plot species list, if they are scored as present.

\subsection{Section 11. Species of Ecological Significance}

For each of the species listed below, a score is entered to indicate the estimated percentage ground cover over the whole plot from living specimens of the species rooted within the plot. As for the other cover estimates, a seasonal maximum is assessed where necessary.

The scores, assessed over the whole plot area, were :

$\begin{array}{lll}0 \text { (zero) } & \text { Absent } & \\ 1 & \text { Up to } 5 \% & \text { cover } \\ 2 & 5-25 \% & " 1 \\ 3 & 25-50 \% & " \\ 4 & 50-75 \% & " \\ 5 & \text { Over } 75 \% & "\end{array}$


The species concerned are:

Rubus fruticosus
Pteridium aquilinum
Chamaenerion angustifolium
Endymion non-scriptus
Urtica dioica
Mercurialis perennis
Sambucus nigra

\author{
(bramble, the aggregate) \\ (bracken) \\ (fireweed) \\ (bluebe11) \\ (stinging nettle) \\ (dog's mercury) \\ (elder)
}

\subsection{Section 12. Permanent Features; Slope, Aspect, and Water}

1 The overall percentage slope of the plot is measured (for which the poles come in useful as aids), and entered to the nearest percent as an integer number, e.g. "12". Where the slope is not uniform, the greatest overall net slope is assessed. No net slope can be entered for a "U"-shaped plot; the same entry is made as for a level plot, 1.e. "0". We used the relaskop for slope measurements, but any clinometer would serve. Entries for measured slopes must be positive numbers.

.2 The aspect of the plot, assuming a slope of more than zero was entered, is measured downhill to the nearest $10^{\circ}$ with a compass and entered as a magnetic bearing, e.g. "270". If the aspect is 0 (zero), it is preferable to enter "360". If the plot is horizontal there is no aspect, i.e. no net slope, so " 0 " is entered. Negative entries are barred.

.3 The presence or absence of water is entered, selecting a score from the following:

$\begin{array}{ll}0 & \text { Ni.l } \\ 1 & \text { Some on surface, probably temporary } \\ 2 & \text { Ditch or holes liable to fill } \\ 3 & \text { Small stream or large ditch with water } \\ 4 & \text { Larger stream ] } \\ 5 & \text { Pond or river ] }\end{array}$

Running water was shown by recording the score as a negative.

If any of the above three items are to be entered as "NOT RECORDED", use the entry "-9" for slope or water and "-99" for as pect.

\subsection{Section 13. Circlets; Standard Recordings}

Circlets were subsampling units, each a $0.1 \mathrm{~m}^{2}$ circle delimited by a wire hoop placed on or near the ground, within which presence/ absence observations were made as described in 3.16 and 5.13 to 5.15 . siting and numbering is shown in Fig. 2; it was standard in all except twelve quadrats at Bix (details in para. 6.1.8). 
Fig. 6 Recording "Features"

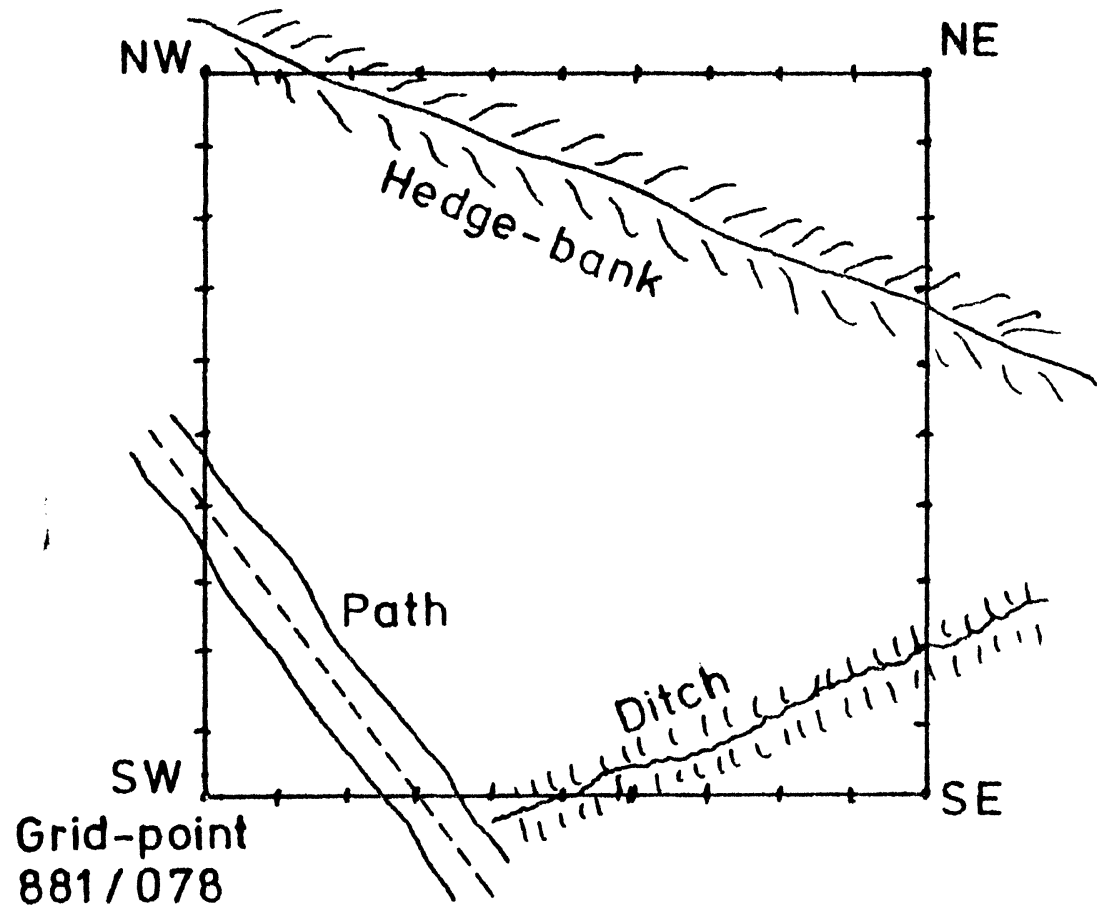

Fig. 6. The features sketched on the above plot chart would appear in the computer record as:

FEATURES. (MAX $=3$ ) DESCRIPTION AND CO-ORDINATES IN THE PLOT

$\begin{array}{llrrrr}\text { DITCH } & \text { I } & 5.0 & 0.0 & 10.0 & 2.0 \\ \text { PATH I M WIDE } & / & 3.0 & 0.0 & 0.0 & 4.0 \\ \text { OLD HEDGEBANK } & / & 1.5 & 10.0 & 10.0 & 6.8\end{array}$


The circlet is placed in turn at 13 positions (Fig. 2), and suitable entries are made under this and the following two sections for observations made on the contents of the circlet. The positions are found using the tapes laid along the diagonals during marking out. They are:

First diagonal (from SW to NE corners of the plot) at

$1,3,5,7,9,11$ and 13 metres along the tape and

Second diagonal (from NW to SE corners) at the

$1,3,5,9,11$ and 13 metre marks.

The centre of the circlet is placed over the mark, but see note at the start of this chapter (para. 5.0) for adjustments made where the ground slopes. The forms (Appendix 2) have thirteen columns for presence/absence entries, one for each circlet position. In this section there are five lines, one for each of the phenomena to be observed.

The whole section may be omitted by a single entry of "-99", otherwise all five lines must have a complete set of entries.

5.13.1 Litter: i.e. dead leaves, twigs etc. This is an almost undefinable term, but for example matted living grass with dead leaves at the base would not count as litter unless there were leaves from elsewhore present as well. If more than a trace of litter is present, then a "l" is entered in the column for that circlet position.

Should more than a trace of woody litter be included (twigs etc.), then the entry is "- 1 " instead. Absence of litter is scored as "O" (zero).

.2 Bare soil: any mineral soll visible without disturbing the surface is scored as " 1 ", otherwise a " 0 " (zero) is entered.

.3 Stones: any stone of diameter greater than about $10 \mathrm{~mm}$ visible without disturbing the surface is entered as " 1 ", otherwise a "0" (zero) is entered.

.4 Moss: entered as " 1 " if any appreciable amount of living bryophyte is present. Lichens, if large, are included, but small lichens growing on wood are not. Should some or all of the hryophyte be growing on wood, living or dead, then the entry is " 1 ".

.5 Moss mat: this classification does not relate to the growth habit of any species, but "mat" is classed as present if bryophytes are abundant, loosely defined as covering more than a tenth of the area of the circlet. This is also a subjective judgment. The entry is "1." or "0" (zero).

Lichens are excluded from this classification.

\subsection{Section 14. Circlets; Bryophyte Classes}

One or more of the following seven species classes were recorded - we cannot claim to have done more than noticed these relatively conspicuous species, nor necessarily to have recorded all of them if some were present in very small quantity: 
Hypnoid: any species showing the branched habit of the genus Hypnum but not included in the following classes:

Mnium hornum

Mnium undulatum

Pseudoscleropodium purum

Rhytidiadelphus squarrosus

Thamnium alopecurum

Thuidium tamariscinum

As soon as any of these is encountered in a circlet, its name is entered, together with a "1" in the appropriate column. Absence in previous circlets is entered as a set of "O"s (zeros). Presence or absence entries are then made for each further circlet. It is not necessary to enter any bryophyte class not found in any circlet.

The list of bryophyte classes must be terminated. This is done either by entering $a$ "/" in the column for that purpose or by entering a "O" in the next vacant species name slot. If no bryophyte class was found in any circlet, then the "/", if used, is placed in the final column of the last entry of 5.13 .

5.15 Section 15. Vascular Plant Recordings.

Entries are made for any live specimen of any vascular species found rooted within a circlet. The species name is placed in the first column, and a " 1 " put in the appropriate column for that circlet position, Where the species is a tree, the "presence" entry is the height of the tallest plant in centimetres, up to a limit of "100" for any plants over $1 \mathrm{~m} \mathrm{high,} \mathrm{and} \mathrm{rounded} \mathrm{to} \mathrm{the}$ nearest $10 \mathrm{~cm}$ except for plants of less than $20 \mathrm{~cm}$ or $s 0$.

Absence of any species already entered for a previous circlet is indicated by a "O" (zero). A11 columns must have an entry. In this way a list is built up of presence/absence scores for any number of species found in the circlets.

As for the previous section, a terminator must be entered, and the same rule applies except that a "O" (zero) has to be used if there are no entries made, i.e. no vascular plants are found.

It is possible to record the presence of water in a circlet; the "species name" can be entered as "WATER", or indeed as anything else with nine or fewer digits.

Problems may arise with small seedlings, perhaps with cotyledons only which are hard to identify. We had no set procedure, but the following seemed reasonable:

If the species cannot be determined with reasonable confidence by looking at other plants in the area, then either enter "genus sp?", e.g. "CAMPA TR?", or, if the species is not at all certain, then perhaps "CAMPA SP." or "CAMPA SP?". In some cases identification may be so hard that plants will be excluded completely. This is less serious than it perhaps sounds, as entries in any section of our forms only mean the recorders were fairly sure that the named species was present. A lack of entry does not prove it was not there. 
The following is an example of set of entries for circlets, in thirteen circlet columns:

Observed Entries

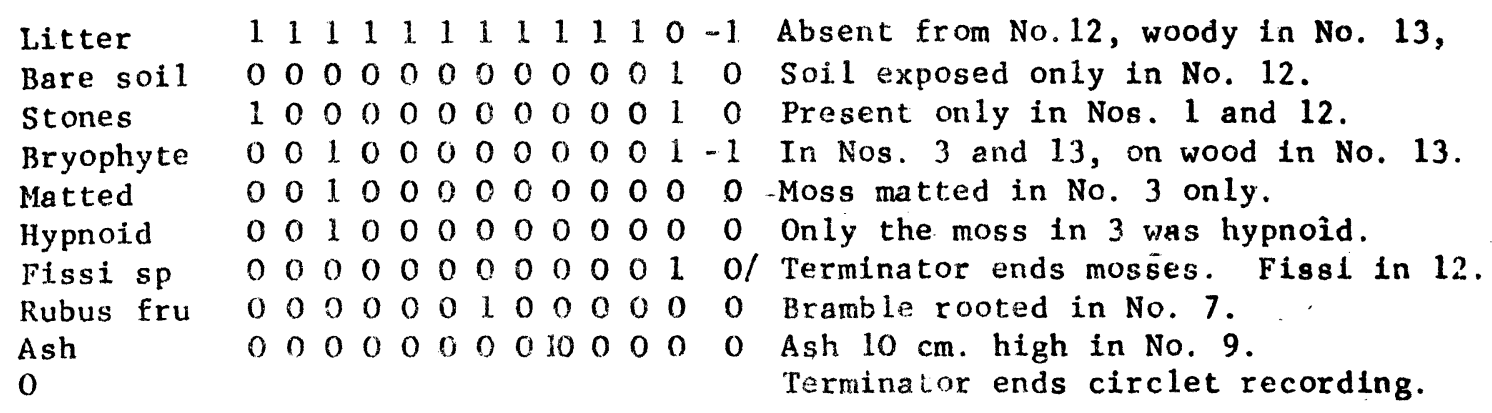

A fuller example is given in Appendix 7, "Readable version".

\subsection{Section 16. Soils Information.}

A number of soil samples were taken at each plot, either at the same time as the botanical recording, or later if time was then short. We developed two methods of taking the samples: either by use of an auger of our own design, or by digging small pits. The former we think preferable, as disturbance to the site is less, but it is not practicable in stony soils. Details of the design and use of the auger and how the pits were dug are to be found in Appendix 4 and Fig. 7 .

The soil samples are meant to be representative of the plot area. We therefore tock four samples at each plot and bulked them together. It may be that the samples bulked are of unequal volume. While we tried to avoid this, it was sometimes inevitable with the auger method. Each sample consists of subsamples taken from three depths: $0-10 \mathrm{~cm}, 10-20 \mathrm{~cm}$ and $20-30 \mathrm{~cm}$, "0" (zero) is taken to mean the top of the mineral soil, ie. base of the litter horizon. To minimise any effect on the plot itself, the samples were taken from points along the edges, just outside the perimeter tapes. Clearly the most even sampling would he got by taking points halfway along each edge, but we sometimes used pairs of points along the edges adjacent to the base corner,especially in thicket conditions. This was to lessen trampling where sampling was done in the winter, and speed up the process, as only two tapes needed to be laid out. The "standard" positions of these points at Wytham were generally at co-ordinates of $0 / 4,0 / 9,4 / 0$ and $9 / 0$ metres, whereas at Halton they were generally at $5 / 0,10 / 5,5 / 10$ and $0 / 5$. The sequence was as follows:

5.16.1 The date, plot number, recorders' initials and page number are entered on the soils form. Only the date is punched.

.2 The sampling method is chosen; auger where possible, otherwise digging.

.3 Tapes are laid out (if not already done at the same time as botanical recording). 


\section{Fig.7 Soil Auger}

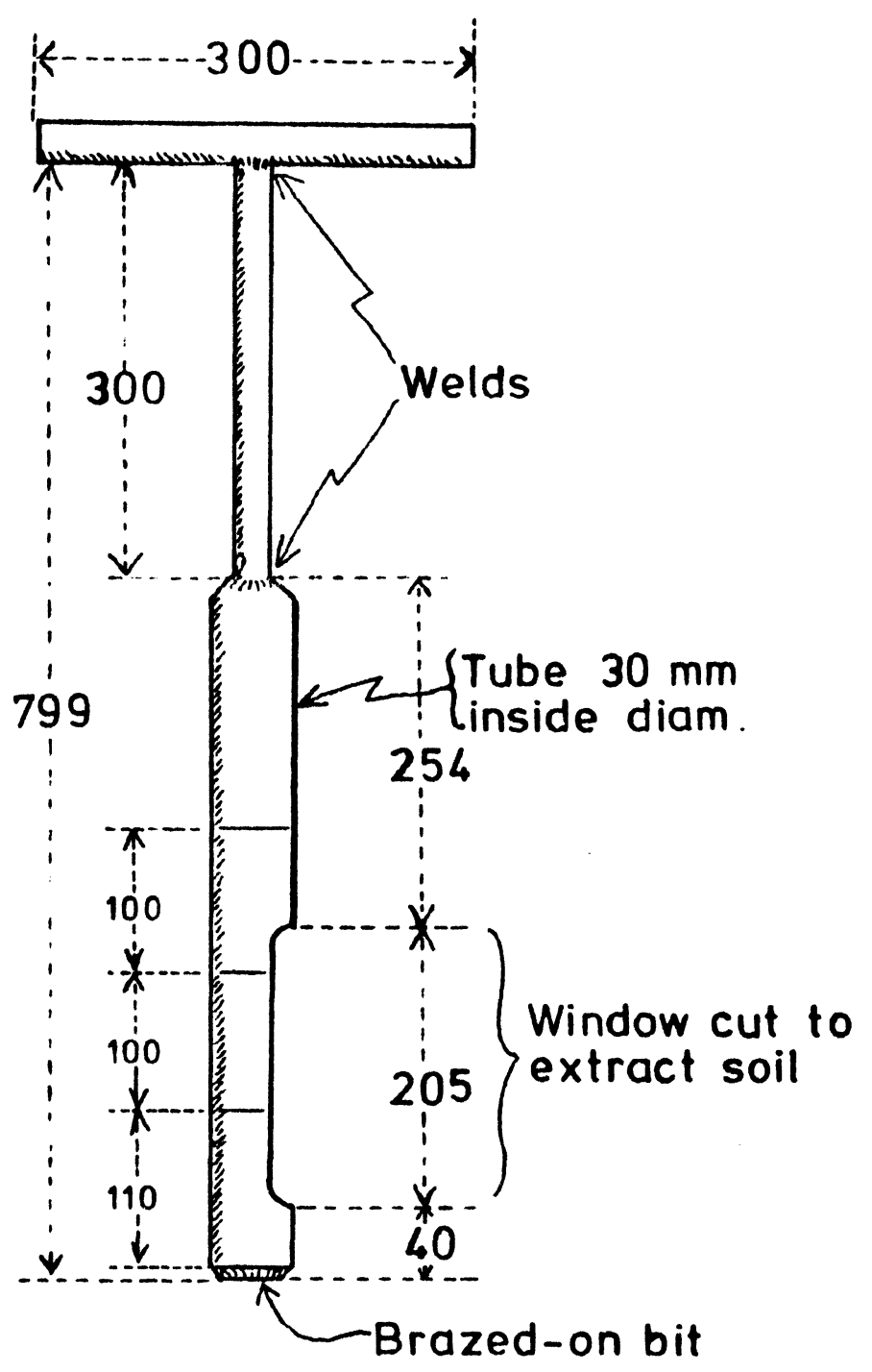

(All dimensions in $\mathrm{mm}$ ) 
.4 The first sample point is chosen. The standard position may be modified by local conditions. If a tree or other feature happens to be very close, then the point has to be at a nonstandard place. We usually shifted points as little as possible;

for example, if there was a tree at $0 / 4$, then the point might be taken as $0 / 4.5$.

5.16.5 For this point, the co-ordinates are recorded on the form. The soil sample is taken and put into bags. Where the auger is used, up to three repeat samples are taken if the full depth is not achieved.

.6 The sampling depth is noted, and any obstruction to the intended depth of $30 \mathrm{~cm}$, or other difficulty, is noted as follows :

N Sample rejected because of animal burrow or other nuisance.

Q No difficulty - no obstruction.

$R$ Rock apparently in situ, e.g. chalk.

S Stone.

W Root or wood.

$\mathrm{X}$ Unknown obstruction.

.7 The type of sampling and number of sample points are noted at the head of the form, e.g. "PITS 4" after 5.16.4, 5.16.5 and 5.16 .6 have been repeated for the other three sample points. The sampling type is entered as "PITS" or "CORE" or "BOTH".

.8 After laboratory work, described in Appendix 4, the $\mathrm{pH}$ and organic matter content of each depth are recorded. Both are entered accurate to one decimal place.

.9 Aliquots of about $25 \mathrm{~g}$ of dried soil are separated from each depth sample and analysed for chemical content, at the Mer lewood Laboratory.

The results appear in the record as shown in Appendix 7 , section 1, "Readable Version". 
$-$ 


\section{VARIATIONS IN THE SYSTEM AT THE THREE SITES}

$6.0^{\circ}$ Because the three sites were recorded over the space of three years, Bix in 1973, Wytham in 1974 and Halton in 1975, there are differences between the methods used at each site and the "final" method as defined in Chapter 5. The system was generally consistent within any one reserve; the differences are given in the following sections.

\section{$\underline{6.1} \quad \underline{B i x}$}

1 Plots were recorder at every $100 \mathrm{~m}$ grid intersection, not at alternate ones as : $t$ Wytham and Halton. Of the 101 plots marked out, 5 cov $\therefore$ not be re-located and were omitted (at his stage a t tal detector was not available).

.2 Some sections of ta were not recorded at all. These were:

5.11 ecolo izally significant species

$\underline{5.12}$ permaient features

$\underline{5.13}$ soil information

.3 Some sections were partly recorded; the items omitted were:

5.1 general description - plot typicality and slope class; planting dates.

5.2 leading trees - heights

$\frac{5.3}{5.9}$ other trees dead - diameters

$\underline{5.9}$ features - were limited to two.

.4 In the circlet recordings, bryophyte growing on wood had a separate entry rather than a negative entry under "MOSs". An entry of "WOOD" was made under section 5.15 (translated by the programs to the species "WOOD*MOSS"). Tree species in quadrats were simply entered as " 1 ", meaning present, without height.

.5 Relaskop observations were made at (A) SE corner, and (B) NW corner of the plot, as in Fig. 3.

.6 The diagonals for quadrat placement were No. 1 NW-SE and No. $2 \mathrm{SW}-\mathrm{NE}$, also as in Fig. 3. Cover estimates used the NW-SE diagona 1 .

.7 Extra bryophyte species other than those listed in the classes in Appendix 1 occasionally appear, mostly in plots where "EJ" was present.

Their omission from other plots does not mean that they were absent.

.8 Some records for plots recorded before 1st June 1973 are incomplete; items were added to the forms as recording proceeded. Items sometimes omitted include: bole and crown damage codes for leading trees, component species for upper cover \%; other trees dead. 
For a few plots, the circlets were recorded at positions one metre apart along diagonal 1 only (Fig. 3). The plots which contain these inconsistencies are: $721 / 874,5,6$, $7,8,9, ; 880,1,2,3$ and $722 / 874,5$. Cover estimates also used this diagonal.

6.1.9 Our definition of "tree" was not always adhered to in relaskop sweeps, e.g. "DOGWOOD" appears in some of them.

\subsection{Wytham}

.1 In the description (section 5.1), planting dates, slope class and plot typicality were not recorded.

.2 Only one tree of the four leading trees was heighted (rather than two as in Halton).

.3 Elder was not included in the list of "ecologically significant species".

.4 Trees were sometimes included in circlets if only part of the bole fell within. The final rule was to count as "In" only those trees whose bole centres at ground level fell within the circlet.

.5 Species that gave a positive score under the "ecologically significant species" section were entered as "other species" as we 11 .

.6 A11 soll samples were taken by auger. This means that deeper layers were occasionally not sampled as they would have been if the pit technique had been used. For the earlier soll samples, standards for drying, sieving etc. were not exactly as finalised. This is noted in Appendix 4.

\subsection{Halton}

.1 Entries in the "description" section for slope class and typicality were not 8 tandard, although the standards were imposed before punching the cards. On the forms, the texts "SHEDDING", "RECEIVING" and "UNCLASSIFIED" appear, translated as " -1 ", " +1 " and " 0 " respectively; and for typicality "TYP" or "NOT TYP".

.2 Plots not representative of the vegetation in that they contained little but metalled or surfaced ride were not recorded, or in some cases not laid out. At the other sites, such plots were always recorded.

\subsection{Inconsistencies Occurring in al1 Reserves Examined}

There were, inevitably, a number of inconsistencies dependent on which observers were present. Some hinge on definitions that are subjective, others on traits of a given observer. The list that follows is not complete, and does not attempt to assign quirks to particular recorders. The variables were: 
6.4.2 Accuracy of cover estimates and scores for "ecologically significant spp".

.3 Consistency in naming tree species. In some cases the full binomial was used throughout; in others only on the first entry, with the English name used for later entries. This meant for some cases that two species names resulted from the computer programs. For example, entries for four leading trees of "IARIX DEC ...", "LARCH ...", "LARCH ...", "LARCH ..." result in "LARIX DEC ..." "IARIX SP ...", ... This is perhaps an advantage, as it is possible that the recorder did not examine every tree of Larix or Salix sufficiently closely. The list of translations provided by the programs is relevant to this; it may be found in Appendix 3.

.4 The parts of a tree defined as "bole" or "crown" for damage scores.

.5 Whether species are entered as "impeders" when a tree has a crown class of 4 .

.6 Inclusion or otherwise of trees dead, but of the same species as the leading trees.

.7 Entries for "moss mat"; the definition, like the mat, could be loose.

.8 Inclusion of trees within circlets. (Mentioned in 6.2.4.).

9 The treatment of plots only partly within the woodland boundary, discussed in $\underline{6.5}$.

10 The treatment of multiple-stemmed trees as leaders. If a tree was clearly a coppice growth from a single stool, the largest stem was counted as a single tree, and the others not counted. Where it was not clear whether only one stool was involved, more than one stem may have been included among the leading trees.

6.5 Special Cases. Plots falling partly outside the woodland boundary or on irrelevant ground caused considerable difficulties. Our practice was to omit any relaskop sweep or circlet falling outside the boundary. In such cases the entries "-99" (whole section omitted) or "-9" (single item omitted) were appropriate entries.

In addition, the woodland boundary, fence, ditch or hedge, was entered as a "feature" with its co-ordinates.

In several cases plots within the reserves were clearly grossly atypical or irrelevant. At Bix and Wytham, all plots were recorded, but at Halton, those not representative of the managed area were omitted. Where omissions are made, we advise making an entry in the general description explaining why the plot was omitted, filling up as much of the rest of the "description" (section 5.1) as seems right, and marking all other sections "-99". 
6.6 Persons Engaged in Fleld Recording

The infitials of recorders at our three sites are expanded below; some of them were present at only a very few of the plots.

\begin{tabular}{|c|c|c|c|}
\hline HD & H.C. Dawkins & ) & \\
\hline DR & D.R.B. Field & ) & \\
\hline WA & W.M.W. Adams & ) & \\
\hline PL & $\begin{array}{l}\text { P.S. Lloyd } \\
\text { L. Roberts }\end{array}$ & ) & Department of Forestry, Oxford \\
\hline WR & W. Rides & ) & \\
\hline EJ & E.W. Jones & ) & \\
\hline TS & T.J. Synnot & ) & \\
\hline $\begin{array}{l}\text { NP } \\
\text { VP }\end{array}$ & $\begin{array}{l}\text { N.J. Phillips } \\
\text { Vera N. Paul }\end{array}$ & ) & $\begin{array}{l}\text { Berks., Bucks. and Oxon. Naturalists } \\
\text { Trust. }\end{array}$ \\
\hline RW & R. Webster & ) & Soil Survey of England and Wales \\
\hline DB & D. Briggs & ) & Geography Dept., Univ. of Sheffield \\
\hline $\begin{array}{l}\mathrm{JF} \\
\mathrm{WF}\end{array}$ & $\begin{array}{l}\text { Juliet E.A. Fi } \\
\text { W. Field }\end{array}$ & eld) & Interested parties; other helper \\
\hline
\end{tabular}




\section{CHAPTER 7}

\section{HANDLING AND STORING THE OBSERVATIONS}

7.1 Policy. From the start of the project, we felt strongly that the information gained should be easily accessible. The task of the computer was to facilitate this; its ability to "process" the observatinns was considered a secondary job, which could largely be left to users with particular interests.

We also held it essential that the method of recording should not be so tailored to convenience in computing that it became hard for people to use the system. For this reason, we refrained from using numerical species codes, and allowed the use of botanical names in full or in part, or where customary, the English name could be used.

The time spent by the central processor of the computer (clearly greater with such an approach) we regard as less important than ease of recording.

This includes several aspects: entries on the forms in the field, the preparation of data by perhaps unskilled people, data checking ("validation" in computing jargon), and understanding the printouts produced. In defence of this, it seems true that computer time is becoming cheaper relative to staff time and frustration.

7.2 Equipment Available to the Project. The Department had access to the University computer, an ICL 1906A, with the following configuration:

$256 \mathrm{~K}$ words ( $256 \times 4 \mathrm{~K}$ bytes) of core store;

Disc files up to $245 \mathrm{~K}$ words;

2 drums;

7 and 9 track magnetic tape transports;

Central and remote $c$ ard and paper tape readers;

" " " 120 character single case line printers;

10 inch or 30 inch paper graph plotter;

George 3 operating system.

The languages available were:

COBOL, FORTRAN, ALGOL, BASIC, ALGOL68-R, PIAN, BCPL, SNOBOL.

For ease of processing texts, the versatile high-level language ALGOL68-R was chosen for most of the work. This allows list processing (sorting of texts), the structuring of data into chunks regardless of type, magnetic tape or disc files without much programing effort, and is regarded as "efficient" compared with, say FORTRAN (Fie1d, 1976). ALGOL68-R is implemented on many 1900 machines and is likely to be available on the new 2900 series.

The disadvantage of this language is that it is not used on other makes of machine, being a dialect of ALGOL68 at present confined to the 1900 series. Because of this we paid much attention to the need to transform our freely-laid out and unformatted observations to a version easily readable by programs in less flexible languages such as BASIC, FORTRAN, and ALGOL-60. 
7.3 Other Users. We assume that the computing facilities accessible to others who may wish to use our observations or our system may be more limited. It is probable that 80 -column card readers, and perhaps paper tape readers will be available. Therefore the printouts from our programs can be expressed on paper tape for transfer elsewhere, and one version of the listing program will produce 80-column formats for direct production of punched cards.

7.4 Summarising the taks of the Computer. We required our programs to:

1 Check the observations for correct sequence, completeness, and to some extent remove nonsense.

2. Read the records and decode English names to Latin binomials, and then output them in various formats suitable for storage or for other users, or for tasks such as analysis, listing or mapping.

.3 Demonstrate how searching, tabulation and mapping can be done. Once second-occasion recordings have been carried out, programs will have to perform comparative validation and output, but we have not yet attempted this.

Programs to carry out the three tasks above were constructed, and are described in Appendix 7. Sample outputs are contained in Appendix 8.

7.5 Transfer of Observations to the Computer and Subsequent Handling.

The method we have used is to punch a set of cards direct from the field forms. Since there are few constraints on layout of the information on the punch cards, this requires little training. The restrictions on layout are listed below:

.1 Any number must be terminated by one or more spaces or a new line.

.2 Species names, if one-word texts, must be terminated by two or more spaces or by the characters "," or "/". Two-word texts follow the same rule, but there must be only one space between the two words. A new line also terminates a species name.

.3 The final name in any list of species names must be followed by a list terminator, i.e. "//" or in some cases "0" (zero).

.4 The "general description" of a plot (para. 5.1.5) must be on a single line of its own.

.5 If leading tree information is split over more than one line, the "comment" text must be on the same line as the preceding item, and data for the next tree on a new line (para. 5.2.9).

.6 If "other tree dead" information follows a "comment" text, it is safer to start it on a fresh line (para. 5.3). 
Otherwise, spaces and new lines may appear in any quantity in any position. The program to check the logic of the data is aided if a new line (i.e. blank record) separates each plot.

If the field forms have been filled up properly, the puncher will not have to attend to items 7.5 .2 . or 7.5 .3 .

The punched data were checked by running them through the checking program, correcting any errors found, re-running and so on until error-free. Spelling had to be checked by proof-reading. We did not verify the cards (i.e. punch a second set and compare the two), but carried out several proof-reading checks instead.

In practice we have found it fairly easy to locate punching errors using the checking program. Omission of data items tended to show up close to the point of omission, which meant the program could often diagnose the point fairly well. This was of course due to each section of data each consisting, for the nost part, of different constructions.

\subsection{Data Storage.}

At the time of completion of this document, the observations were stored in the following forms at the Department of Forestry, 0xford :

.1 Original field sheets, format as in Appendix 2.

.2 Punched cards, direct from field sheets but checked and we hope error-free.

.3 Magnetic tape, at the Computing Laboratory (not in Dept. of Forestry).

.4 Soil-samples bagged and stored in the Department of Forestry, as described in Appendix 4, para. 5.

.5 Bound, "readable" computer printout, with sketch-map of plot distribution and copy of Appendix 6.

This last category was also distributed as follows:

Bix (1) Warden's Office, Warburg Reserve, Nettlebed, Oxon.

(2) BBONT Head Office.

(3) Department of Botany, Oxford.

Wytham (1) Wytham Survey Office, Dept. of Zoology, Oxford.

(2) Dept. of Botany, Oxford.

Halton (1) Forester's Office, Chiltern Forest, Wendover.

(2) Library, Forest Research Station, Alice Holt, Wrecclesham.

Copies are also available for the I.T.E. Biological Records, Monks Wood. 


$$
-
$$


CHAPTER 8

\section{CONCLUSIONS AND RECOMMENDATIONS}

8.1 The aims of the project are stated and discussed in Chapter 2 , especially in para. 2.5. We now comment on the methods as they turned out in practice, and how we would modify them if the same objectives were to be pursued in other woods.

8.2 One of the most debatable and frustrating points of technique ground was the use of systematically-rather than subjectively-sited plots. Random arrangements, rejected by the arguments in paras. 2.8.1 and 3.10 , would have been equally irritating. Two defects of the low-fraction systematic arrangement obtruded:

.1 A smal1 event, however important, is unlikely to be detected unless occurring frequently. For instance, a patch $10 \mathrm{~m}$ in diameter of a rare species or an invasive exotic or a focus of disease has to recur over thirty times in Wytham before it has more than an even chance of being detected, and over 150 times before $\mathrm{P}$ (hit) reaches 0.95 . (Table 3 in Appendix 1, and Fig. 12). Hence to some extent the system might fail to achieve one of its objectives - the early detection of a change before it becomes widespread or uncontrollable. A more sensitive system would be to supplement the systematic grid by subjectively-sited but identically-recorded plots in areas of special. interest, but possibly with extra observations depending on the particular event for which the plots were chosen.

.2 The extreme alternative to the systematic grid is to use subjectively-sited permanent plots for any areas or events of special interest, supplemented by temporary plot or transect sampling over the rest of the area whenever a change or event seems important enough to require general quantification. This method can however observe special phenomena on $1 y$, all others being biassed and even the special one requiring considerable extra work before its general impact can be assessed. It could not efficiently detect that important class of event which is "yet undreamed of", nor could it provide the widespread correlates on which a diagnostic and predictive model for a whole ecosystem can be built up. It is of investigative rather than monitoring type and we would not use it for the objectives of this project.

.3 The second apparent defect of rigidly mechanical sample siting was the seeming wastage of plots on uniformative sites such as road-junctions, excayations, car-parks etc. or in positions a metre or two outside the forest boundary. Excepting the last, these misfortunes occurred at one, two and four percent of the plot sites in Bix, Wytham and Halton respectively, reflecting the graded and metalled roads of the latter compared with the mostly herbaceous rides in the other two.

.4 Wastage of lesser degree seemed to lie in the many plots which straddled some extreme vegetation boundary such as 
edges of conifer plantations, rides or blackthorn thickets. For the surveillance purpose such plots are as valuable as any, but for analytical or modelling purposes subjective siting would be more informative. Out of 123 plots at Halton, $59 \%$ were classed as "typical", that is they might we 11 have been chosen as representative of the site and vegetation in which they lie if selection had been deliberately for that purpose. At the other extreme, $28 \%$ lay across conspicuous site/vegetation boundaries which form no small part of Halton wood, and $12 \%$ were on lesser boundaries or for other reasons were unsatisfactory for ecological modelling.

.5 Vexatious though these sitings seemed at the time, we concluded that they appeared to be sc for humanly subjective reasons, and that bias would result if plots were "moved" to apparently useful positions. Apart from the supplementary plots suggested in 8.2.1, the main series must remain entirely unbiassed if the surveillance system is to provide information for management of the whole woodland area.

.6 The location of plots at grid points (Bix \& Halton) rather than near them (Wytham) may be a mistake. Should the actual National Grid intersections be required by other investigators, the surveillance plots risk an atypical amount of trampling and other interference. We would prefer to have placed the Bix and Halton plots at a constant distance and bearing from grid-points, not necessarily exactly as in Wytham (para. 4.4.4) but at a similar distance. Why we did not do so at the time is a mystery.

\subsection{Plot Frequency}

As with plot size, there can be no ideal frequency for a multiplicity of observations, all with different and unknown probabilities of detection. The number which seems reasonable will also depend on the extent to which subjectively-sited plots are used, as suggested in 8.2.1. Given that these are established in areas of especial interest, we judge that the overall surveillance system would be adequately served by forty to sixty systematically distributed plots, a number which ensures no unsampled block can exceed from $1 / 25$ th to $1 / 50$ th of the total area.

\subsection{Monumentation}

While trying to re-find plot markers with a metal detector, we found various difficulties in the system. Unless the grid point is known to within a few metres, it must be at least approximately found by re-survey from the nearest known point, which may be another plot or some other suggested point perhaps a hundred metres distant. This could mean thickets, steep slopes or other sources of error and considerable delay. The plot position can only be "approximately known" if it records some striking feature, or some exceptional tree, which has persisted since the last time of observation. There are often plots in which no such feature can be found, at least none which might still be there a few decades later. This was the reason for markers projecting above ground at Bix, for the $100 \times 100 \mathrm{~m}$ grid system of chestnut stakes in Wytham, and for the forty-odd oak stakes 
$e^{\prime}$ strategic grid intersections at Halton.

Another difficulty was that our markers were not the only metal objects to be found in woodland soil. Shot-gun cartridge cases, fragments of wire and discarded equestriana sometimes confounded the detector. We saw no way out of this difficulty short of greater expense for magnetized markers and more specialized detection equipment, if the principle of "easy to detect but difficult to encounter" was to be preserved. The Wytham solution was the best, but that depends on a low level of casual interference and vandalism. In more vulnerable places some naturally persistent feature, in or near the plot, would have to be used, and the markers would have to be readily re-found with the minimum of burrowing, once detected electronically.

\subsection{Tree Recording}

Accepting that it is impracticable as well as unprofitable to measure or even put into size-classes all trees in a plot (para. 3.12), we found only one defect in the leading-tree principle namely that one can fail to measure quite a large species B or C if four larger specimens of $A$ have already taken up the leader niches. $B$ and $C$ would of course appear in the species list, and possibly among the canopy scores, impeders and relaskop tally, but we were still dissatisfied. It might be better to record the leading specimen of every tree species present, rather than the four leaders irrespective of species. However, this raises several problems: how many heights as well as diameters? Would it be lesirable to measure the second of each species also? should one record the four leaders first and then the leader of every other species not yet recorded? We did not test this suggestion but recognize that considerably more time would be taken with each plot if it were done, particularly if it seemed necessary that more heights had to be measured.

8.7 Our information on canopy density and composition was not satisfactory, and we considered repeating it along the other diagonal but feared to multiply what was already doubtful. There seemed no way to reduce its subjectivity short of presence/absence recording of similar information above each circlet. But with this, it would be difficult to make consistent judgments of what constitutes canopy above a circlet - one leaf, one branch, dense follage? The problem remained unresolved.

\subsection{Ground Flora Observations}

We found the circlet observations simple and objective, but time-consuming, and were in doubt only about their number and distribution. The thirteen circlets on two diagonals were placed in that way to be easy to locate precisely. A square grid of, for instance, 16 circlets covers the area better but would have entailed placing four tapes across the plot instead of two, with their ends less easily located. Since circlet recording in any complex vegetation was laborious, especially in casualty gaps and at ridesides, we were shy of putting down more circlets.

8.9 The "ecosig" observations were also simple in practice, especially with the plot divided into four triangles by the diagonal tapes, but were more subjective than we would have liked. There was 
also the problem of how many species it was reasonable to record in this way, since "ecologically significant" would be differently defined by every ecologist.

As it turned out, the elder was not worth recording in this category, being in woodland and generally too straggly in form for easy assessment of cover. We concluded that the ecosig observations were worthwhile with our particular distribution of circlets, but would be superfluous if 16 or more subsamples were put in.

8.10 The long-stop to all other botanical records was the "other species present" category covering the whole plot. Given our limited botanical ability it was also the easiest to carry out and will be the easiest to repeat, requiring only a search and nomenclatural fidelity. It is not an observation which could be omitted when a lmost all others are selective or are sub-samples. Apart from the relaskop sweeps, it is the only potentially "complete" record from the sample plot. However, it would not contain sufficient information for correlation with other events within plots, without the circlet, leading tree, canopy and ecosig observations.

\subsection{Information on Soils}

We found the constraints described in para. 3.19 to be extremely restricting, and could think of no improvements other than analyses of more minerals. We could however have used our small holes for bulk density measurements, had we used glase bead or water-balloon techniques, though accepting that considerably fewer plots would be established in the time.

More complete mineral analyses can be done when required on the dried soil samples retained in oxford, duplicates of the ones which were sent for analysis at the Merlewood Laboratory.

\subsection{Organisation and rate of fieldwork}

The work for each plot has four separable components: surveying to find the grid-point, demarcation and staking of the plot itself, botanical recording, and soil collection. Only the third must be done in summer. In practice we found it most economical to complete the first two jobs in winter or early spring when vegetable impediments are least, doing the last two simultaneously in summer. A day's fieldwork on botanical recording and soil collection by two to three persons achieved from three to eight plots, averaging 4.1 at Halton, 3.5 in Wytham and 4.6. at Bix (no soils from there). Adding in the work on survey and demarcation raises the cost to 1 manday per plot, and further addition of laboratory work on the soils, punching computer cards and checking the printed observations must raise the cost to 2 mandays per plot.

In fact the project occupied about 1200 mandays (500 technician, 700 post-doctoral, omitting week-ends, holidays, day-release, etc.). At two mandays per plot, about 760 days were directly occupied with survey, collection and processing of the observations and soils, leaving about 440 on the preliminary study tours, preparation of materials, development of computer programs, and the usual "overheads". 
8.13 It is important to realize how much of the 2-mandays element was occupied with physical difficulties in the dense, thorny thickets of all three woods and in the extremely stony soils at Halton. In closed woodland on deep stoneless soils, 8 plots were easily recorded per day, and in sandy soils the laboratory work would also have been reduced. Botanical work at ride edges and in other rich herbaceous vegetation would have been greatly accelerated had we been more experienced botanists. Perhaps twice the speed in recording circlets and "other species present" was achieved when we had the assistance of Dr. E.W. Jones or Dr. P.S. Lloyd.

8.14 It is therefore possible that a more botanically experienced team working on kindlier soils could halve the time that we required for the observations, collections and laboratory work. Given the programs that we developed, a sixteen-week summer seas on with 20 plots recorded per week (rainy days must be allowed for) including the laboratory processing, should be feasible for a two-man team within a year, the preceding and following weeks being adequate for preliminary survey, demarcation, soil analyses (if not done elsewhere), data processing and completion. Such a 300-plot project could reasonably cover any area from 300 to 1200 hectares, depending on the sampling intensity required.

\subsection{Summary of Recommendations}

Before making recomnendations it is necessary to re-state and define the objectives for which the recommendations are made.

"To devise a system of permanent low-fraction sampling of polyspecific uneven-aged woodland capable of diagnosing and predicting long-term changes in specific composition and growth over large areas."

The critical words are understood as follows:

system: described in sufficient detail and supplies with computer programs so that others could employ - or modify - the whole package without help from its originators.

permanent, long-term: such that the sample points and the records made thereat can be precisely re-located for the forseeable future, certainly for a century ahead and preferably longer.

low-fraction: such that the work would be practicable over any large managed area, by adjustment of the sampling fraction.

polyspecific uneven-aged: (the latter word has been added since para. 2.5) suitable for mixed irregular woodland, also for monocultures but the former requires elaborations not necessary in the latter.

diagnosing: suggestive (though not probative) of causes, by correlation of changes between variables. It was this and the next objective that made it necessary to observe and measure soil characteristics as well as the vegetation. 
predicting: given that parallel changes are recorded over several periods, models of the ecosystem could be fitted and some degree of prediction achieved.

large areas: the vaguest term in the objective. Intended to convey the managerial scale, the whole forest or larger management unit thereof. In Britain this could be from fifty to thousands of hectares, but similar systems overseas have been applied to tens of thousands.

8.16 Not surprisingly we judged our system capable of fulfilling these objectives, subject to a few improvements. We therefore take the system as set out in Chapters 3 to 7 and list here only the recommended improvements:

$.1 \quad$ Plot distribution and frequency. We stick by a systematic grid of main-series surveillance plots near to but not at National Grid 100-metre intersections, with between forty and sixty plots for a whole "management area" - i.e. individual "forest". These should be supplemented by any number of special-purpose plots, subjectively sited in ecologically critical areas. The latter must be marked, recorded and surveyed into the $100 \mathrm{~m}$ intersections just: as are the main series plots, but may of course have additional information, which would constitute a "Section $17 "$ in the record, requiring an addition to the computer programs.

.2 Monumentation. Underground markers should, if financially feasible, be magnetized and entirely encased in a tough and waterproof alrtight sleeve (e.g. alkathene tube sealed at both ends). It is however still more important that they should be easy to find with the minimum of burrowing. Even the slightest projection from the snil is undesirable if any heavy vehicles are likely to work in the wood. It would also be useful if the markers were put in at all four corners of each plot, instead of in only two as Wytham and Halton.

.3 It would be very helpful to give the description and position, within or near to every plot, of some probably persistent feature that might help to locate it at least two or three decades into the future. Irregularities of the ground, larger trees, etc. located by internal co-ordinates or external distance and bearing, could save much time in re-locating plots by survey from greater distances. Paintspotting of nearby and persistent-barked trees is not an entirely futile idea in drier types of woodland.

4 Typicality. Where a plot is recorded as TYPICAL, a short text should follow to indicate what site or vegetation was in mind. The term would be clearer if the word EXEMPLARY were used, provided the phrase "EXEMPLARY OF..." were completed.

.5 Leading Trees. Having recorded the four leading trees by the rules we followed, the leading (greatest diameter if $>5 \mathrm{~cm}$, otherwise the tallest) specimen of each other tree species not yet on the L-T list, but only one of each species, should 
be added with records just as for the first four.

8.16.6 Relaskop Sweeps. All four corners of the plot should be tallied; the result divided by two will give a very reasonable estimate of basal area per hectare in the vicinity as well as within the plot.

8.17 It is perhaps worthwile to put the various categories of observations in priority sequence. Which sections would be dropped if finance, labour and time were to be progressively reduced? The following is our particular order of priority, most valuable sections first:

\begin{tabular}{clc} 
Priority & \multicolumn{1}{c}{ Section title } & Section No \\
\cline { 3 - 3 } 1 & General description & 1 \\
2 & Relaskop sweeps & 4,5 \\
3 & Ecologically significant spp. & 11 \\
4 & $\begin{array}{l}\text { Other species found } \\
\text { (i.e. al1 species other than }\end{array}$ & 10 \\
& those already recorded) & \\
& & 2 \\
5 & Leading trees & 16 \\
6 & Soils & $13,14,15$ \\
7 & Quadrat recordings & 9 \\
8 & Features in the plot & $6,7,8$ \\
9 & Cover \& Canopy & 12 \\
10 & Permanent features & 3 \\
11 & Other trees dead &
\end{tabular}

In fact, our "system" permits any selection of the above to be omitted, and some could very easily be augmented, with no change and little change respectively to the programs. 


\section{Fig. 8 \\ Examples of "shapeless events"}

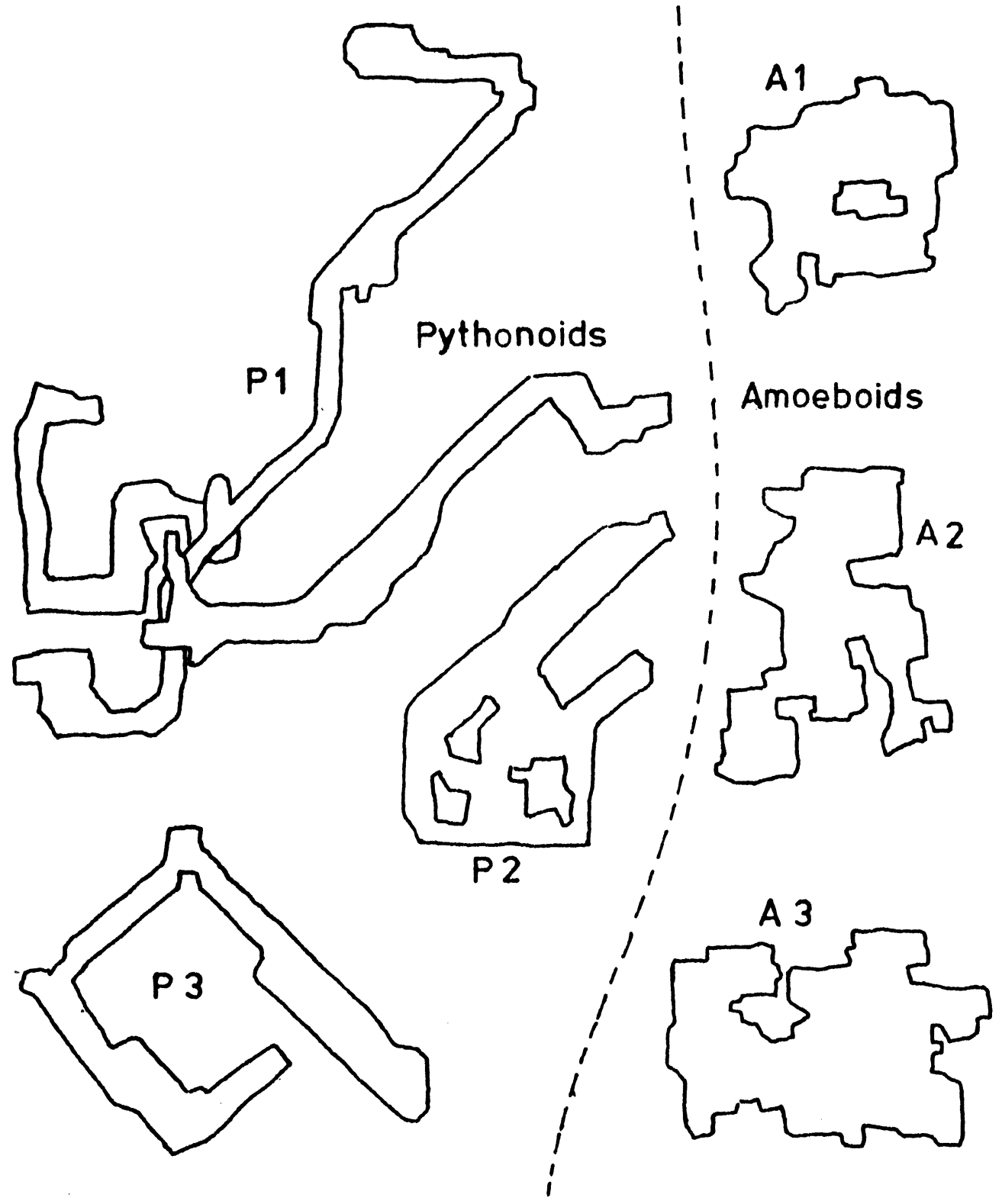

Fig. 8. The above shapes are drawn around line-printer outputs from the BUDDHA program. They show clear signs of the "8-fold path" imposed hy line-printer format.

P. 1 is a complex shape created by three pythonoids interlocked.

P. 2 resulted from a single pythonoid, convoluted to produce lagoons. 


\section{of Events}

1. A major object of surveillance sampling is efficiency in detecting phenomena ("events") of unpredictable extent and distribution. It is important to understand that the events in question include changes in what is already there as well as new occurrences, hence can be qualitative and amorphous as well as geometrically definable. It was largely the detective role of the sample that led to a systematic layout, albeit a square one to fit the National Grid rather than a theoretically nore efficient triangulinr arrangement.

The number of plots used was a natter of experience and expediency, together with a wish to be well down in the t-table, rather than of prior but unobtainable knowledge of population distribution. We therefore wished to quantify the probable success of the samples, in the detection of events of any size, shape or distribution, by theory and by modelling.

2. We start by considering shapes of four types, defined and representative as follows:

(i) Point; theoretically of zero area, in practice the centre-points or co-ordinate positions of trees and most herbs and shrubs. Defects of the model are that few events in the field can be so precisely located, and that the entities of this survey signalled by points are not themselves size-less and so cannot coincide, and must therefore be slightly more dispersed than points need to be.

(ii) Circle; representing multi-stemmed or spreading herbs or shrubs, tree canopies, small areas of animal activity or disease, or other ecological conditions spreading from a focus. Defects in the model: few of these events are likely to be precisely circular in plan, hence (iii) and (iv) below.

(iii) Amoeba; a shape of irregular outline, with some degree of central mass supporting stubby pxotuberances (pseudopodia) and finger-like projections, as for instance in Fig. 8. Many ecological phenomena resemble this shape: colonies of plants, patches of soil disturbance, waterlogged hollows, rabbit and badger colonies. (More extreme forms of this model known as Spider and Octopus were also used in the modelling).

(iv) Python: serpentine shapes but occasionally interlocking and branching (Fig.8), strongly resembling the colour patterns conmon on soil maps where strata or water-tables outcrop in undulating topography. 
3. The probability of detecting points and circles, given their geometrical limitations plus certain assumptions as to spatial distribution, can mostly be predicted by theory. The other shapes, being impossible to define precisely, could only be studied by modeliling. For this purpose an ALGOL 68R program was constructed (by B.W. Dawkins) to generate random shapes with Amoeboid and Pythonoid constraints, to distribute them randomly, and to sample the resulting field with square plots of varying size and spacing. Something of the working of the program can be inferred from its name: BUDDHA. A random spot is chosen from which an 8 -fold path (2 vertically, 2 horizontally, 4 obliquely) is traced out with symbols on the line-printer, to produce an Illusion, as depicted in Fig. 8.

4. Let us emphasize that our object was to detect a phenomenon rather than to calculate the sampling error of a measured variable about an estimated mean. The statistical interest therefore lies almost entirely in the probability of hit or miss, of any example or replicate of the relevant entity or event, by any one of the plots. Since $P$ (miss) is easier to handle than $P$ (hit) when several plots or events are involved, we shall mostly use $P$ (miss) and aim to calculate the minimum dimension or repetition of an event which has a probability of less than 0.5 , or of 0.05 , of being missed.

5.

(iii)

If a similar field contains one point sampled by two random square quadrats each of side $q$, remembering that the two may not overlap, $P($ hit $)$ is now $2 q^{2} / g^{2}$ and

$$
P \text { (miss) }=1-\left(2 q^{2} / g^{2}\right)
$$

and therefore in general with $\mathrm{m}$ random quadrats seeking n random points:

$$
P \text { (miss) }=\left(1-\mathrm{mq}^{2} / \mathrm{g}^{2}\right)^{\mathrm{n}} \text {. }
$$

This would obviously become zero when $\mathrm{mq}^{2}=\mathrm{g}^{2}$, that is when the whole field is occupied by quadrats.

(iv) In our situation we always have a number ( $k$ ) of equal-area fields, the grid squares, each occupied by a single plot of side $q=10 \mathrm{~m}$. The proportion of ground occupied by plots is therefore $q^{2} / g^{2}$ however large the area, and the extension of equation (3) to

$$
P(\text { miss })=\left(1-m q^{2} / \mathrm{kg}^{2}\right)^{n}
$$


reduces to equation (2) because $m=k$. Hence equation (2) also applies to the probability of missing $n$ random points in our sampling scheme independently of the size of the forest sampled, and whether the points are scattered over the whole area or are confined to a few (but not too few) of the grid squares. The random proviso still holds, and this is examined further in runs of BUDDHA described later.

(v) The following predictions can now be made:

IABLE 1. (App. 1)

Probabilities of Missing Point Events

\begin{tabular}{|c|c|c|c|c|}
\hline & B]X & WYTHAM! & HALTON & Lnitis \\
\hline $\begin{array}{l}\text { No. of fields each with } \\
\text { one } 10 \times 10 \mathrm{~m} \text { plot: }\end{array}$ & 96 & 163 & 123 & No. \\
\hline Area of each field: & 1 & 2 & 2 & ha. \\
\hline Tota 1 area sampled: & 96 & 326 & 246 & ha. \\
\hline Sampling proportion: & 0.01 & 0.005 & 0.005 & p \\
\hline$P$ (miss) single point: & 0.99 & 0.995 & 0.995 & $P($ miss $)$ \\
\hline \multicolumn{5}{|l|}{ For $\mathrm{P}$ (miss) $\quad 0.5$} \\
\hline No. of random points: & 70 & 140 & 140 & points \\
\hline No. per hectare: & 0.73 & 0.43 & 0.57 & No. / ha \\
\hline Mean $\Delta$ spacing: & 123 & 164 & 142 & m \\
\hline \multicolumn{5}{|l|}{ For $\mathrm{P}$ (miss) $\quad 0.05$} \\
\hline No. of random points: & 300 & 600 & 600 & points \\
\hline No.per hectare: & 3.1 & 1.8 & 2.4 & No./ha \\
\hline Mean $\Delta$ spacing: & 61 & 80 & 69 & $\mathbf{m}$ \\
\hline$(\Delta$ spacing $=\sqrt{10}$ & ne & wh & $=$ no. & $r$ hects \\
\hline
\end{tabular}

It will be shown later how a systematic distribution of points over a limited sampled field increases the probability of the plots missirg them, and how bunching (extreme clustering) of points may incresse or decrease $P$ (miss). The latter effect especially is most easily examined by a study of area events, starting with the circle as the simplest.

6

\section{Detection of Circular Events - "Blobs"}

Consider a square field of side $g$ sampled by a single square plot of side $q$, seeking a single circular blob of diameter $b$. In contrast with the detection of a point event, $P(h i t)$ is now more than $\mathrm{q}^{2} / \mathrm{g}^{2}$ because the blob will be detected immediately its margin overlaps the plot, when its centre is still only a shade under $b / 2$ metres from it. There is therefore a zone of detection around the plot as wide as the radius of the blob. This "hit area" may be 
pictured as an eroded square if the blob is smaller than the plot, or a dimpled circle if it is larger. It envelops the plot (Fig. 9) and has an area:

$$
H=q^{2}+2 q b+\pi b^{2} / 4
$$

7. It may also be pictured as a circle enveloping the blob, but with a misty edge since a square (the plot) has a variable radius. The hit area is a zone described by the centre-point of the square as it pirouettes around the blob keeping in contact with it, giving a stochastic margin with a clear maximum and minimum and a not-so-clear notional mean diameter of:

$$
\mathrm{h}=\mathrm{b}+\mathrm{fq} \quad \ldots \ldots \ldots \ldots \ldots \ldots \ldots
$$

where $f$ is a function of the ratio of blob-diameter (b) to plot-side (q) as follows:

TABLE 2. (App. 1 )

Relation of a circular hit area diameter to ratio

\begin{tabular}{|c|c|c|}
\hline & & Exponent $x$ in \\
\hline$\frac{\text { Ratio }}{b / a}$ & $\frac{\text { Plot diameter factor }}{\mathrm{f}}$ & $f=(4 / \pi)^{x}$ \\
\hline Very sma 11 & 1. 1284 (minimum) & 0.5 \\
\hline 0.01 & 1.1297 & 0.505 \\
\hline 0.1 & 1.. 1401 & 0.546 \\
\hline 1.0 & 1. 1954 & 0.743 \\
\hline 10 & 1.2578 & 0.955 \\
\hline 100 & 1. .2715 & 0.999 \\
\hline Very large & 1.2732 (maximum) & 1.0 \\
\hline
\end{tabular}
of circle-diameter over sample-square side.

Note that b/q "very small" is the equivalent of the pointevent situation, while "very large" resembles a circle event sampled by a point quadrat. Given that $\mathrm{H}$ may be calculated from equation (4) and its diameter $h=\sqrt{4 \mathrm{H} / \pi}$, f was derived from $(h-b) / q$ for a set of arbitrary $b$ values and:

$$
x=\log . f / \operatorname{lng} \cdot(4 / \pi)
$$

The values of $x$ in $f=(4 / \pi)^{x}$ become linear on $\log (b / q)$ with a probit transformation. The situation is illustrated in Fig. 10.

The value of $f$ leads to the notional diameter of the hit area, for any particular b/q ratio. It is not equidistant. between the maximum circle outside which a hit is impossible (for which $f=\sqrt{2}$ ) and the minimum within which a hit is inevitable $(f=1,0)$. This is illustrated in Fig. 9 . 


\section{Fig. 9 Hit area for circular event}
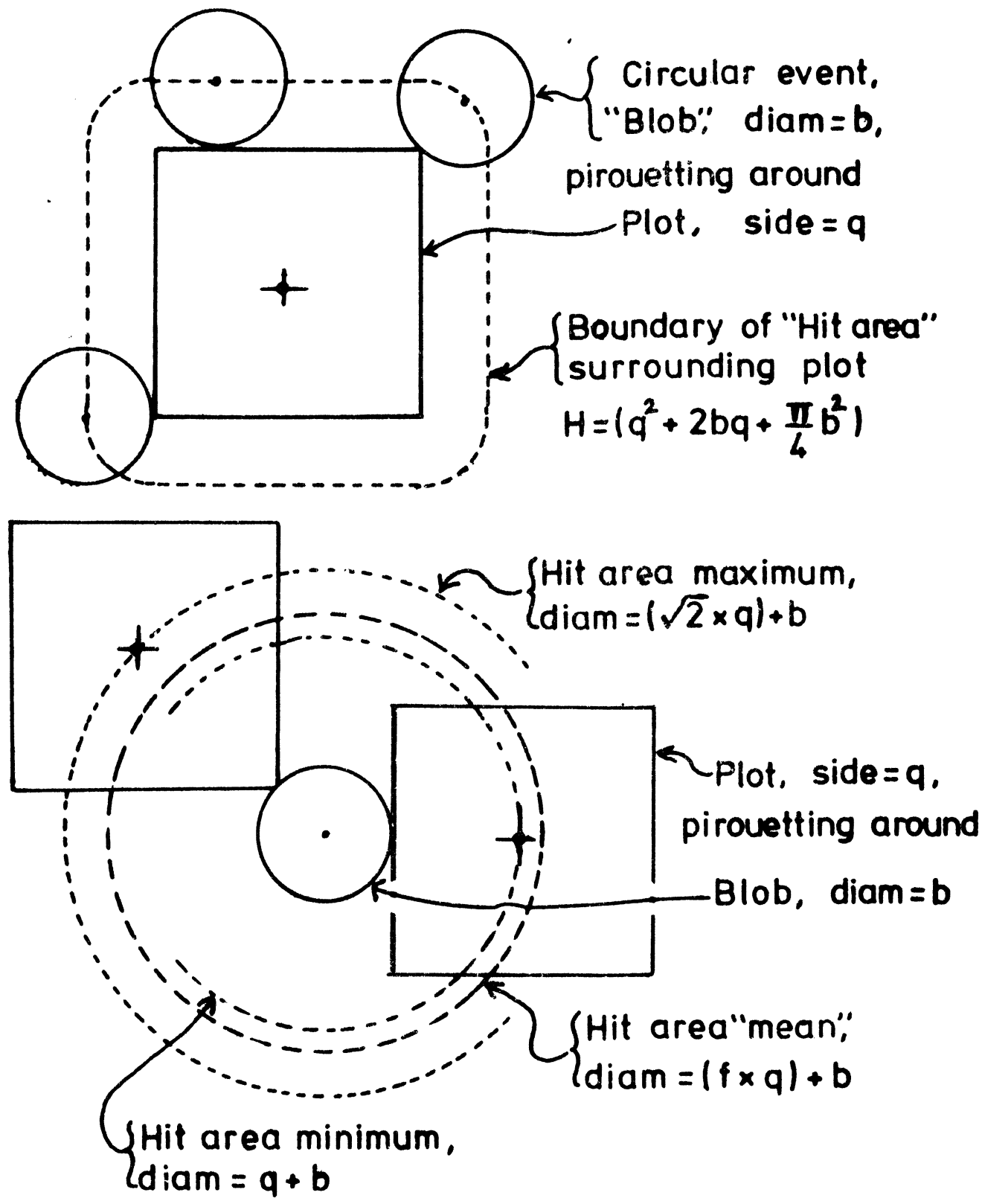

Fig. 9. In the above expression diam $=(f \times q)+b$, $f=(4 / \pi)^{x}$ where

$$
\begin{aligned}
x & =1.0 \text { for a b/g ratio "very large" } \\
& =0.5 " \text { " " " " " small" } \\
& =0.672 \text { in the above example where } \\
& b / q=5 \mathrm{~m} / 10 \mathrm{~m}=0.5 .
\end{aligned}
$$




\section{Fig.10 Hit area diameter,}

for circular event, as related to ratio of event size to sample-plot size.

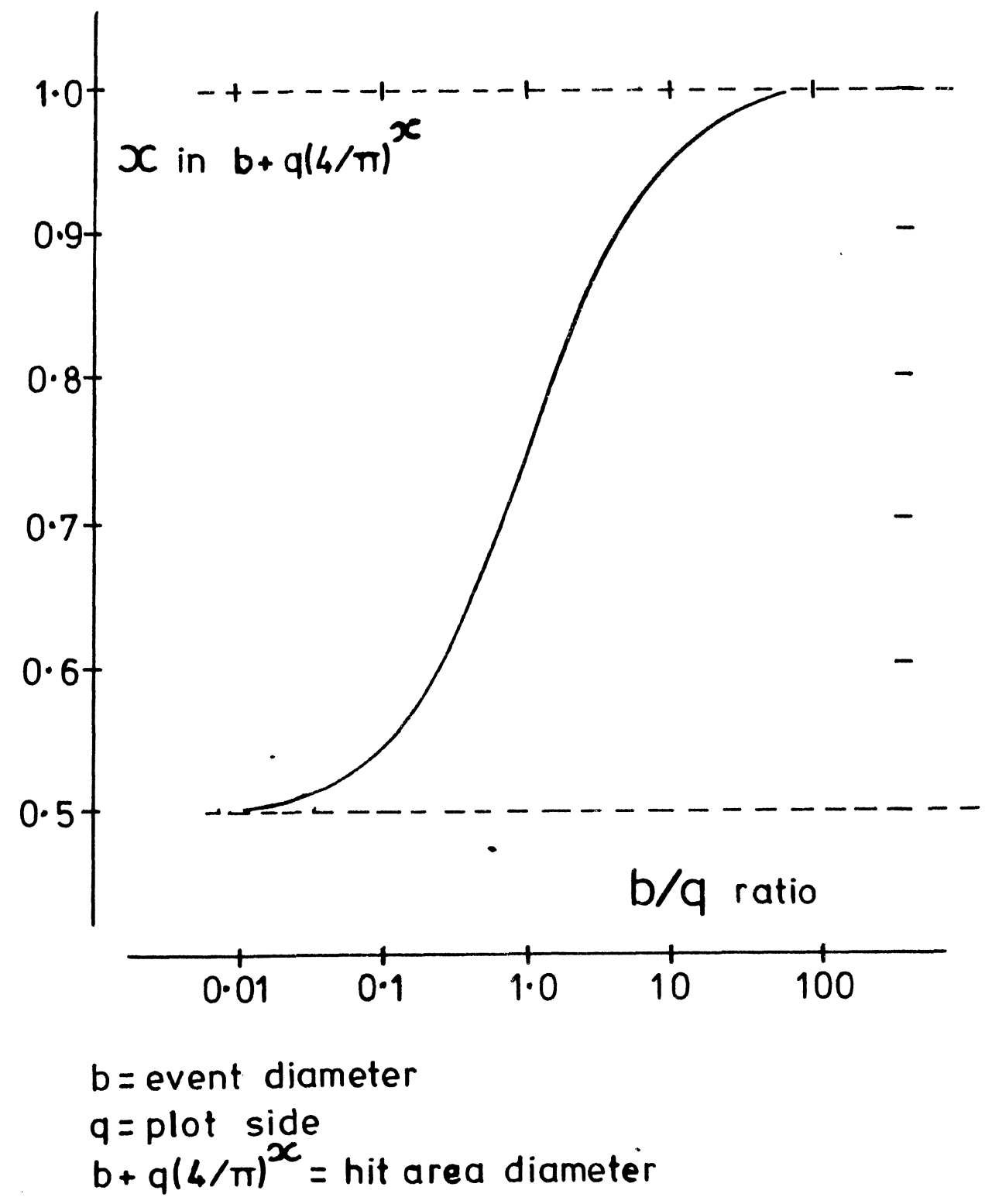


8. Returning to the single field containing a single plot and circular blob. $\mathrm{P}(\mathrm{hit})$ is clearly $\mathrm{H} / \mathrm{g}^{2}$ rather than $\mathrm{q}^{2} / \mathrm{g}^{2}$, and provided the blob is sma11:

$$
P(\text { miss })=\left(1-H / g^{2}\right)
$$

so, for the situation with several fields and numerous ( $n$ ) blobs:

$$
\begin{aligned}
& \mathrm{P}(\text { miss })=\left(1-\mathrm{H} / \mathrm{g}^{2}\right)^{\mathrm{n}} \ldots \ldots \ldots \ldots \ldots \ldots \ldots \ldots \\
& \text { Compare equation }(2) .
\end{aligned}
$$

The blob-size proviso is important, especially when equation (6) is extended to systematically distributed plots, when several theoretical complications occur, not found when the events to be detected are points. For instance :

(i) Blobs, having area, cannot be freely randomly distributed without overlapping. If they are not "allowed" (i.e. not recognised in the field) to do this, then there must be a minimum distance between their centres and they take on some degree of enforced spacing, "over-dispersion". This must be proportional to their size, and so lead to a measure of systematic distribution tending to risk correlation with the systematically spaced plots. Blobs which coalesce generate amoeboid shapes whose behaviour is discussed from para. 10 onwards. Hence equation ( 6$)$ can only apply to relatively sma11 blobs not too frequently yccurring.

(ii) Secondly, in theory, $\mathrm{P}$ (miss) should become zero when any blob is sufficiently large to generate a hit area equal to $\mathrm{g}^{2}$, so that $\mathrm{H} / \mathrm{g}^{2}$ is unity. In fact, however, $\mathrm{P}$ (miss) does not reach zero until blob-size is a little greater, namely when $b=\sqrt{2}(g-q)$. For example, when grid-fields are $100 \times 100$ m sampled by systematically distributed 10 x 10 m plots (as in our Bix sample), blobs of $100.26 \mathrm{~m}$ diameter generate a hit area of $10,000 \mathrm{~m}^{2}$ and therefore a theoretica $1 \mathrm{P}$ (miss) of zero (equation (6). Yet it is obvious that a blob of diameter $127 \mathrm{~m}(<\sqrt{2}(\mathrm{~g}-\mathrm{q}))$ could be fitted into such a grid field and entirely escape detection. The discrepancy is due to the fact that any blob of diameter greater than $\mathrm{g}-\mathrm{q}$ is capable of scoring two hits, yet we are treating this as no more significant than one - both are equally not a miss. Hence equation (6) becomes unreliable, by being a slight underestimate, when blob diameter approaches $g-q$, but becomes instantly zero when it exceeds $\sqrt{2}(g-q)$.

(iii) P(miss) also becomes zero when a certain maximum number of blobs, which by definition cannot coalesce or they become amoeboid, are packed into a single field. The critical number is approximately

$$
\mathrm{N}(\max )=\left(\mathrm{g}^{2}-\mathrm{H}\right) / \mathrm{b}^{2} \mathrm{x}\left(\operatorname{Sin} .60^{\circ}\right) \ldots \ldots \ldots \ldots(7)
$$

This operates in the reverse direction from the effect of large blob size, because here $P$ (miss) will be overestimated if there is any marked tendency for blobs to cluster in a single gridsquare. 
TABLE 3. (App. 1 )

Probabilities of Missing Circular Events

and

Number of Events for P(miss) of 0.5 and 0.05

\begin{tabular}{|c|c|c|c|c|c|}
\hline \multicolumn{2}{|c|}{$\begin{array}{l} \\
\\
\text { Grd field side: } \\
\text { Plct side: } \\
\text { For st area: }\end{array}$} & $\begin{array}{r}\text { BIX } \\
100 \\
10 \\
96\end{array}$ & \multicolumn{2}{|c|}{141.41} & $\begin{array}{r}\mathrm{m} \\
\mathrm{m} \\
\mathrm{ha}\end{array}$ \\
\hline$\frac{\frac{B 1 o b}{d i a m}}{b}$ & $\begin{array}{l}\text { Hit area } \mathrm{H} \\
\mathrm{P} \text { (miss) }\end{array}$ & $\begin{array}{r}121 \\
.9879 \\
\end{array}$ & \multicolumn{2}{|c|}{$\begin{array}{r}121 \\
.9939 \\
\end{array}$} & $\begin{array}{l}\mathrm{m}^{2} \\
\mathrm{P} \\
\end{array}$ \\
\hline 1.0 & $\begin{array}{l}\mathrm{N}(\mathrm{P} .5) \\
\% \text { of area } \\
\mathrm{N}(\mathrm{P} .05) \\
\% \text { of are } 1\end{array}$ & $\begin{array}{l}57 \\
.005 \\
247 \\
.020\end{array}$ & \multicolumn{2}{|c|}{$\begin{array}{c}115 \\
\left.\right|_{495} ^{1} .004 \\
\mid\end{array}$} & $\begin{array}{l}\text { no. } \\
\% \\
\text { no. } \\
\%\end{array}$ \\
\hline \multirow[b]{2}{*}{5.0} & $\begin{array}{l}\text { Hit area } \\
P(\text { miss })\end{array}$ & $\begin{array}{l}220 \\
.9870\end{array}$ & \multicolumn{2}{|c|}{$\begin{array}{c}220 \\
.9890 \\
1\end{array}$} & $\frac{m^{2}}{p}$ \\
\hline & $\begin{array}{l}\mathrm{N}(\mathrm{P} .5) \\
\% \text { of area } \\
\mathrm{N}(\mathrm{P} .05) \\
\% \text { of area }\end{array}$ & $\begin{array}{r}31 \\
.064 \\
135 \\
.28\end{array}$ & $\begin{array}{c}.038 \\
.16\end{array}$ & $\begin{array}{r}.050 \\
.22\end{array}$ & $\begin{array}{l}\text { no. } \\
\% \\
\text { no. } \\
\%\end{array}$ \\
\hline \multirow[b]{2}{*}{10.0} & $\begin{array}{l}\text { Hit area } \\
\mathrm{P} \text { (miss) }\end{array}$ & $\begin{array}{c}379 \\
.9621\end{array}$ & \multicolumn{2}{|c|}{$\begin{array}{r}379 \\
.9810 \\
1\end{array}$} & $\begin{array}{l}\mathrm{m}^{2} \\
\mathrm{P}\end{array}$ \\
\hline & $\begin{array}{l}\mathrm{N}(\mathrm{P} .5) \\
\% \text { of area } \\
\mathrm{N}(\mathrm{P} .05) \\
\% \text { of area }\end{array}$ & $\begin{array}{r}18 \\
.15 \\
78 \\
.64\end{array}$ & \multicolumn{2}{|c|}{$\left..087 *\right|_{157} ^{36}$} & $\begin{array}{l}\text { no. } \\
\% \\
\text { no. } \\
\%\end{array}$ \\
\hline \multicolumn{6}{|c|}{$\begin{array}{l}\mathrm{H} \quad=\left(\mathrm{q}^{2}+2 \mathrm{qb}+\pi \mathrm{b}^{2} / 4\right) \\
\mathrm{P}(\mathrm{miss}) \quad=\left(1-\mathrm{H} / \mathrm{g}^{2}\right) \\
\mathrm{N}(\mathrm{P} .5) \quad=10 \mathrm{~g} 0.5 / \log \times(\mathrm{P} \text { miss }) ; \mathrm{N}(\mathrm{P} .05) \text { similarly. } \\
\% \text { of area } \quad=\left(\mathrm{N} \times \mathrm{b}^{2} / 4\right) \times 100 / \mathrm{g}^{2} ; \text { for } \mathrm{N}(\mathrm{P} .5) \text { and } \mathrm{N}(\mathrm{P} .05) . \\
\% \text { for example: } 36 \text { circular blobs of diam. } 10 \mathrm{~m} \text { occupy } .087 \% \text { of } \\
\text { the Wytham area and } 12 \% \text { of Halton, and have a probability of } \\
\text { being missed of } 0.5 .\end{array}$} \\
\hline
\end{tabular}


As an example, just over 48 blobs, each $15 \mathrm{~m}$ diameter, more than fil $1 \frac{1}{2}$ a $100 \mathrm{~m}$ gridsquare (minus the hit area of $576.7 \mathrm{~m}^{2}$ ), yet:

$$
P(\text { miss })=(1-576.7 / 10,000)^{48}=0.0578
$$

whereas it should be zero, given that we are considering a single gridsquare.

9. Fortunately these theoretical complications do not affect the calculation of $\mathrm{P}$ (miss) for cases where blobs are small and infrequent, which is the situation we are mainly concerned with. Large or frequent events are too sure of detection to be a worry, especially as they are still more likely to be detected when of complex shape. The probability of detecting circular blobs in this particular survey is summarised in Figs. 11 and 12 and in Table 3. The Table also gives the limiting number of blobs for $P$ (miss) of 0.5 and 0.05 in the three surveyed woods.

\section{Detection of Shapeless Events}

10. Theory can predict the probability of detecting randomly distributed points or circles but such shapes have only limited ecological application. Some of the phenomena we are concerned with may be "shapeless", that is, geometrically undefinable. When such are sought by square sample plots, hit area must always be greater than if the events were circles or compact polygons, the more so if they are ramified or reticulate. Fig. 13 shows a shapeless event, representing a feature of drainage, animal influence or vegetation boundary, with an area of $400 \mathrm{~m}^{2}$ being sought by a square plot of $100 \mathrm{~m}^{2}$ - like ours. If the event had been circular, its hit area would have been $951 \mathrm{~m}^{2}$, giving a $P$ (miss) of 0.9525 if it occurred in one of the Wytham or Halton 2-ha gridsquares (equations (4) and (6)). In fact, its hit area for the $10 \times 10 \mathrm{~m}$ plot was found by the BUDDHA simulation program to be $2949 \mathrm{~m}^{2}$, which is 3.1 times the theoretical circular-event value. We called this ratio the "shape factor" and used the same program to. investigate its likely range in the woodland inventory.

11. Shape factor we define as the ratio of actual hit area to the theoretical hit area of the same event compressed into a circle. Shape factor cannot be predicted unless the shape which generates it is definable, hence our simulation program to study its behaviour. We ran the program with events ranging from 5 to $500 \mathrm{~m}^{2}$ in area, with square plots from $1 \mathrm{~m}^{2}$ to $100 \mathrm{~m}^{2}$, and with shapes such as those shown in Figs. 8 and 13, though more bizarre as well as simpler ones turned up. The shape factors generated varied from little above unity for the less enterprising amoebae to just under 5 for the most grotesque of the pythonoids, such as the gregarious cluster shown in Fig. 8. The results are summarised in Fig. 14 .

12. In general we concluded that the events we are concerned with, such as patches of peculiar flora, site, soil, wind-throws, animal disturbance, human incursions etc. are plausibly represented by the shapes tested, and consequently are much more likely to be detected by our plots than we would be suggested by the areas they occupy. 


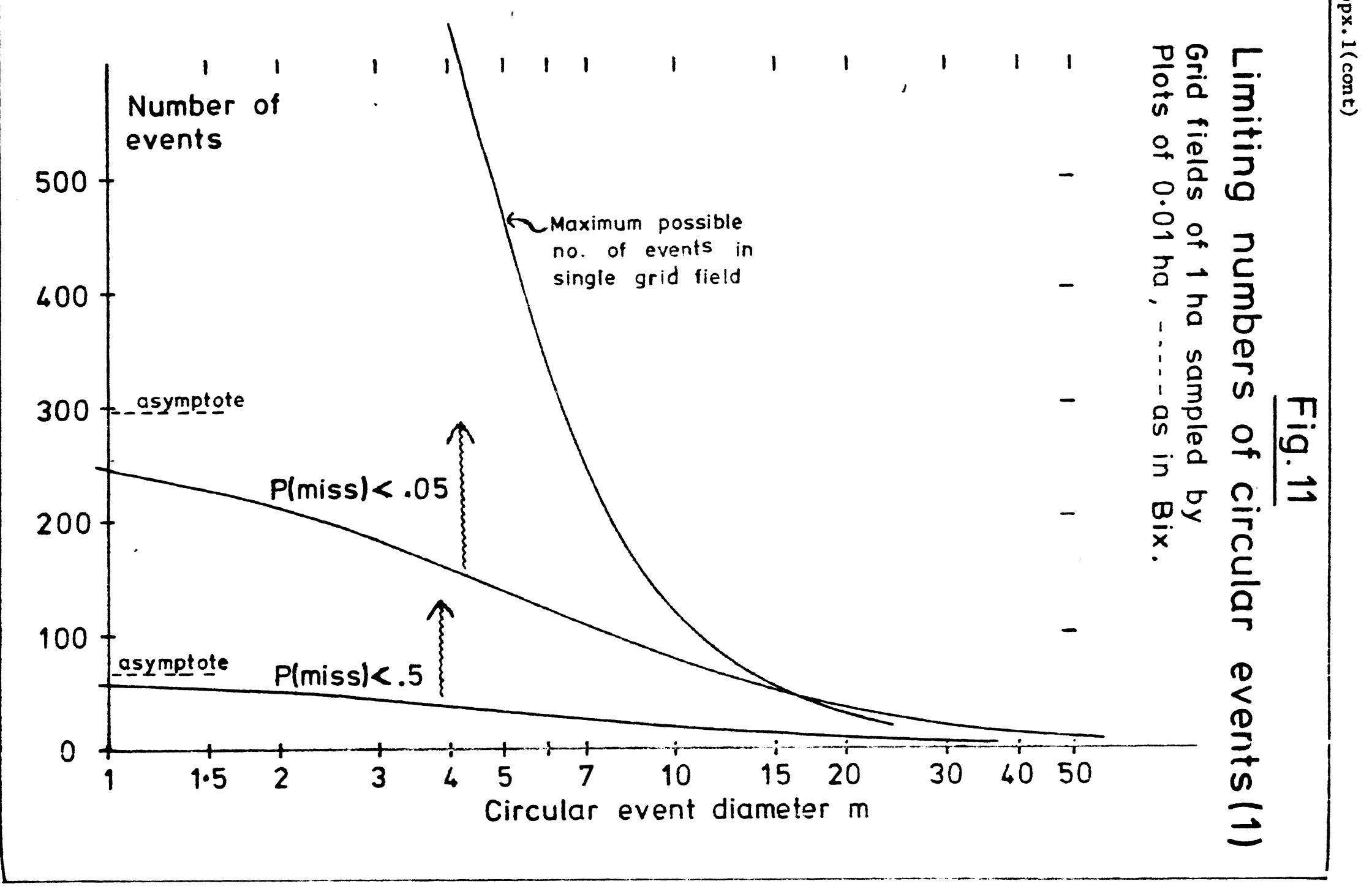




\section{Fig. 12}

Limiting numbers of circular events (2)

Grid fields of 2 ha sampled by

Plots of $0.01 \mathrm{ha}, \ldots .-$ as in Halton

and Wytham.

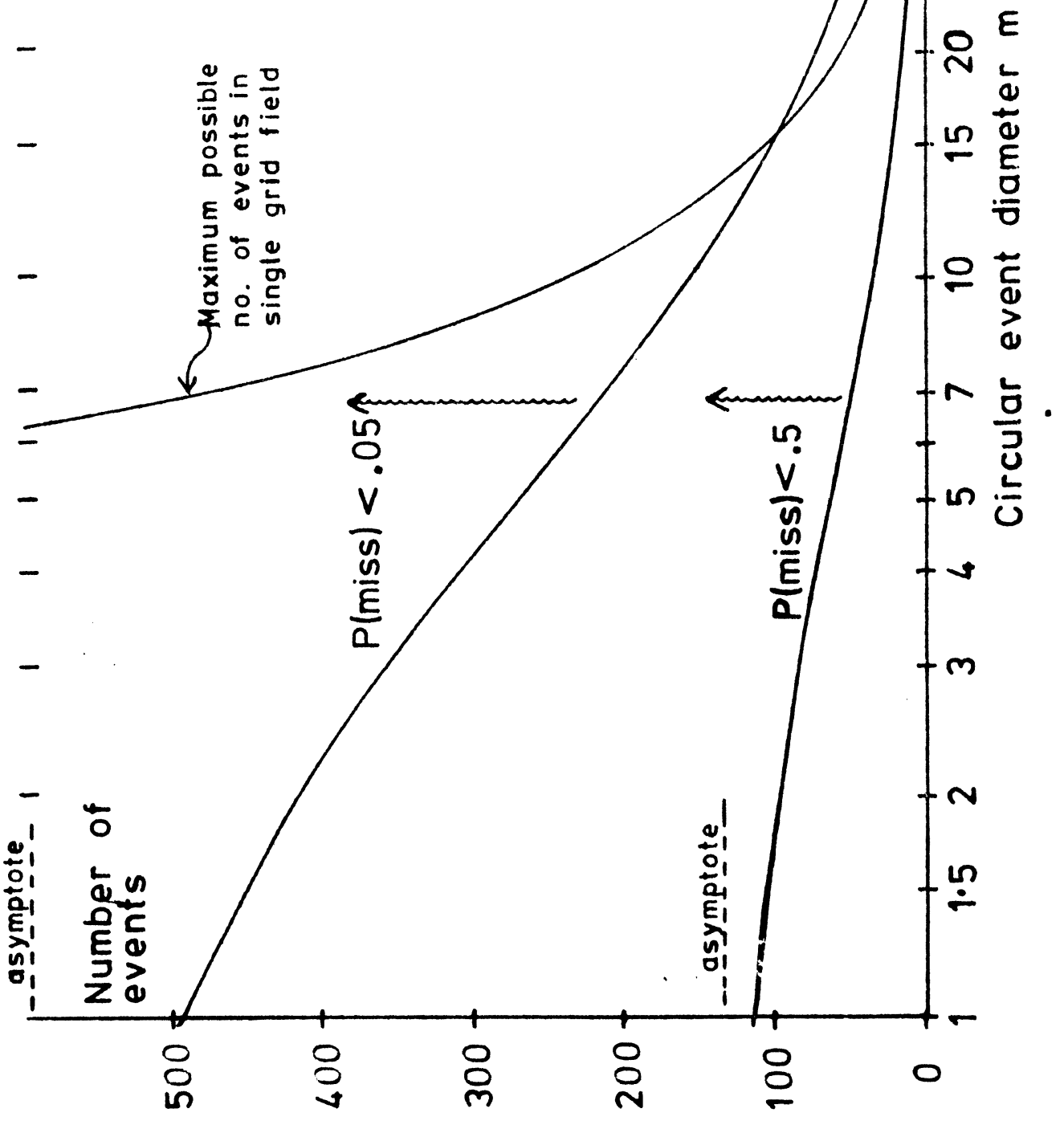




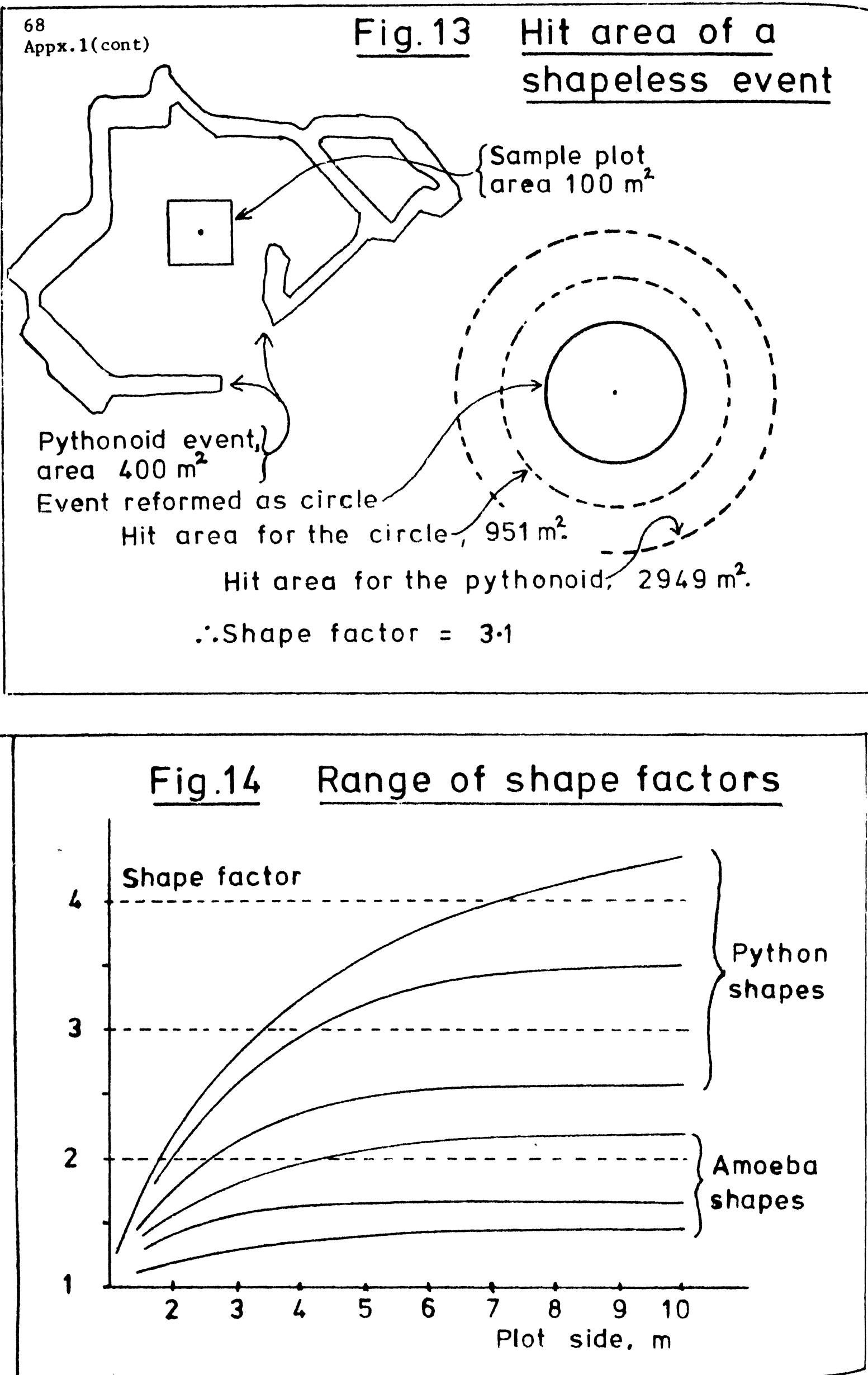


The probability of detection can quite easily be pushed up by a factor of two to four - the "shape factor".

13. However, it must be noted that there is no obvious limit to shape factor. A network of filaments - a creeper for instance could occupy a very small proportion of a sampling field, yet leave no spaces within which a sampling plot could fit unscathed. Even in Fig. 13, a plot of twice the diameter would cause a very much larger hit area, because the lagoon in that particular event would leave very little hit-free space for the plot. Thus, for any event:

(i) a relatively small plot will generate a hit area only slightly greater than event area, a shape factor of little more than unity, but:

(ii) a relatively large plot will produce a hit area similar to that caused by a convex envelope entirely encircling the event, ramifications and re-entrants and all.

Probability of detection is therefore greatly affected by the degree of ramification and reticulation of any event, relative to the dimensions of the sampling plot.

The effect of distribution of events

14. It is convenient to consider distribution of events in three classes:

S: systematic; over-dispersed, territorial, selfrepe11ing.

R: random; independent of each other.

C: clustered; under-dispersed, social, self-attracting.

The detection of $\mathrm{R}$-distributed events has already been discussed in paras. 5-9; it remains to discover how $S$ - and C-distributions behave, and how likely they are to occur. First, however, certain deductions can be made from theory.

15. Given that our sampling plots were $10 \times 10 \mathrm{~m}$ square quadrats, distributed on a square grid of side $\mathrm{g}(100 \mathrm{~m}$ or $141.4 \mathrm{~m})$, it can be shown that:

S-distributed events spaced at intèrvals of $s$ metres (omitting for simplicity the complication of two directions), provided they are repeated for at least as far as the product of their own and the sample-plot spacing (i.e. $s \times g)$, must inevitably be detected and therefore have a $P($ miss $)$ of zero.

However, we are concerned only with limited areas and plausible situations, e.g.

(2) S-distributed small events limited to very few replications are more likely to be missed than hit by a systematic sample of similar spacing, or of a low multiple of that spacing. This is because there is more space between events than within them, so that the chance of the systematic grid 
coinciding with the events is small, and, of course the distance $s \times g$ is unlikely to be reached.

However, this effect will be considerably modified by the relative sizes (hit area) of events and plots, a point we could only investigate by modelling. The BUDDHA program was again used to test the uncertainties of the last few statements, and the frequency with which systematic and clustered distributions of events might turn up in purely "random" situations.

16. Program BUDDHA first sets up a grid field of $100 \times 100$ units, then places therein from one to 81 points randomly or systematically as required. Each run of the program generates an event at each point by random budding in random (out of eight) directions for random distances, with constraints on each increment and therefore frequent restarts from random buds on previously established branches. It the constraints on distance and reticulation which caused the different shapes we required, and which prevented the globular entanglement of a normal random walk.

The eventful field is then sampled by square plots at a range of systematic spacings, the whole grid of plots being moved across the field into all its possible positions, recording actual hits and misses for comparison with expectations from the theory of randon sampling argued in paras. 6 to 13.

17. The following combinations were tested:

(1) Simulated events:

(i) five shapes of types point, amoeba, python, spider and octopus.

(ii) numerous random and then nine systematic spacings from $100 \times 100 \mathrm{~m}$ to $11 \times 11 \mathrm{~m}$.

(iii) numerous areas (of event) from $1 \mathrm{~m}^{2}$ to $500 \mathrm{~m}^{2}$.

(2) Sampling plots:

(i) six sizes from $1 \times 1 \mathrm{~m}$ to $10 \times 10 \mathrm{~m}$.

(ii) twenty spacings from $10 \times 10 \mathrm{~m}$ to $100 \times 100 \mathrm{~m}$.

The whole investigation, including the investigation of shape factor used about 200 event "maps" with about 100 combinations of spacing and size of sample plot.

18. In any one run, misses could be more than, equal to, or less than the random-sampling prediction (equation (6)), the significance thereof being assessed by a chi-squared test of conformity. When misses exceeded expectation during runs of randomly-placed events, the latter must by chance have taken up an approximately systematic distribution relative to that of the sample plots. This was in fact checked by printing out the event-map and measuring spacing between events (Figs. 15, 16, for instance). When misses fell short of expectation, a clustered distribution must have arisen, though this 
does not need to be a cluster in the usual sense, as will be explained. The two situations are illustrated in Figs. 15 and 16.

\section{The pseudo-systematic distribution}

19. Fig. 15 depicts one of the event-maps produced by the BUDDHA program, in which nine amoeboids were placed "randomly" in a field of $100 \times 100 \mathrm{~m}$. The field was then sampled by a grid of square plots, of fourteen spacings ranging from $12 \times 12 \mathrm{~m}$ $(g=12)$ to $100 \times 100 \mathrm{~m}(g=100)$, the latter consisting of $j u s t$ one plot, each spacing being set down in all its possible $\mathrm{g}^{2}$ positions in the field. Two spacings are shown: 18 x 18 in Fig. 15 and $22 \times 22$ in Fig. 16.

In the case of Fig. 15, hits were hi.ghly significantly fewer than expected $\left(X^{2}=156 \mathrm{~d} . \mathrm{f} .=1\right)$ because the events have taken up, very nearly, a spatial distribution in units of 18 in both the directions of the sampling grid. Their centres are near to 18 , or 36,54 etc. metres North-South or East-West of each other. If they are all re-plotted in a single $18 \times 18 \mathrm{~m}$ square in the same co-ordinate positions, they occupy the middle of it leaving considerable areas free. Otherwise expressed, the grid of plots shown in Fig. 15 can be shifted around quite energetically without any event being detected by any plot. This pseudo-systematic distribution of events arose in numerous runs of the program, though with only one quarter of the frequency with which "dispersed clustering" occurred.

\section{The Dispersed-Cluster distribution}

20. Fig. 16 depicts the same map as Fig. 15, but this time the sampling grid is spaced at $22 \times 22 \mathrm{~m}$. The grid of plots can now scarcely be moved in any direction without at least one event being detected by one plot. This is confirmed by re-plotting the events in a single $22 \times 22 \mathrm{~m}$ square, which leaves very little unoccupied space for the single sampling plot, which must fall somewhere in that square. Misses were in fact significantly fewer than expected $\left(\boldsymbol{X}^{2}=26\right.$, d.f. $\left.=1\right)$, and the distribution could be called a dispersed cluster. It is certainly dispersed, but for that particular dimension of systematic grid it behaves as if it were a cluster. Thus a single event-map can show a systematic distribution relative to one sample spacing, and yet be a dispersed-cluster relative to another. Our interest was to discover the frequency with which the two types might occur in a random world. 


\section{${ }_{\text {Appx.1 }}^{72}$ Fig. 15 Pseudo-systematic distribution}

(cont)

Nine Amoeboid events randomly positioner in frame $100 \times 100 \mathrm{~m}$, sampled by metro-square plots at $18 \mathrm{x} 19 \mathrm{~m}$ spacing.

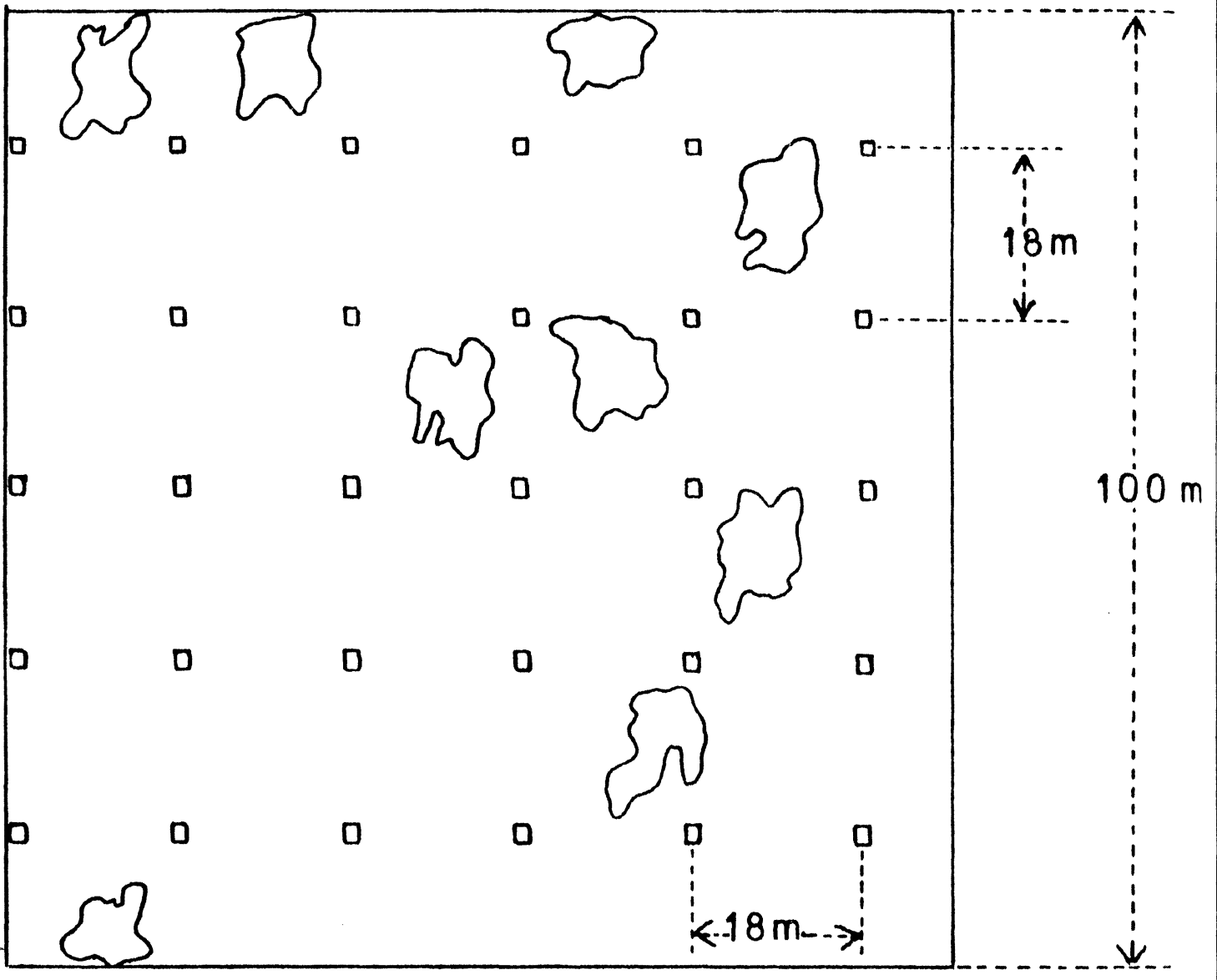

The nine events re-plotted in a single $18 \times 18 \mathrm{~m}$ square, give an "occupied area" shaded black.

Fig. 15. This particular disposition of randomly placed events happens to have taken up positions at approximate multiples of $18 \mathrm{~m}$ spacing, hence gives a $\mathrm{P}$ (miss) higher than expected for a random situation. 


\section{Fig.16 Dispersed-cluster distribution}

Nine Amoeboid events randomly positioned in frame $100 \times 100 \mathrm{~m}$, sampled by metre-square plots at $22 \times 22 \mathrm{~m}$ spacing.
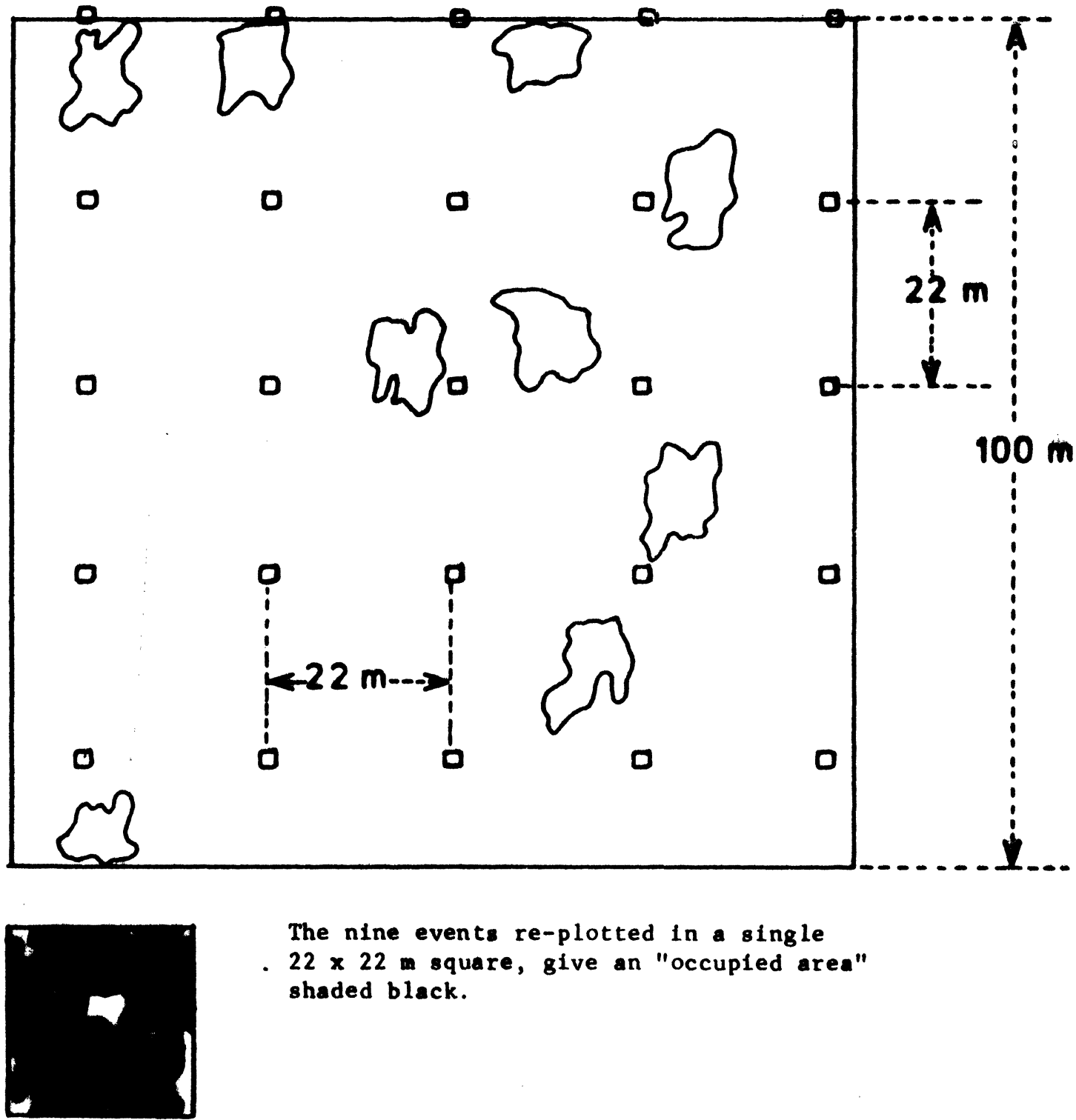

The nine events re-plotted in a single

- 22 × 22 m square, give an "occupled area" shaded black.

Fig. 16. This is the same disposition of randomly placed events as shown in Fig. 15, but in this case sampled by plots at $22 \times 22$ $m$, relative to which the events are effectively clustered neatly within a notional $22 \times 22 \mathrm{~m}$ square. Hence $\mathrm{P}$ (miss) is much lover than expected for a random situation. 
74 - Appx.1( end)

21. One particular series of fifty event-maps was designed specifically to test the frequency of pseudo-systematic and dispersed-cluster effects. Each $100 \times 100 \mathrm{~m}$ map was sampled by $1 \times 1 \mathrm{~m}$ plots at twelve different spacings from $10 \times 10 \mathrm{~m}$ to $50 \times 50 \mathrm{~m}$.

The 600 runs gave the following outcome, sorted by the $\mathrm{X}^{2}$ criterion at P.05:

$80 \%(79.83)$ had proportions of hits and misses 1ying within the expectation for a random discribution;

$15.7 \%$ showed hits significantly greater than expected, therefore had events of the dispersed-cluster type;

$4.3 \%$ missed the events significantly more often than expected, indicating a pseudo-systematic distribution.

It was to be expected that around five percent of the event-maps would turn out to be "non-random", since a P.05 criterion was used. The fact that twenty percent did so was surprising, and particularly gratifying in that much the most frequent kind of non-randomness, arising from random* causes (a1l in quotes if not shrieks), was that which results in increased probability of the events being detected by a systematic grid.

Experience with most soil and vegetation, provided it is not modified by extremely territorial animals (e.g. termites), suggests that clustering or zoning is more likely than regularity. Even when the latter occurs, it is usually as a pattern on which clusters or zones are based. If this argument is accepted then our systematic sample is further vindicated, at least for efficiency of detection, whatever might be the behaviour of its sampling error.

*We had already tested the ALGOL-68 random number generator using analysis of variance of a series of block-sizes and by pattern analysis of a run of several thousand numbers. 


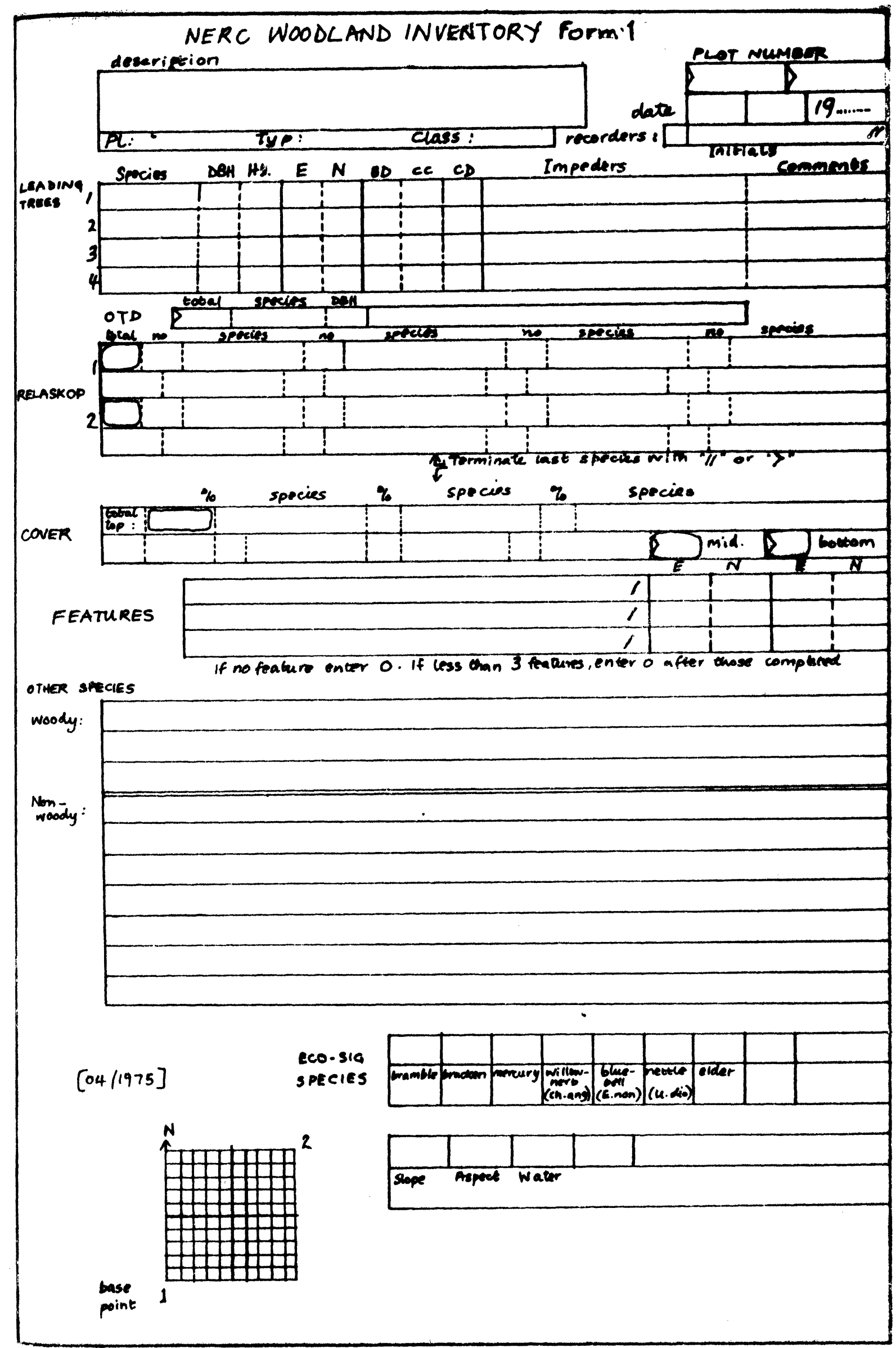


76 - Appx. 2 (cont)

NERC WOODLAND INVENTORY: FOrm 2

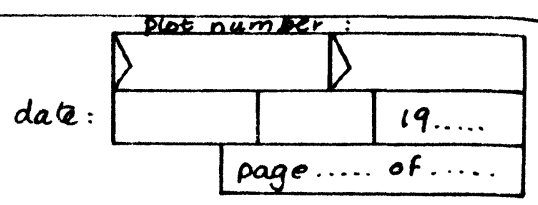

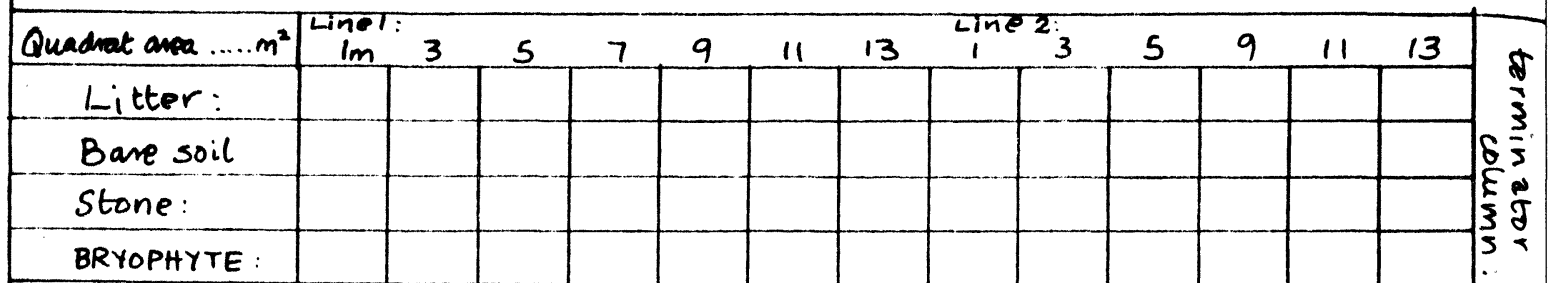

: MAT 
NERC INVENTORY: FORM 3: Soll data (MK II)

Page .... of ....

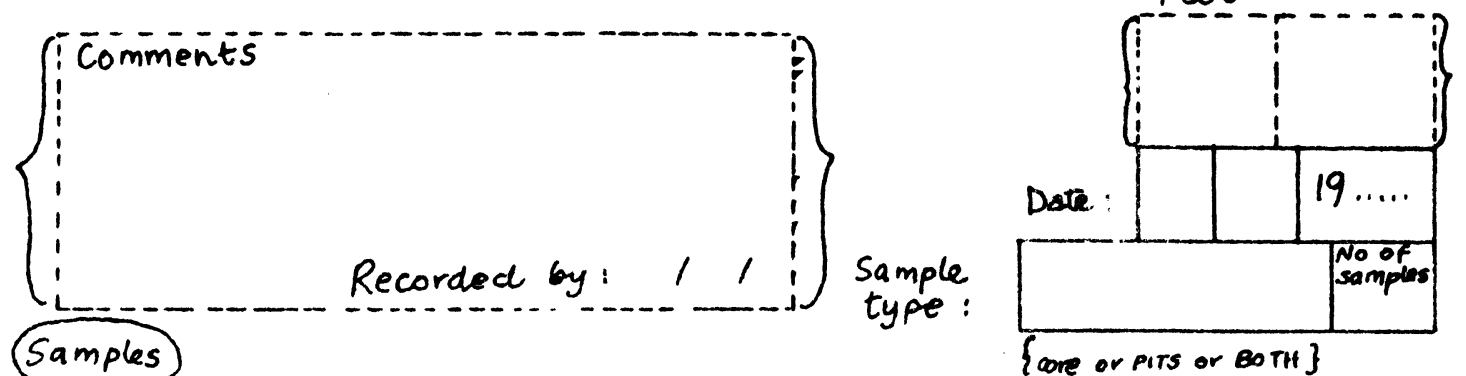

Samples

\{core or pirs or Both\}

\begin{tabular}{|l|l|l|l|l|l|l|l|l|l|l|l|}
\hline$E$ & $N$ & Depth & Code & $E$ & $N$ & Depth & Code & $E$ & $N$ & Depon & Code \\
\hline & & & & & & & & & & & \\
\hline & & & & & & & & & & & \\
\hline & & & & & & & & & & & \\
\hline
\end{tabular}
(PH)

$\{$ Codes: $R=$ Rock, $S=$ Stone,$W=$ root,$N=$ sample rejected, $X=$ unkenown, $Q:$ sample ok $\}$

NATER, CaCl2

Analyses

WATER

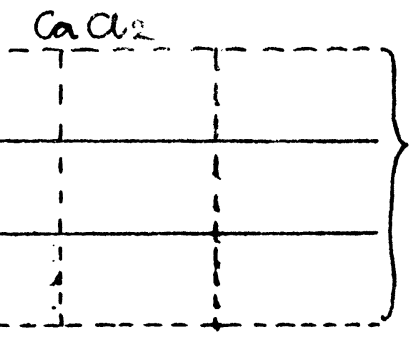

(O.M. $\%$

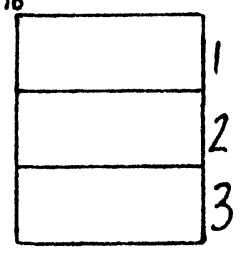

LAYER WE M. FoC TACID TTITRE O'Shood Add MEW TITRE

MECHANICAL:

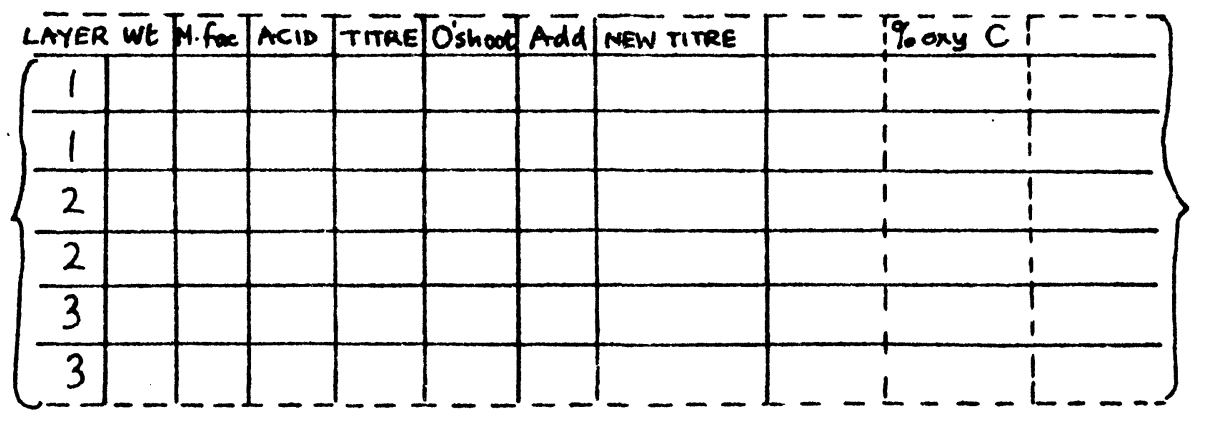

$\%$

CHEMICAL

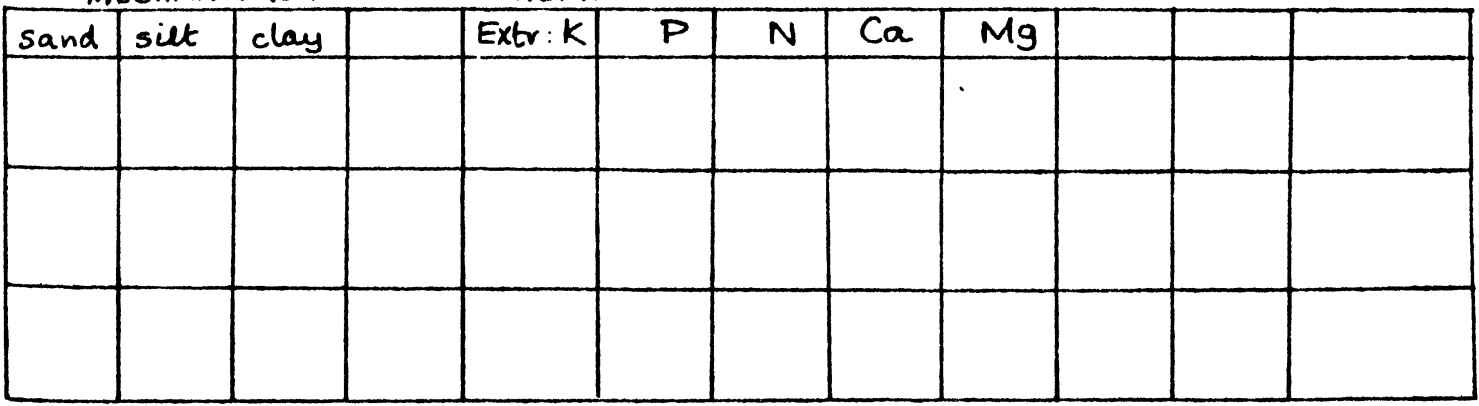




\section{-}


APPENDIX 3

\section{Recording of Specific Names}

Botanical nomenclature followed the Clapham, Tutin and Warburg floras as available in 1973. Except for the few mosses recorded in circlets (para. 5.14), only vascular plants were noticed.

Names of three types were recorded:

(1) Latin binomials, usually abbreviated to eight letter texts e.g. "FRAXI EXC" (5-space-3). However several were shorter, e.g. "POA PRA", and if longer texts were written the program would reduce then to the 5-3 format.

(2) One-word English names, for a predetermined 1ist of such names, given below, of we11-known trees and shrubs, e.g. "BIRCH", "ELDER", or the first three letters of such names, with or without a full stop. All such English names are translated by the programs to give 5-space-3 latin binomials in the printed outputs.

(3) Forestry Commission abbreviations, again of a pre-determined list, mostly of 2-digit size e.g. "NS", but 3-digit were also acceptable e.g. "HBM", "BEE". As with the Bnglish names, the program translates the F.C. abbreviacion to the latin binomial before outputting.

The specified list of acceptable English and F.C. names is given below, but in reading it remember that (with one exception) only the first three letters are needed, and only two if it is an F.C. abbreviation. The exception is CHE which could be cherry or chestnut, and therefore needs the first four letters to avoid ambiguity.

English names and forestry Commission abbreviations accepted by the CHECKIN Program (App. 7).

(There is no limit on the number of latin binomials that can be accepted, since no translation is involved. Only English and F.C. names are built into the program, along with their latin equivalents).

\section{Botanical binomial}

$\begin{array}{cl}\text { Abies } & \text { alba } \\ \text { " } & \text { grandis } \\ " & \text { procera } \\ " & \text { sp } \\ \text { Acer } & \text { campestre } \\ " & \text { platanoides } \\ \text { " } & \text { pseudoplatanus }\end{array}$

Aesculus hippocastanum Alnus glutinosa
Acceptable other names and abbreviations (abbreviations to first three letters are a11 acceptable except "Che".

\author{
SF \\ GF \\ NF \\ Fir \\ Maple \\ NM \\ Sycamore \\ HC \\ A lder
}


Betula pendula

Buxus sempervirens

Carpinus betulus

Castanea sativa

Chamaecyparis lawsoniana

Corylus avellana

Crataegis monogyna

Cupressocyparis leylandii

Euonymus europeus

Fagus sylvatica

Fraxinus excelsior

Ilex aquifolium

Juniperus communis

Larix decidua

" leptolepis

" sp

Ligustrum vulgare

Malus sylvestris

Picea abies

" omorika

" sitchensis

Pinus contorta

" nigra

" pinaster

" radiata

" strobus

" sylvestris

Populus tremula

$"$ sp

Prunus avium

" spinosa

Pseudolsuga menzeisii

Pyrus communis

Quercus cerris

" robur

Rhamnus catharticus

Rosa sp

Salix caprea

Sambucus nigra

Sequoia sempervirens

Sorbus aria

" aucuparia

" torminalis

Taxus baccata

The lycrania sanguinea

Thuya plicata

Tilia sp

Tsuga heterophylla

Ulmus glabra

" procera

Unknown, unidentified

Viburnum lantana

" opulus
Birch, Bi

Box

Hornbeam, HBM

Chestnut

Laws on, LC

Haze 1

Hawthorn

Leyland

Spindle

Beech, Be

Ash

Holly

Juniper

EL

$\mathrm{JL}$

larch

Privet

Crab

Norway, Spruce, NS

ns

Sitka, SS

ir,

CP, AP, Corsican

MP

Rad

Weymouth, WP

Scots, rine, SP

Aspen

Poplar

Cherry, Gean

Blackthorn, Sloe

Douglas, DF

Pear:

Turkey

Oak, Quercus

Buckthorn

Rose

Sallow

E1der

Seq

Whitebeam

Rowan

Service

Yew

Dogwood

RC, Thuya

Li.me,

Western, WH

Wych

F. $1 \mathrm{~m}$

NK

Viburnum

Guelder

Note that some abbreviations are translated by the programs into a generic group rather than a species. Thus "LARCH" (or, of course, "IAR") becomes "LARIX sp" in output, similarly with "LIME", "ROSE", "POPIAR", "FIR". Others are more specifically translated; 
Appx. 3(end) -81

"OAK" always becomes "QUERC ROB" and "PINE" always becomes "PINUS SYL", and there are others like this. When in doubt in the field it is always safest to record the latin binomial, the epithet of which can be "sp". or even "sp?", when it will be treated by the program exactly as written. Note that no query mark or fullstop or other character will be noticed by the program if placed after the third letter of an English name or after the third of a latin specific epithet. "LARCH?" would simply be translated as "LARIX SP" as above.

It is also worth noting that a temporarily unidentified plant can be entered as "UNKNOWN" or if collected for later identification as for example specimen No. 18 then "SPECM N18", in which case that is exactly how they would appear in the record. 


$$
-
$$




\section{APPENDIX 4}

\section{Soil Collection and Analysis}

1. Fieldwork, as detailed in para. 5.16, samples were taken of three layers of soil $(0-10,10-20$ and $20-30 \mathrm{~cm})$ from four sites at each plot, which were then bulked into a single batch from each layer.

Soils were collected at a11 plots in the Wytham and Halton woods. All the Wytham samples were taken by core auger, most of the Halton ones by digging pits, as the auger proved unusable in the clay-with-flints and chalk soils common there. The dimensions of the auger are given, in millimetres, in the illustration (Fig. 7). It was made of mild steel tube, welded in four sections. Marks scored on the barrel at $10 \mathrm{~cm}$ intervals showed the depth penetrated. An allowance of $2.4 \mathrm{~cm}$ ( 1 inch) was made for compression of the first core. This, while arbitrary, seemed in practice a reasonable estimate. A single core obtained by twisting the auger into the ground should measure $1.0 \mathrm{~cm}$ long by $3 \mathrm{~cm}$ diameter, giving a volume of approximately $70 \mathrm{cc}$.

At each of the four sample points, the following method was used. Litter was cleared from the spot until mineral soil was exposed. Cores were then taken. If an obstruction was met before $30 \mathrm{~cm}$ was reached, not surmountable by extra force on the auger, up to two further attempts were made to get a set of cores a small distance $(0.2 \mathrm{~m}$ or occasionally 0.1$)$ away. The samples from the deepest boring were retained in such cases. If none achieved full depth, the third core may represent less than a $10 \mathrm{~cm}$ layer. If the depth at a given attempt exceeded $26 \mathrm{~cm}$, those cores were usually retained and no further borings were made. The cores were placed in separate $11 \times 6$ inch $(28 \times 15 \mathrm{~cm})$ heavy-guage polythene bags, labelled "1", " 2 " and " 3 ". This process was repeated at each sample point, aggregating the cores for each depth in the three bags. Finally, the three bags were packed together in a further bag, labelled with the grid reference of the plot and tied with a twistgrip.

The soil sampling at Wytham was done at different times from the ecological recording, and spanned the winters of 1974 and 1975. (App.3).

At Wytham, the sampling points were generally on the west and south sides of the plot, co-ordinates $0 / 4,0 / 9,4 / 0,9 / 0$.

At Halton, the soil samples were all taken at the same time as the recording was done, and therefore points midway along each side of the plots were usually selected (Fig. 2). At most plots samples were got by digging pits at the sample points. Because spades are of little use on highly flinty soils, we evolved the method of loosening the flints by levering with a "wrecking bar" (sometimes known as a crate lever) and removing soil with a trowel. Each pit had to be $30 \mathrm{~cm}$ deep, but we found a width of $20-25 \mathrm{~cm}$ often enough to allow cleaning of the side and scraping away samples for each depth with a trowel marked in $10 \mathrm{~cm}$ steps. Where the soil was very stony, it was not possible to obtain a sample evenly distributed 
over the $10 \mathrm{~cm}$ span: soil often had to be scraped away wherever there seemed to be any soil to scrape. The samples obtained were wrapped in the same way as above.

Where the soils overlaid chalk, it was often hard to distinguish parent material from soil, i.e. there was no clear boundary. In such cases samples were usually taken regardless of any soil/rock boundary.

Samples were stored for as short a time as possible before processing. If more than a day intervened, they were put in a fridge to reduce $\mathrm{pH}$ shift. Some of the first-collected Wytham samples were kept for several days at room temperature.

2. Laboratory work. The following processes were followed for the sample bags of each plot:

(a) The samples were unwrapped, and the four cores for each depth put together into an aluminium drying tin and broken up by hand into pieces not larger than 1-2 cm across, depending on consistency. The $\mathrm{pH}$ determination was then performe $\mathrm{f}$ on the fresi samples: 2 aliquots were taken from each tin (i.e. each a gregated depth samp e), weighed to $10 \mathrm{~g} \pm 0.1 \mathrm{~g}$ ) - each aliquot made up by ielecting and breaking smal1 pieces (not greater than coout $0.5 \mathrm{~g}$ ) from as many of the soil pieces as possible, so that scil from all cores was roughly equally incorporated. Becense the soil was fresh, this was a subjective process.

(b) $\quad \mathrm{pH}$

Both aliquots were macerated into suspension, one in distilled water, the other in $0.01 \mathrm{M} \mathrm{CaCl}_{2}$ (hydrated) solution. This was done by putting the aliquot into a McCartney bottle, adding about half the solvent, and grinding with a high-speed electric homogeniser for 20-60 secs (depending on the soil texture). The result was poured off into a $100 \mathrm{~m} 1$ beaker, the remainder of the solvent added to the bottle and mixed. The bottle was shaken, and the remainder added to the beaker.

The resulting suspensions were left to stand "overnight" minimum time: $6 \mathrm{hrs}$ ).

The $\mathrm{pH}$ was then measured using a Beckman $\mathrm{pH}$ meter with Beckman glass electrode and Russe $11 \mathrm{KC} 1$ bridge electrode. The meter needle was allowed to gettle for at least 10 secs before the reading was noted. Repeat check readings were taken until variation between readings was less than 0.2 units.

With the water 'solvent' especially, a slow drift was sometimes found, and the asymptotic reading had to be estimated. Buffer standards were used to adjust the meter deflection.

After the $\mathrm{pH}$ had been taken, the soil suspensions were discarded. 


\section{(c) Organic matter determination}

The rest of the soil sample was dried slowly in a small oven at $40^{\circ} \mathrm{C}(1)$, or air-dried in the lab., and then broken down to a size passable through a $2 \mathrm{~mm}$ sieve. An iron sieve was used for the earlier Wytham samples, but a brass Endecott sieve for all the Halton samples. Roots and stones were removed as far as possible by hand and not crushed - although there had to be an arbitrary size limit for both these procedures. This breaking down $(2)$ was done with a steel hammer: with clay soils, considerable effort was needed. Additions of trace elements and distortion of soil texture by this treatment were not thought to be significant.

Aliquots of about $2 \mathrm{~g}$ were taken from each tin and dried at $100^{\circ} \mathrm{C}$ for at least an hour just before the organic matter determination was done.

From each $2 \mathrm{~g}$ aliquot, a $1 \mathrm{~g}$ sample $( \pm 0.01 \mathrm{~g}$ or $0.05 \mathrm{~g}$ in earlier samples) was weighed into a Erlenmeyer flask for the Walkley-Black carbon determination.

To each flask was added $10.0 \mathrm{ml} \mathrm{N}$ 'Analar' potassium dichromate solution by pipette, followed by $20 \mathrm{ml}$ concentrated sulphuric acid ('Analar') gently poured in from a measuring cylinder. Each flask was covered with a small beaker to limit escape of fumes, and aliowed to stand, with occasiona 1 swirling, for 30 mins ( \pm less than 5 mins). Then $100 \mathrm{~m} 1$ approx. of distilled water was added to each, and the mixtures allowed to cool.

For the titration, $2 \mathrm{~m} 1$ of indicator (n-phenyl-anthranilic acid) was added, and $0.5 \mathrm{~N}$ 'Analar' ferrous ammonium sulphate run in from a burette until the end point was reached (colour change: wine-red to khaki-green). A lamp trained on the flask helped to show this change.

A blank - no soil - titration was included in each session to standardise the solutions.

3. Calculations

$1 \mathrm{~m} 1$ of dichromate was taken as equivalent to $3 \mathrm{mg}$ carbon. With $N$ as the normality of the ferrous ammonium sulphate,

percentage of oxidisable carbon $=\frac{(\text { blank titre }- \text { actual titre) } \times N \times 3}{10 \times \text { wt.soil } \times \text { moisture factor }}$

(1) The earlier Wytham samples were dried at higher temperatures: this was thought undesirable in that it may affect nitrogen analyses.

(2) An alternative method known to us was to freeze the samples wet, and then slowly air-dry in a cabinet. This breaks down clay aggregates well, but we felt as much effort would be needed to build the apparatus and transport samples to/from a freezer than was needed for our method. 
86 - Appx.4(end)

The moisture factor, with dry soil, is 1. A recovery factor of $\times 1.33$ was used, and the percentage organic matter derived by multiplying by a further factor of 1.73 .

For high organic matter contents (greater than $12 \%$ ), the amounts of dichromate and sulphuric acid have to be doubled. This was always done for the sample from the top $10 \mathrm{~cm}$ : sometimes it was needed for other samples. In these cases, $150 \mathrm{ml}$ or so of distilled water was added to dilute the mixture before cooling.

4. Chemical analyses

Subsamples of $25 \mathrm{~g}$ were separated from the main samples with a randomising separator and sent to ITE Merlewood for analysis of tota $1 \mathrm{~N}$ and extractable $\mathrm{K}, \mathrm{P}, \mathrm{Mg}, \mathrm{Ca}$.

The methods used may be found in S.E. Allen's "Analysis of Ecological Materials".

5. Storage at the Department of Forestry, Oxford.

The dried soil remaining was stored in $6 \times 4$ inch polythene bags, with plastic 'Dymo' labels with the grid reference of the grid point and the depth layer, e.g.: 465078.1 where the '.1' refers to the depth stratum $0-10 \mathrm{~cm}$. Each bag was sealed with a 'twistgrip' and the three bags laced in a larger ( $11 \times 6$ inch) polythene bag labelled with 'Textmark' ink. 
APPENDIX 5

\section{METAL DETECTION}

\section{Requirements}

1. Our plots had to be marked invisibly and permanently. "Invisibly" could be defined as: easy to find by those whose business it is, difficult to encounter by the casual, irrelevant or mischievous. By "permanent" we intended certainly over fifty years, preferably over more than a century.

2. We considered the markers should be placed below ground surface; the two alternatives seemed to be:

(a) magnets, detected by magnetometer (e.g. Wadsworth, 1970);

(b) unmagnetized meta1, using a metal detector.

The first was rejegted on grounds of cost and doubtful permanence. Our markers had to be cheaper than good magnets would have been, and we had redundant mild steel lighting conduit readily available. To insure for long life, we used stainless steel tube iaced inside the conduit, each assembly being sunk vertically with a mallet.

\section{Detection}

3. The detector had to be reliable and especially robust, easily portable in forest conditions and fast in locating our markers. We investigated a variety of equipment.

(i) A simple detector was built for us for testing in the field. This worked on a common and cheap principle: a beat-frequency oscillator, of which the note changes pitch with changes in the inductance of the search coil. It performed poorly and was sensitive to vegetation.

(ii) A "Heathkit" detector, loaned by courtesy of Thames Valley police. Worked on similar lines to (i), was not sensitive enough and could easily be knocked out of tune by impact with bushes, twigs, etc.

(iii) A "Dekko" prototype, by courtesy of the Oxford University Archaeology Department. Worked on a different principle, that of induction, as described by Colani and Aitken (1966), Foster and Hackens (1969). The machine was cumbersome but detected metal conduit better than the previous two. However, stainless steel tubes on their own were extremely difficult to locate.

(iv) A machine built for the Army, tested by courtesy of the Procurement Executive of the Ministry of Defence, gave a similar performance to the Dekko. 
(v) Finally we tested and purchased a C400 Mark III made by Geo-Electronics of Stanford-in-the-Vale, oxon. This works on a pulse induction principle, on re-chargeable batteries, and uses both dial and earphones to indicate a "hit". It is sensitive to stainless steel as well as to other metals, and is unaffected by contact with shrubbery and other woodland impediments. 
APPENDIX 6

\section{Description and Use of Computer Programs}

1. The project ended up with two preparatory programs and several examples of analytical programs for tabulating, listing, graphing and mapping various sections of the observations. Their names and purposes were:

(i) Preparatory programs (ALGOL-68)

CHECKIN: takes raw data from the punched card record and checks that it is complete, picks out any obvious mistakes of magnitude, arrangement or spelling, and gives appropriate error message: .

LISTJUT: given thet data has been checked by the above program and corrected: this produces listings of files of several kinds for a variety of uses including storage, of all or part of the observations.

(ii) Anglytical programs, take data from a file produced by LISTOUT. Two examples are given:

WOODMAP: plots a crude line-printex map of the whole wood, with single "symbols" at each plot positin, to indicate any chosen presence/absence or simple quantitative feature.

PLOTMAP: draws a simple diagram for use in the field of each plot (one per line-printer sheet), showing positions of leading trees and listing the relaskop tallies, ecosig scores, upper canopy percentages and leading-tree characters. Intended for use in the field as a kind of annotated notebook.

Examples of output from both of these are given in Appendix 7. Details of scope and use of the analytical programs are available at the Department of Forestry, 0xford.

\section{Use of the preparatory programs: CHECKIN and LISTOUT}

2. Unless otherwise stated:

(i) Numbers should be separated from each other and from texts by two spaces (one space may be technically sufficient but is inconvenient for checking).

(ii) Text phrases or sentences should be separated from any neighbouring matter by two spaces, but words within a phrase or sentence should be separated by only one space.

A latin binomial is a phrase.

There are places where separators such as / or // are also required; these are marked on the field forms and described in Chapter 5 . 
(iii) The words "card" and "line" are synonymous in the following instructions.

3. Certain items of information are required at the head of data fed into both CHECKIN and LISTOUT, namely:

(i) A line with the site title, preceded by the word SITE

On the next line:

$$
\text { e.g: SITE WYTHAM }
$$

(ii) The number of plots being presented

$$
\text { e.g. } 163
$$

(iii) Four numbers, giving in turn the lowest easting, highest easting, lowest northing, and highest northing of the grid references of all the plots.

$$
\text { e.g. } 110 \quad 250 \quad 880 \quad 910
$$

For CHECKIN, no other information is needed, but for LISTOUT the above must be preceded by a steering section.

4. Steering prefixes for LISTOUT program

(i) Output type. There are four options, each called up by the textual (not numerical) instruction given:

OUTPUT TYPE ONE produces the "human-readable" form, laid out with informative headings as in the example given in Appendix 7.

OUTPUT TYPE TWO (or THREE) produces formatted versions with species names compressed to eight characters, e.g.: URTICDIO (or left as nine characters, e.g.: URTIC D10), the latter with the space as written.

OUTPUT TYPE FOUR gives a formatted, mostly numerical form, with al1 species names encoded as 3 -digit numbers.

(ii) Titles. Output types 2,3 and 4 can be supplied with titles at the head of each of the seventeen data sections. Titles are section names abbreviated as follows:

$\begin{array}{rll}1 & \text { GENERAL DESCR IPTION } & \text { (*PLOT*) } \\ 2 & \text { LEADING TREES } & \text { (LTREES) } \\ 3 & \text { OTHER TREES DEAD } & (\text { O.T.D.) } \\ 4 & \text { FIRST REIASKOP SWEEP } & \text { (1 SKOP) } \\ 5 & \text { SECOND " } & (2 \text { SKOP) } \\ 6 & \text { UPPER COVER } & \text { (COVERU) } \\ 7 & \text { MIDDLE LAYER COVER } & \text { (MIDCOV) } \\ 8 & \text { BOTTOM LAYER COVER } & \text { (BOTCOV) } \\ 9 & \text { FEATURES IN THE PLOT } & \text { (FEATRS) } \\ 10 & \text { OTHER SPECIES FOUND } & \text { (SPECIS) } \\ 11 & \text { ECOLOGICALLY SIGNIFICANT SPECIES (ECOSIG) } \\ 12 & \text { PERMANENT FEATURES } & \text { (PMFTRS) } \\ 13 & \text { QUADRATS : STANDARD } & \text { (QUAD S) }\end{array}$


14 QUADRATS : BRYOPHYTES (B QUAD)

15 " : HIGHER PLANTS (H QUAD)

16 SOILS INFORMATION (SOILS)

17 This is the whole-plot species list

collected and sorted by the program.

Its title is: (TOT SP)

If titles are required, the instruction is:

TITIES

The titles when inserted by the program will each be followed by a line-count for the ensuing section.

If titles are not required, enter:

NO TITI.ES

This instruction is the one appropriate for output type 1 which is already very thoroughly supplied with headings.

(iii) Species code numbering. Three-digit codes will be assigned to each species appearing in the data if this instruction is given:

\section{SPECIES NUMBERED}

This would be especially useful in outputs type 2 ad 3 if these are to be used for programs with poor text-handling facilities. It is also appropriate for output type 4.

\section{SPECIES NOT NUMBERED}

wil1 leave al1 names as texts.

(iv) Sorting. If species code numbers in the whole-plot list (item 17 ) are to be put in numerical sequence, the instruction is :

\section{SORTING}

The instruction:

\section{NO SORTING}

will leave the codes in the alphabetical sequence of the names that they represent. This is the appropriate instruction in output type 1 .

(v) Section selection. Here it is possible to choose which sections of data are to be produced and which suppressed. Each section is called up by the digit 1 (unity) and is suppressed by 0 (zero), in a string of seventeen digits, one for each section, entered without spaces. Then follow six dummy digits, for which zeroes may be used. Finally in the 24 th position the digit 1 causes all "impinging" species (as well as those rooted within the plot) to be included in the within-plot species list at item 17. Impinging species are those recorded as impeders, in relaskop tallies, and in the upper cover. 
A zero at the 24 th position will restrict the within-plot list to those species rooted in the plot.

\section{1}

This is however a "default" instruction and, if such information is required, will be assumed by the program and can be omitted. Any lesser requirement must be fully specified.

For instance, a printout of the leading-tree information and total species list alone would be given by

\section{1}

(vi) Area species list. The program can accumulate a species list over a whole "area" with numerous plots. The list can then be expressed in three modes. The instruction:

\section{AREA SPECIES LIST}

will print all three modes, which are

Alphabetical list of species, each name followed by its code number.

Code-number list of species in numerical sequence of codes, each code followed by it: species name.

Frequency list; the species in order of frequency, each name preceded by the number of plots in which it occurred.

The instruction: CODE LIST ONLY

will print only the second of the above lists.

Example in Appendix 7 .

The instruction:

NOT REQUTRED

(or indeed any other text) will omit the lists altogether.

Whether the lists contain impinging as well as rooted species will depend on the content of the within-plot species 1ists, already determined in para.(v) above.

5. The LISTOUT program, having read the steering instructions, will permit the presence of up to ten cards with any contents before finding the one with the SITE prefix (para.3(i) which marks the start of the data proper. The program will add a descriptive text to the end of each output run, outlining the steering actually followed, as a check on input.

Both preparatory programs are very thoroughly described by comments incorporated within them. 
$\begin{array}{lllllll}457 & 086 & 2 & 9 & 75 & 2 & \mathrm{WA} / \mathrm{DF} / /\end{array}$

ASH SAPLINGS WITH ONE SYCAMORE OVER BROW OF HILL.

$\begin{array}{lll}-99 & -99 & -99\end{array}$

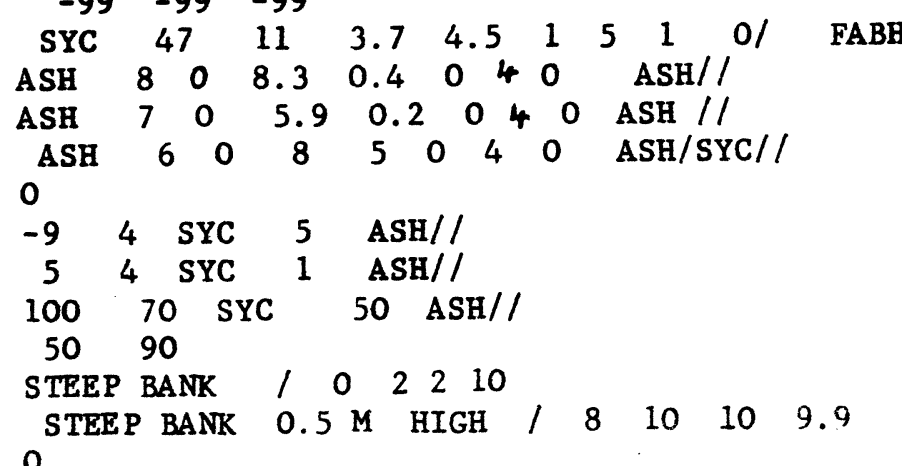

HAW / DOG/ROSE/

DACTY GLO/ HYPER HIR/ GEUM URB/ FESTU GIG/ TAMUS COM/ CAMPA TRA/

FRAGA VES/ EUPHO AMY/ GLECH HED/ CAREX SYL/SANIC EUR//

$50020000-9 \quad 20900$

$\begin{array}{llllllllllllllllllll}-1 & 1 & -1 & 1 & -1 & 1 & 1 & 0 & 1 & 1 & -1 & 1 & 1\end{array}$

$\begin{array}{llllllllllllll}1 & 1 & 1 & 1 & 1 & 1 & 1 & 0 & 1 & 1 & 1 & 0 & 0\end{array}$

$\begin{array}{llllllllllllll}0 & 1 & 0 & 1 & 1 & 0 & 0 & 0 & 0 & 0 & 1 & 1 & 0\end{array}$

$\begin{array}{lllllllllllllllllllllllllll}1 & 1 & -1 & 1 & 1 & -1 & 1 & 1 & 1 & 1 & 1 & 1 & 1\end{array}$

$\begin{array}{llllllllllllll}1 & 1 & 0 & 1 & 1 & 1 & 1 & 1 & 0 & 0 & 1 & 1 & 1\end{array}$

THUID TAM 100000111100000000

HYPNOID $\quad \begin{array}{lllllllllllllllll}1 & 1 & 1 & 1 & 1 & 1 & 1 & 1 & 1 & 1 & 1 & 1 & 1 & /\end{array}$

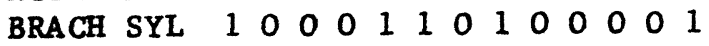

RUBUS FRU $111110 \begin{array}{lllllllllll}1 & 1 & 1 & 0 & 1 & 0 & 1 & 0 & 1 & 0\end{array}$

MERCU PER $1 \begin{array}{lllllllllllll}1 & 1 & 0 & 1 & 1 & 1 & 1 & 0 & 1 & 1 & 1 & 1 & 1\end{array}$

CIRCA LUT 000001100000000000

ASH $\quad 0000025102010001001001000$

AJUGA REP 000000000111000000

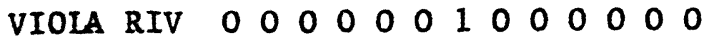

ANGEL SYL 00000000010000001

$\begin{array}{llllllllllllllllllllll}230276 & \text { CORE } & 4 & 4 & 0 & 5 & R & 4.2 & 0 & 27 & R & -99 & 9.5 & 0 & 27 & R & -99 & 0 & 4 & 29 & R\end{array}$

$\begin{array}{llllllllllllll}-99 & 0 & 9 & 15 & R & 0 & 9.2 & 5 & R & 0 & 9.4 & 22 & R\end{array}$

$\begin{array}{lllllllll}7.7 & 7.6 & 8 & 7.6 & 8.1 & 7.7 & 11.5 & 6.8 & 4.7\end{array}$

$\begin{array}{llllllllllllllll}18 & 28 & 1.2 & .69 & 14000 & 110 & 13 & 15 & 1.2 & .43 & 18000 & 120 & 8.9 & 10 & 1.1 & .24\end{array}$

21000130 
ASH SAPLITNGS WTITH ONE SYCAMORE OVER BROW'OF HILL.

PIANTING_DATES: $\quad-99 \quad 0 \quad 0$ PLOT_CLASS: $-99 \quad$ SLOPE_CLASS: -99

IBADING TREES: THE 4 LARGEST IN THE PLOT.

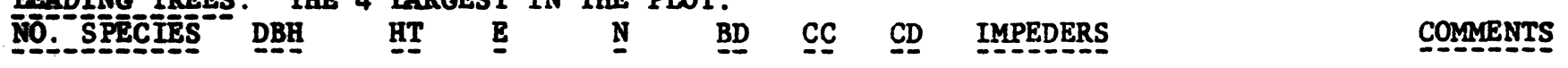

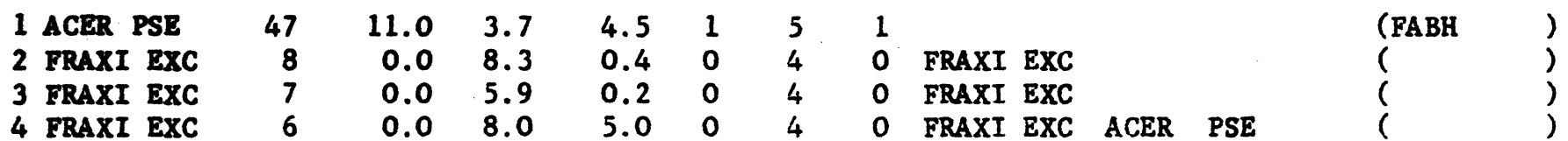

OTHER TREES DEAD : TOTAL, SPECIES AND DBH

o

REIASKKOP_COUNTS FROM POINTS A AND B. (ARC 2 OF INSTRUMENT).

-9 :TOTAL 4 ACER PSE 5 FRAXI EXC

5 : TOTAL 4 ACER PSE 1 FRAXI EXC

COVER PERCENTS. TOP COVER ( $>2.5 \mathrm{M})$ WITH SPECIES PERCENTS.

100 :TOTAL 70 ACER PSE 50 FRAXI EXC

MIDDLE AND BOTTOM COVER PERCENTS

50

90

FEATURES. (MAX $=3$ ) DESCRIPTION AND CO-ORDINATES IN THE PLOT

$\begin{array}{llrrrr} & & \text { E } & \text { N } & \text { E } & \text { N } \\ \text { STEEP BANK } & / & 0.0 & 2.0 & 2.0 & 10.0 \\ \text { STEEP BANK } 0.5 M \text { MIGH } & / & 8.0 & 10.0 & 10.0 & 9.9\end{array}$

*NONE 
OTHER_SPECIES : I.E. NOT FOUND IN ANY OTHER CATEGORY SAVE ECOSIGS

CRATA MON THELY SAN ROSA SP DACTY GLO HYPER HIR GEUM URB FESTU GIG TAMUS COM CAMPA TRA FRAGA VES EUPHO AMY GLECH HED CAREX SYL SANIC EUR

ECOOSIGS - SELECTED SPECIES MEASURED ON A 0-5 SCALE

RUBUS FRU PTERI AQU MERCU PER CHAMA ANG ENDYM NON URTIC DIO SAMBU NIG

0

2

0

$-9$

SLOPE (\%), ASPECT (DEGREES) AND WATER (0-5 SCALE)

20

90

0

CIRCLET_RECORDINGS.

$\begin{array}{lrrrrrrrrrrrrr}\text {.LITR } & -1 & 1 & -1 & 1 & -1 & 1 & 1 & 0 & 1 & 1 & -1 & 1 & 1 \\ \text {.SOIL } & 1 & 1 & 1 & 1 & 1 & 1 & 1 & 0 & 1 & 1 & 1 & 0 & 0 \\ \text {.STNE } & 0 & 1 & 0 & 1 & 1 & 0 & 0 & 0 & 0 & 0 & 1 & 1 & 0 \\ \text { MOSS } & 1 & 1 & -1 & 1 & 1 & -1 & 1 & 1 & 1 & 1 & 1 & 1 & 1 \\ \text {.MOSS MAT } & 1 & 1 & 0 & 1 & 1 & 1 & 1 & 1 & 0 & 0 & 1 & 1 & 1 \\ & & & & & & & & & & & & & \\ \text { THUID TAM } & 1 & 0 & 0 & 0 & 1 & 1 & 1 & 0 & 0 & 0 & 0 & 0 & 0 \\ \text { HYPN* MOS } & 1 & 1 & 1 & 1 & 1 & 1 & 1 & 1 & 1 & 1 & 1 & 1 & 1 \\ & & & & & & & & & & & & & 1 \\ \text { BRACH SYL } & 1 & 0 & 0 & 0 & 1 & 1 & 0 & 1 & 0 & 0 & 0 & 0 & 1 \\ \text { RUBUS FRU } & 1 & 1 & 1 & 0 & 1 & 1 & 0 & 1 & 0 & 1 & 0 & 1 & 0 \\ \text { MERCU PER } & 1 & 1 & 0 & 1 & 1 & 1 & 1 & 0 & 1 & 1 & 1 & 1 & 1 \\ \text { CIRCA LUT } & 0 & 0 & 0 & 1 & 0 & 0 & 0 & 0 & 0 & 0 & 0 & 0 & 0 \\ \text { FRAXI EXC } & 0 & 0 & 0 & 0 & 25 & 10 & 20 & 100 & 0 & 100 & 100 & 100 & 0 \\ \text { AJUGA REP } & 0 & 0 & 0 & 0 & 0 & 0 & 1 & 1 & 0 & 0 & 0 & 0 & 0 \\ \text { VIOIA RIV } & 0 & 0 & 0 & 0 & 0 & 0 & 1 & 0 & 0 & 0 & 0 & 0 & 0 \\ \text { ANGEL SYL } & 0 & 0 & 0 & 0 & 0 & 0 & 0 & 1 & 0 & 0 & 0 & 0 & 0\end{array}$

(continued on p.96) 
SOILS INFORMATION

DATE OF SAMPLING: 23276 ; METHOD= CORE; NO OF SITES: 4

$\begin{array}{llllllllll}\text { SITE TRIES } & E & N & \text { DEPTH CODE } & E & N & \text { DEPTH CODE } & \text { E } & N & \text { DEPTH CODE }\end{array}$

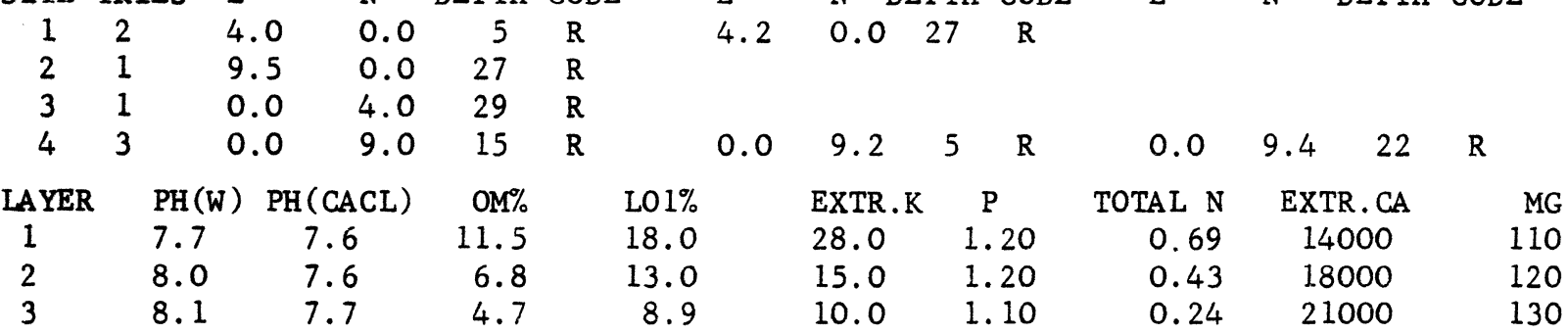

ALL_SPECIES FOUND IN THE PLOT: (FROM ALL SECTIONS OF DATA)

$\begin{array}{llllllllll}. \text { LITR } & \text {.MOSS } & \text {.MOSS MAT } & \text {. SOIL } & \text {.STNE } & \text { ACER PSE } & \text { AJUGA REP } & \text { ANGEL SYL } \\ \text { BRACH SYL } & \text { CAMPA TRA } & \text { CAREX SYL } & \text { CIRCA LUT } & \text { CRATA MON } & \text { DACTY GLO } & \text { EUPHO AMY } & \text { FESTU GIG } \\ \text { FRAGA VES } & \text { FRAXI EXC } & \text { GEUM URB } & \text { GLECH HED } & \text { HYPER HIR } & \text { HYPN* MOS } & \text { MERCU PER } & \text { ROSA } & \text { SP } \\ \text { RUBUS FRU } & \text { SANIC EUR } & \text { TAMUS COM } & \text { THELY SAN } & \text { THUID TAM } & \text { VIOLA RIV } & & & \end{array}$

(end of "readable version") 
$\begin{array}{llllllll}457 & 086 & 2 & 9 & 75 & 2 & \mathrm{WA} / \mathrm{DF} / & /\end{array} / /$

ASH SAPLINGS WITH ONE SYCAMORE OVER BROW OF HILL.

\begin{tabular}{|c|c|c|c|c|c|c|c|c|c|c|c|}
\hline-99 & 0 & & $(-99$ & ) & -99 & & & & & & \\
\hline 001 & 47 & 11.0 & 3.7 & 4.5 & 1 & 5 & 1 & 0 & 0 & 0 & (FABH \\
\hline 002 & 8 & 0.0 & 8.3 & 0.4 & 0 & 4 & 0 & 002 & 0 & 0 & ( \\
\hline 002 & 7 & 0.0 & 5.9 & 0.2 & 0 & 4 & 0 & 002 & 0 & 0 & ( \\
\hline 002 & 6 & 0.0 & 8.0 & 5.0 & 0 & 4 & 0 & 002 & 001 & 0 & ( \\
\hline
\end{tabular}

$\begin{array}{rrrrr}-9 & 4 & 001 & 5 & 002\end{array}$

$\begin{array}{rrrrr}100 & 4 & 001 & 1 & 002 \\ 100 & 70 & 001 & 50 & 002\end{array}$

50

90

$\begin{array}{lllllrrr}\text { STEEP BANK } & & & & 0.0 & 2.0 & 2.0 & 10.0 \\ \text { STEEP BANK } 0.5 \text { M HIGH / } & 8.0 & 10.0 & 10.0 & 9.9\end{array}$

$\begin{array}{lll}10.0 & 10.0 & 9.9\end{array}$

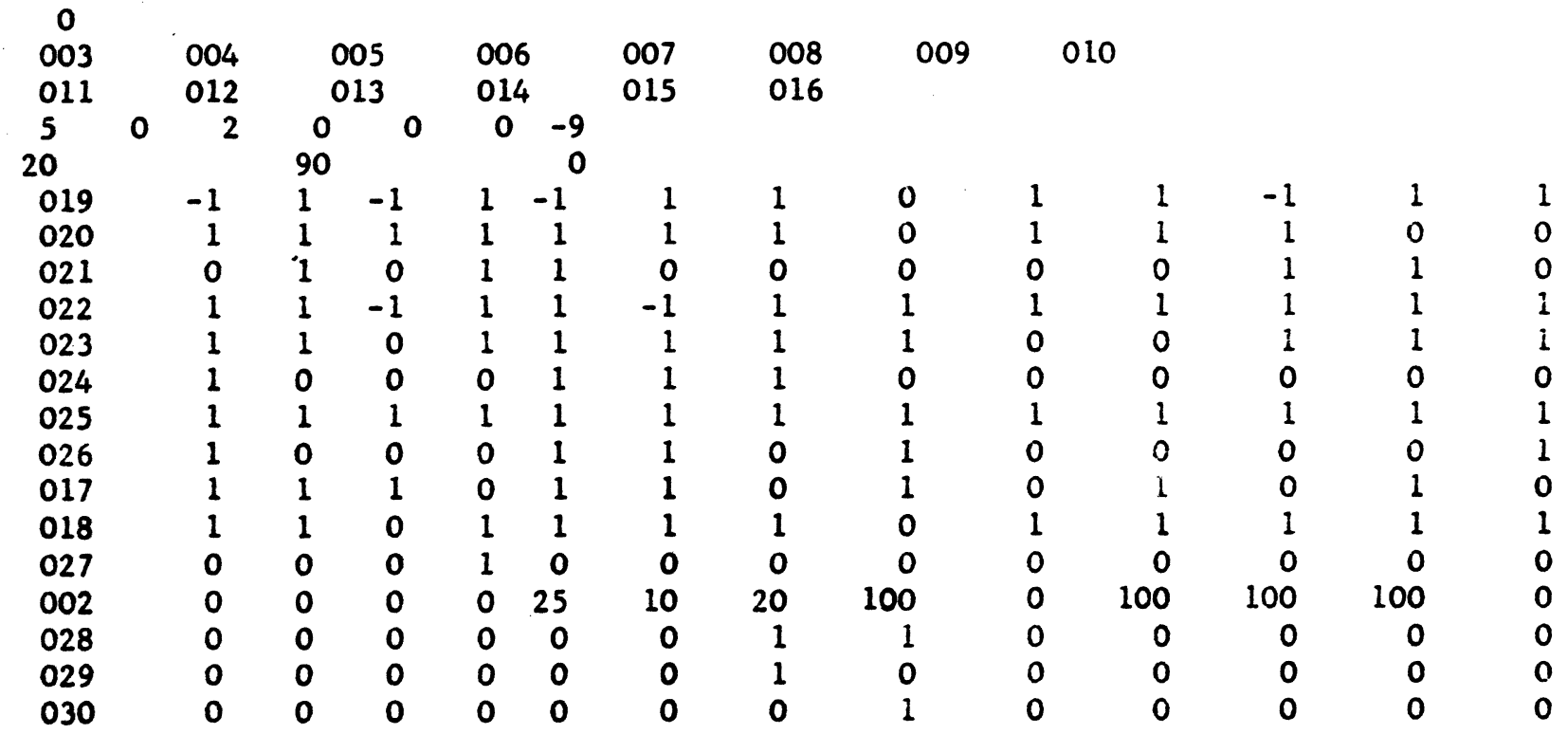

(end of circlets record; output continued on p.98) 


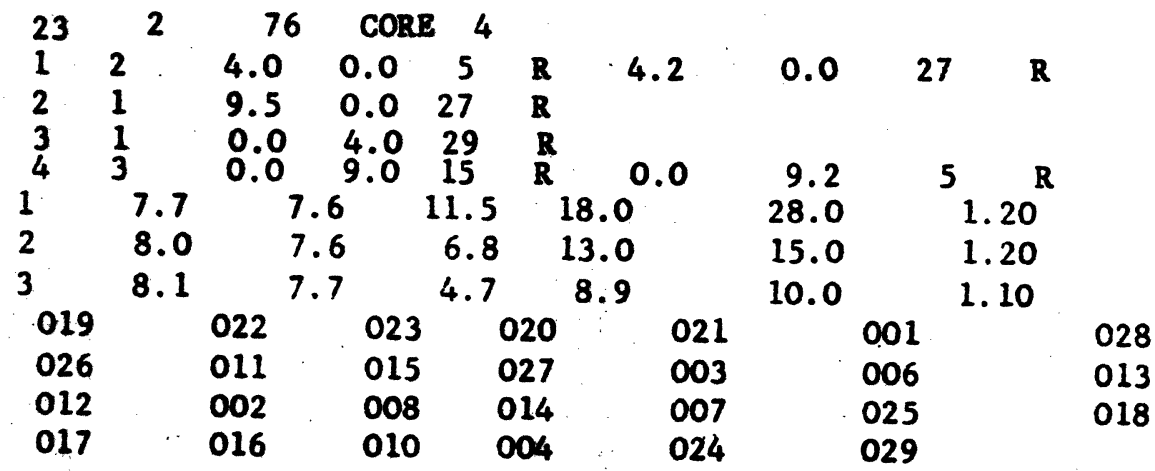

$\begin{array}{ccccc}0.0 & 9.4 & 22 & \text { R } & \\ 0.69 & 14000 & & 110 \\ 0.43 & 18000 & & 120 \\ 0.24 & 21000 & & 130 \\ 030 & & & \\ 009 & & & \\ 005 & & & & \\ & & & \end{array}$


4. OUTPUT; PLOT MAP VERSION, FOR FIELD AMNOTATION

(from Program PLOTMAP)

RECORDED: 02/09/75 BY: WA/DF/ / WYTHAM PLOT: 457/086

ASH SAPLINGS WITH ONE SYCAMORE OVER BROW OF HILL.

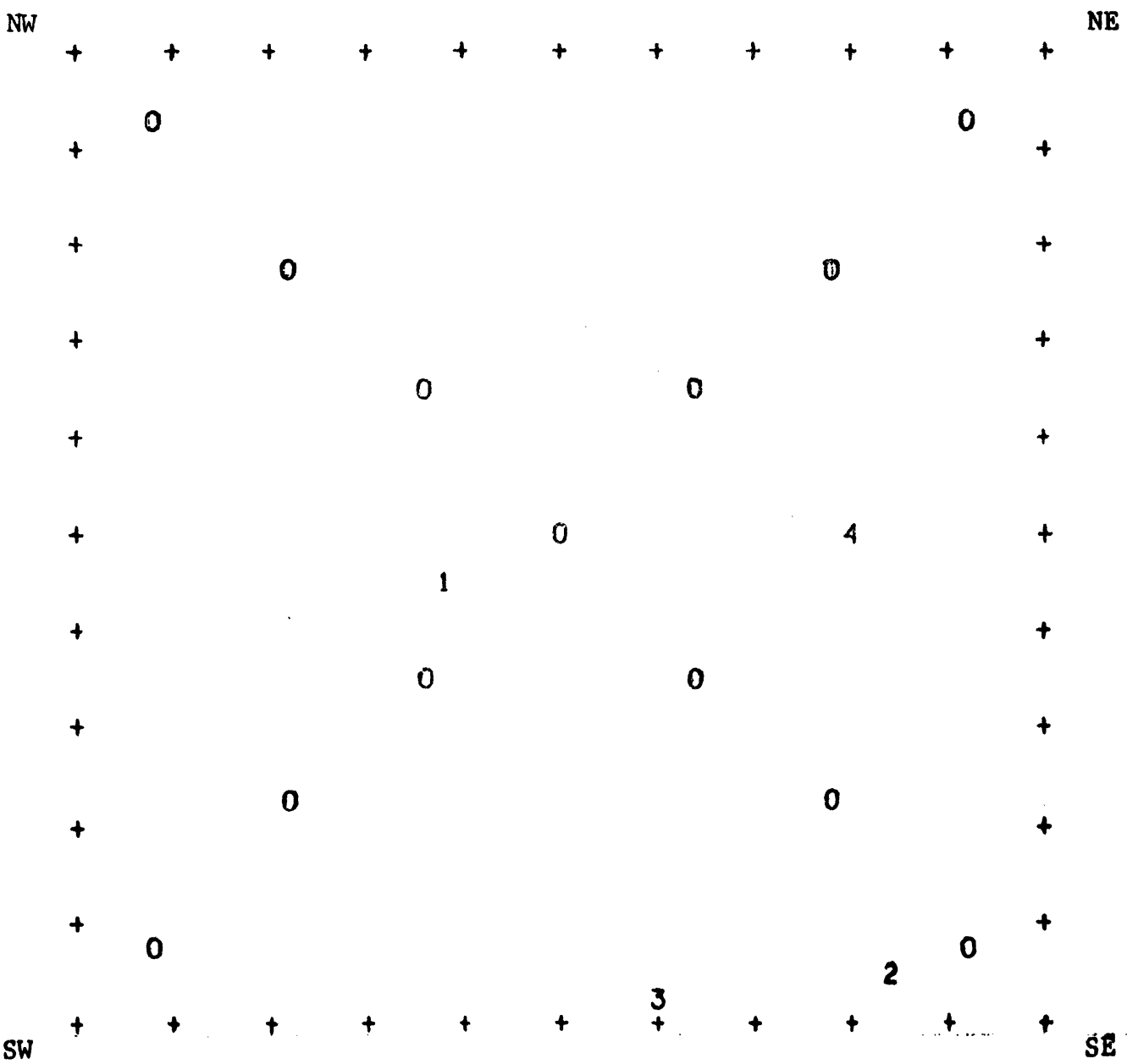

\begin{tabular}{|c|c|c|c|c|c|c|c|c|c|c|c|}
\hline RELAS & KOP & SW & CAI & NOPY & PERCI & & $\mathrm{ECOS}$ & & SCORE & ELASI & \\
\hline ACER & PSE & 4 & ACER & PSE & 70 & RUBUS & FRU & 5 & ACER & PSE & 4 \\
\hline FRAXI & EXC & 5 & FRAXI & EXC & 50 & PTERI & $\mathrm{AQU}$ & 0 & FRAXI & EXC & 1 \\
\hline & & & & & & MERCU & PER & 2 & & & \\
\hline & & & & & & CHAMA & ANG & 0 & & & \\
\hline & & & & & & ENDYM & NON & 0 & & & \\
\hline & & & & & & URTIC & DIO & 0 & & & \\
\hline
\end{tabular}

L_E_A_D_I_N_G

\begin{tabular}{|c|c|c|c|c|c|c|}
\hline No & SPECIES & DIAM & HT & CR & IMPEDERS & \\
\hline 1 & ACER PSE & 47 & 11 & 5 & 0 & \\
\hline 2 & FRAXI EXC & 8 & - & 4 & FRAXI EXC & \\
\hline 3 & FRAXI EXC & 7 & - & 4 & FRAXI EXC & \\
\hline 4 & FRAXI EXC & 6 & - & 4 & FRAXI EXC & ACER PSE \\
\hline
\end{tabular}


5. OUTPUT: FROM HALTON SAMPIE

Example of Terminal Species List

*ALL SPECIES IN THE AREA, (= 305) SORTED ON:

ALPH

CODE

FREQUENCY.

\begin{tabular}{|c|c|c|c|c|c|c|c|c|}
\hline \multicolumn{2}{|l|}{. LITR } & 003 & 001 & PICEA & $A B I$ & 123 & . LITR & \\
\hline \multicolumn{2}{|l|}{. MOSS } & 006 & 002 & FRAXI & EXC & 123 & .MOSS & \\
\hline MOSS & $\mathrm{MAT}$ & 007 & 003 & . LITR & & 123 & .MOSS & MAT \\
\hline \multicolumn{2}{|c|}{ SOIL } & 004 & 004 & SOIL & & 123 & . SOIL & \\
\hline \multicolumn{2}{|l|}{. STNE } & 005 & 005 & . STNE & & 123 & - STNE & \\
\hline ABIES & GRA & 197 & 006 & MOSS & & 104 & FAGUS & SYL \\
\hline ACER & CAM & 028 & 007 & .MOSS & MAT & 94 & RUBUS & FRU \\
\hline \multirow{2}{*}{$\begin{array}{l}\text { ACER } \\
\text { A CER }\end{array}$} & PIA & 174 & 008 & FAGUS & SYI & 77 & FRAXI & EXC \\
\hline & PSE & 030 & 009 & ROSA & SP & $7 / 4$ & MERCII & PER \\
\hline ACHIL & MIL & 157 & 010 & QVERC & ROB & 73 & BRACH & SYL \\
\hline \multirow{2}{*}{$\begin{array}{l}\text { AESCU } \\
\text { AGRIM }\end{array}$} & HIP & $07 / 4$ & 0.11 & PLNUS & SYI, & $6 \sqrt{6}$ & HYPN: & MOS \\
\hline & EUP & 153 & 012 & SAMBU & $N T^{\circ}$ & & DESCH & $\mathrm{CAE}$ \\
\hline \multirow[t]{4}{*}{ "OP } & CAN & 053 & 013 & $C R A^{T A}$ & & & - กIA & RIV \\
\hline & REP & 134 & 014 & $r$ & & & & $\mathrm{BI}$ \\
\hline & & 288 & 01 & & & & & \\
\hline & & 191 & & & & & & \\
\hline
\end{tabular}

( 1 is t interrupte d)

UIMUS

UIMUS GLA

ULMUS PRO

URTIC DIO

VALER OF?

VALER OFF?

VERBA TH?

VERON ARV 124

VERON CHA 127

VERON MON 193

VERON SP 290

VIBUR IAN 029

VICIA SAT 291

VIOIA HIR 125

VIOIA RIV 051

VIOLA ODO 158

$-999$

End of tist

$\begin{array}{lll}\text { UU MOL } & 1 & \\ \text { VERON SP } & 1 & \text { L. } \\ \text { VICIA SAT } & 1 & \text { ULML } \\ \text { LUZUL CA? } & 1 & \text { ULMUS L } \\ \text { RUMEX EIA } & 1 & \text { ASPER CYN } \\ \text { ORIGA VU? } & 1 & \text { ATROP BEL } \\ \text { SCABI SP } & 1 & \text { VALER OF? } \\ \text { SILEN VUL } & 1 & \text { VALER OFF } \\ \text { CAREX SY? } & 1 & \text { VERBA TH? } \\ \text { ULMUS GIA } & 1 & \text { VERON ARV } \\ \text { POPUL NIG } & 1 & \text { MILIU MON } \\ \text { LYSIM NUM } & 1 & \text { VERON MON } \\ \text { DESCH CAM } & 1 & \text { MNIUM HOR } \\ \text { HORDE EUR } & 1 & \text { BROMU ER? } \\ \text { SAGIN AP? } & 1 & \text { MOEHA SAT TRI } \\ \text { CALAM EPI } & 1 & \text { BROMU STE } \\ \text { JUNCU CON } & 1 & \text { VIOIO ODO }\end{array}$

$\begin{array}{rr} & \\ & \text { UU MOL } \\ & \text { VERON SP } \\ 292 & \text { VICIA SAT } \\ 293 & \text { LUZUL CA? } \\ 294 & \text { ORIMX EIA } \\ 295 & \text { SCABI SP } \\ 296 & \text { SILEN VUL } \\ 297 & \text { CAREX SY? } \\ 298 & \text { ULMUS GIA } \\ 299 & \text { POPUL NIG } \\ 300 & \text { LYSIM NUM } \\ 301 . & \text { DESCH CAM } \\ 302 & \text { HORDE EUR } \\ 303 & \text { SAGIN AP? } \\ 304 & \text { CALAM EPI } \\ 305 & \text { JUNCU CON } \\ & \end{array}$

ULML

ULMUS ᄂ

ASPER CYN

ATROP BEL

VALER OF?

VALER OFF

VERBA TH?

VERON ARV

MNIUM HOR

BROMU ER?

VICIA SAT

VIOLO ODO 


\title{
and papers consulted
}

\author{
Allen, S.E. 1974. Chemical analyses of ecological materials. \\ Blackwe11, Oxford. \\ Badan, (1966) Inventaires par Echantillonage; Chapter in \\ Instructions d'amenagement, 1966 , \\ Service Cantonal des Forets, Vaud, Suisse
}

Bates, R.G. (1964). Determination of $\mathrm{pH}$ : Theory and practice. John Wiley, New York.

Bunce, R.G.H. and Shaw, M.A. (1973). A standardized procedure for ecological survey.

J. Env. Man. 1, 239-258.

Burley, J., Andrew, I.A. and Palmer, J.R. (1974). Information collection, storage and retrieval in forestry.

Paper to 10th Comm. For. Conf. 1974.

Colani, C. (1966). A new type of locating device.

Archaeometry, 9, 3-8.

Colani, C. and Aitken, M.J. (1966). A new type of locating device;

II. Field Trials.

Trials.

Archaeometry, 9, 9-19.

Colani, C. and Aitken, M.J. (1966). Utilization of magnetic viscosity effects in soil for archaeological prospection. Nature $212,1446-7$.

Cousens, J.E. (1957). The sampling of regenerated forest in Malaya. Paper for Brit. Comm. For. Conf. 1957, Pp. 22.

Davis, T.A.W. and Richards, P.W. (1934). The vegetation of Moraballi Creek, British Guiana, Part II.

J. Eco1. 22, 106-55.

Dawkins, H.C. (1958) The management of natural tropical high forest with special reference to Uganda.

Institute Paper No. 34. Comm. For. Inst., Oxford.

Dawkins, H.C. (1952). Experiments with low percentage enumerations in tropical high forest.

Emp. For. Rev. 31, 131-45.

Dawkins, H.C. (1971). Techniques for long-term diagnosis and prediction in forest communities.

Paper in: The scientific management of animal and plant communities, 33-44.

11th Symposium Brit. Ecol. Soc., Norwich, July 1970. 
Dunham, Sir K. (1973). The advancement of environmental science. Brit. Assoc. Advancement of Science, Canterbury Meeting, 1973.

Eggeling, W.J.. (1947). Observations on the ecology of Budongo Forest, Uganda, J. Eco1. 34, 20-87.

Field, D.R.B. (1976). Surveillance of Woodland.

in Applications of ALGOL-68. Proc. Conf. Univ. of E. Anglia, 1976.

Foster, T. and Hackens, T. (1969). Decco metal detector survey on Delos, Archaeometry, 11, 165-72.

Fox, J.E.D. (1970). Yield plots in regenerating forests. Malay. Forester 33, 7-41.

Hamilton, G.J. and Christie, J.M. (1971). Forest Management Tables (Metric). For. Comm. Booklet No. 34;

Stationery office.

Letourneau, L. (1966). A forestry inventory by continuous forest control. Forestry Chron. 42, 414-9.

Lloyd, P.S., Moffett, U. and Windle, D.W. (1972). Computer storage and retrieval of botanical survey data.

J. Appl. Ecol. 9, 1-10.

Loetsch, F., Zöhrer, Z. and Haller, K.E. (1973). Forest Inventory, Vol. 2. BLV Verlags., München.

Morris, M.J. (1973). Estimating understorey cover with rated microplots. U.S.D.A. Forest Service Res. Paper RM-104, Apri1, 1973.

Nea1, D.L. and Nea1, J.L. (1973). Uses and capabilities of electronic capacitance instruments for estimating standing herbage. J.Br. Grassland Soc. 28, 81-9.

O'Regan, W.G., Seegrist, D.W. and Hubbard, R.L. (1973). Computer simulation and vegetation sampling.

J.Wild1. Management 37, 217-22.

Rudeforth, C.C. and Webster, R. (1973). Indexing and display of soil survey data by means of feature cards and Boolean maps.

Geoderma 9, 229-48.

Schmid, P. and Werner, J. (1970). Swiss continuous forest inventory, Instructions. Swiss Forest Research Institute, Birmensdor $\mathrm{f}$, Zurich.

Shain, W.A. and Rudolph, V.J. (1965). Continuous forest inventory in American forest management.

Quart. Bu11. Minn. State Univ. Agr. Expt. Sta. 47 (3), 387-429. 
Schantz, H.L. and Turner, B.L. (1958). Vegetational changes in

Africa over a third of a century.

Rep. No. 169, College of Agriculture,

University of Arizona.

Shaw, M.W. and Bunce, R.G.H. (1971). Nationa1 Woodlands Classiflcation 1971 Handbook of field methods.

Woodland Research Section, Merlewood, Mimeo July 1971.

S.P.N.R. (1969). Biological sites recording scheme.

S.P.N.R. Conservation Liais on Committee Tech.

Pub. No. 1 .

Sykes, J.M. and Horri11, A.D. (1976). Kirkconne11 Flow Nature

Reserve; Report on a vegetation survey.

Institute of Terrestrial Ecology, 1976.

Vos. J.E. (1964). Sampling in space and time.

Rev. Inst. Statist. Inst. 32, 226-41.

Wadsworth, R.M. (1970). An invisible marker for experimental plots.

J. Eco1. 58, 555-7.

Ware, K.D. (1962). Continuous forest inventory with partial replacement. Forest Sci. Monog. No. 3.

Wyatt-Smith, J. (1962). The swing from qualitative to quantitative assessment of individual tree crown parameters in the Malayan Forest Service.

Malayan Forester 26, 276-91. 


\section{Fig.17 Plot distribution - Bix}

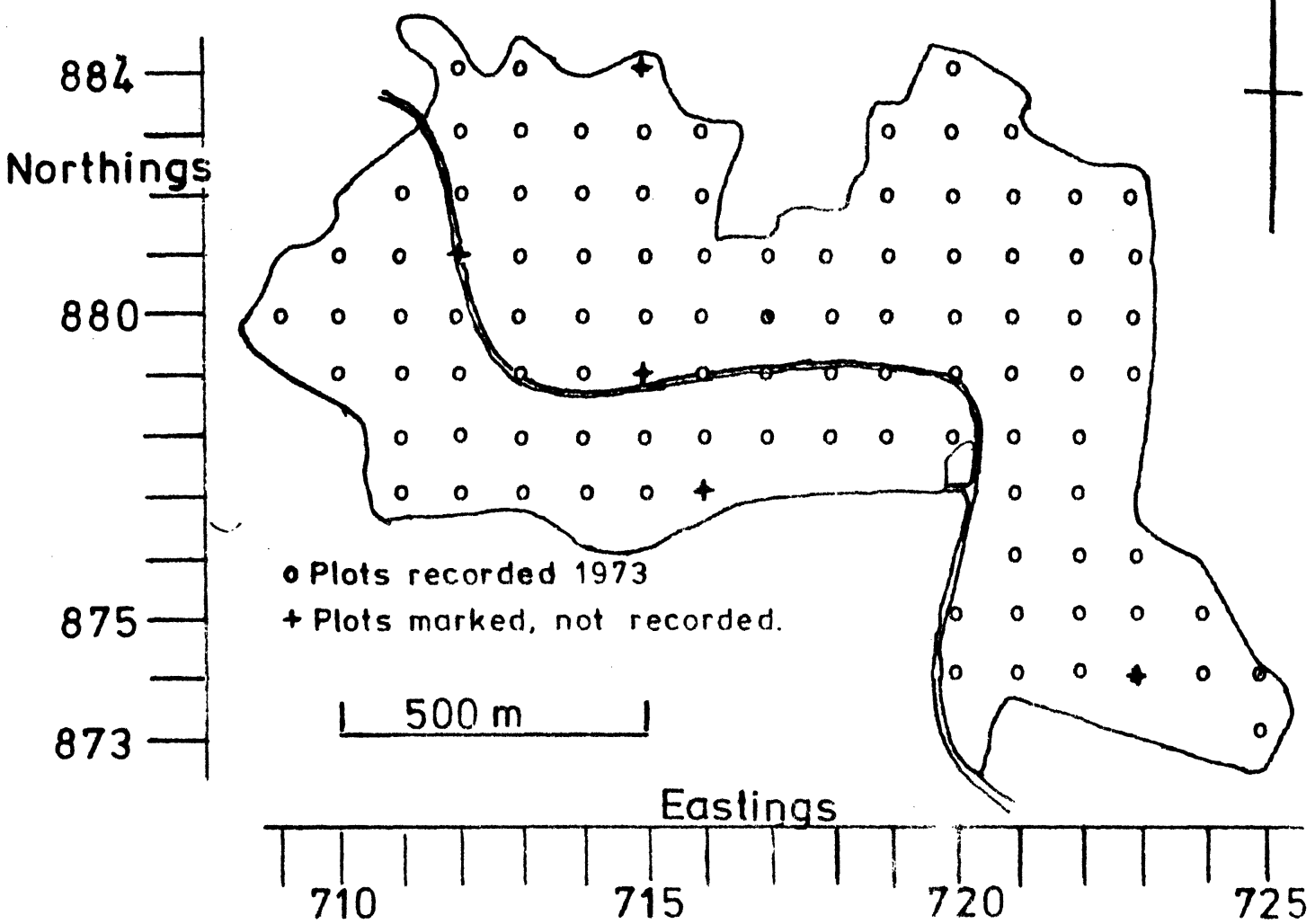

The same - if sampled at half the intensity

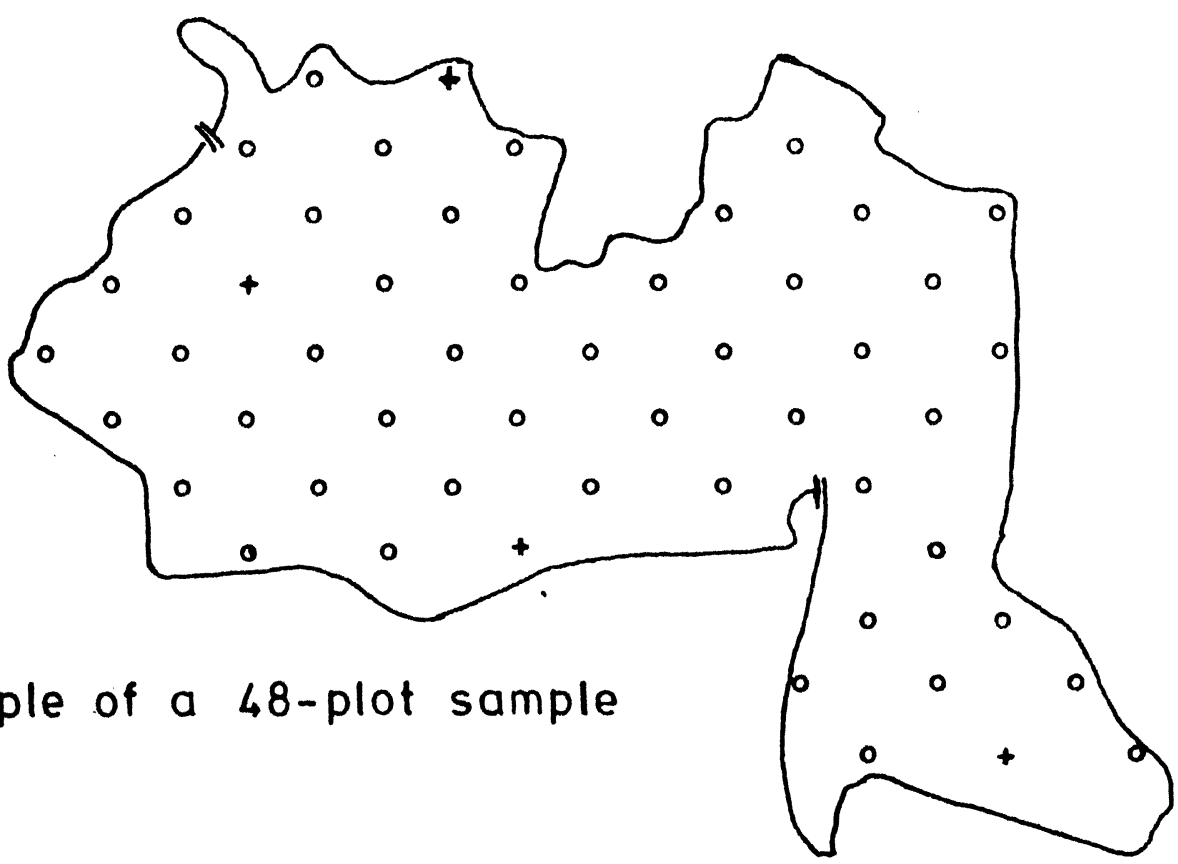

Example of a 48-plot sample 


\section{Fig. 18 Plot distribution, Wytham}

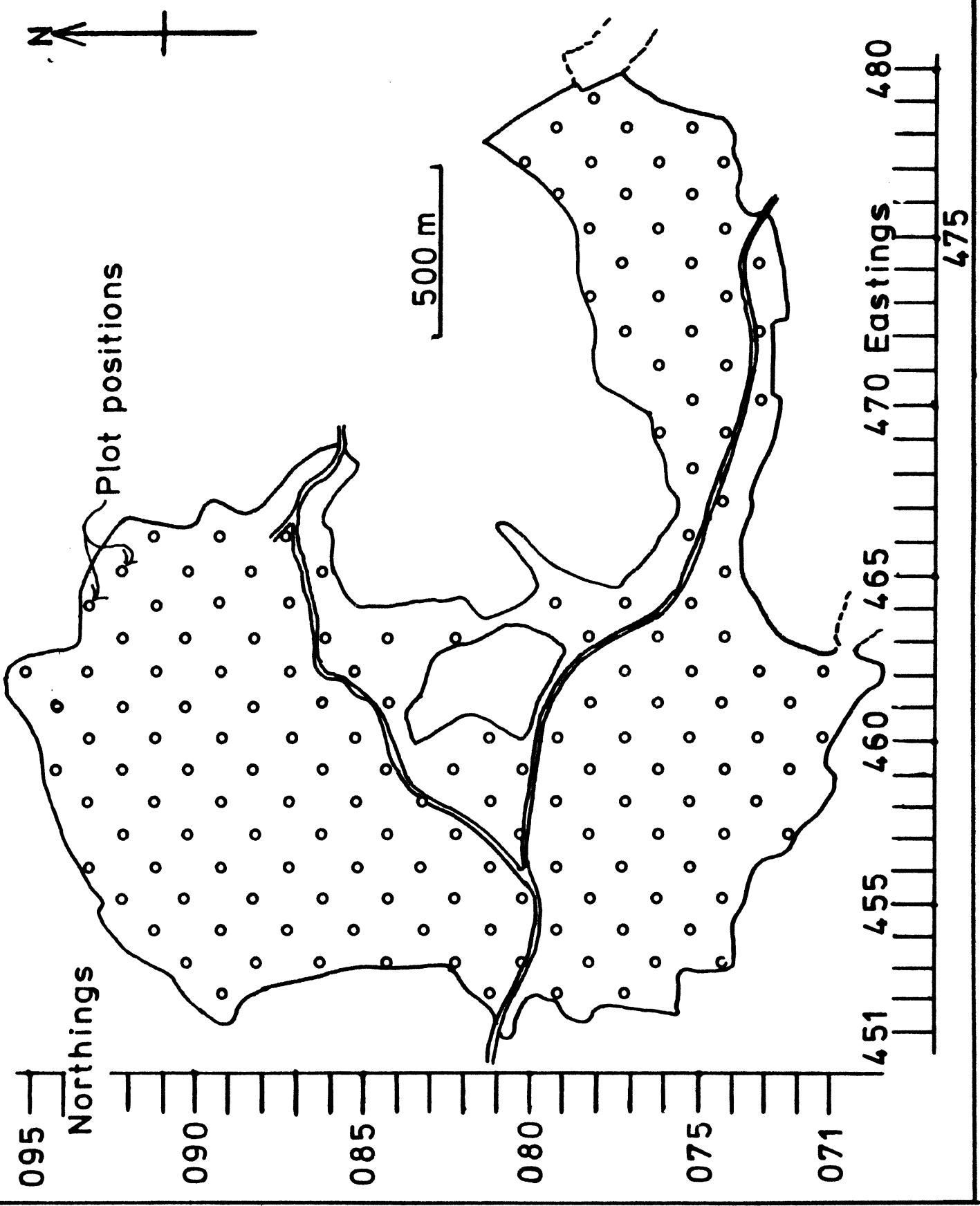




\section{Fig.19 Plot distribution, Halton}

- Plots

+ Unusable sites

- Stakes

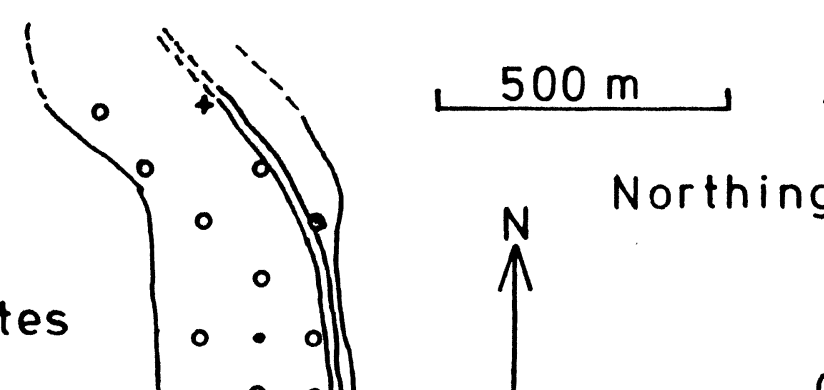

095

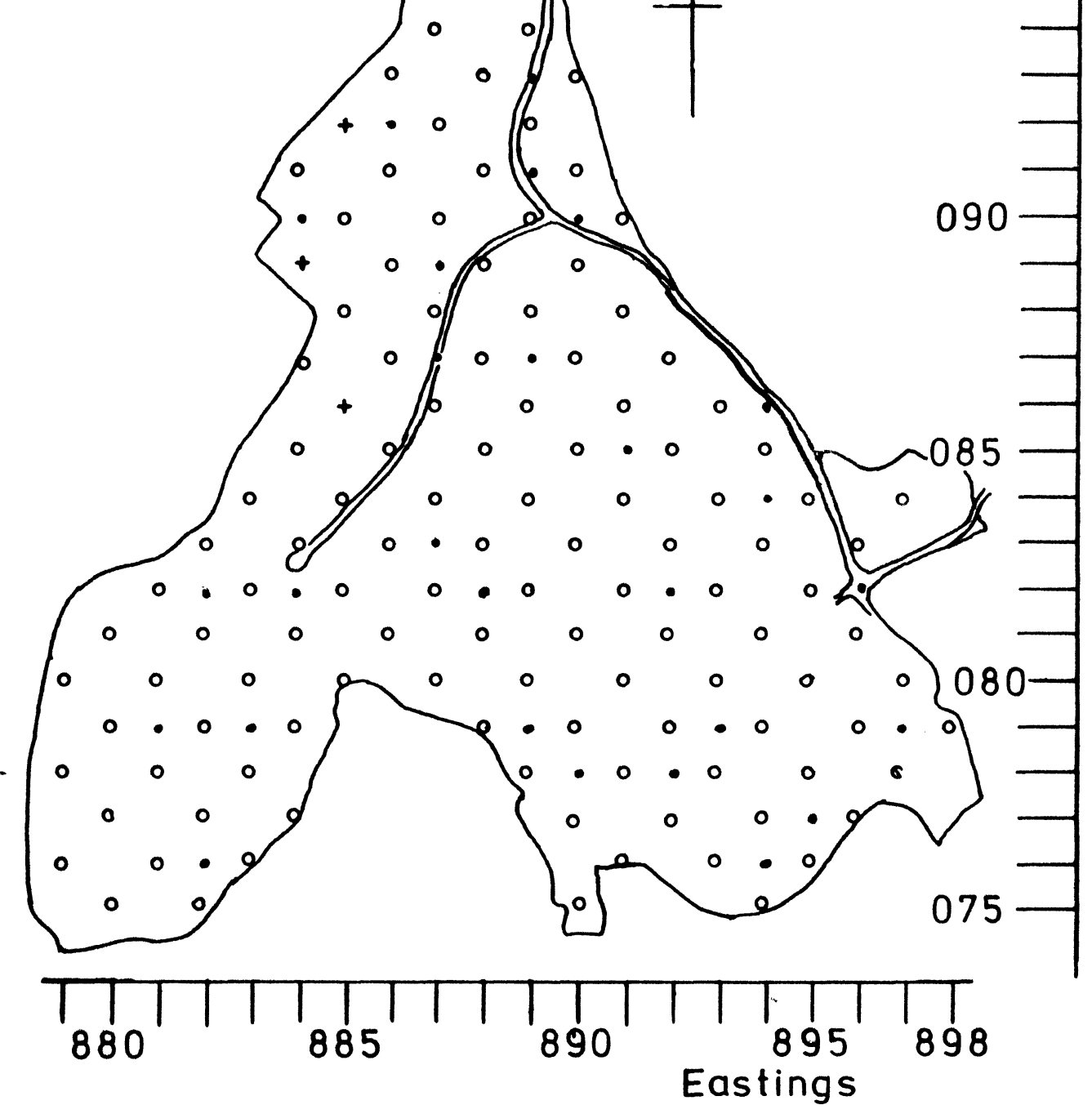




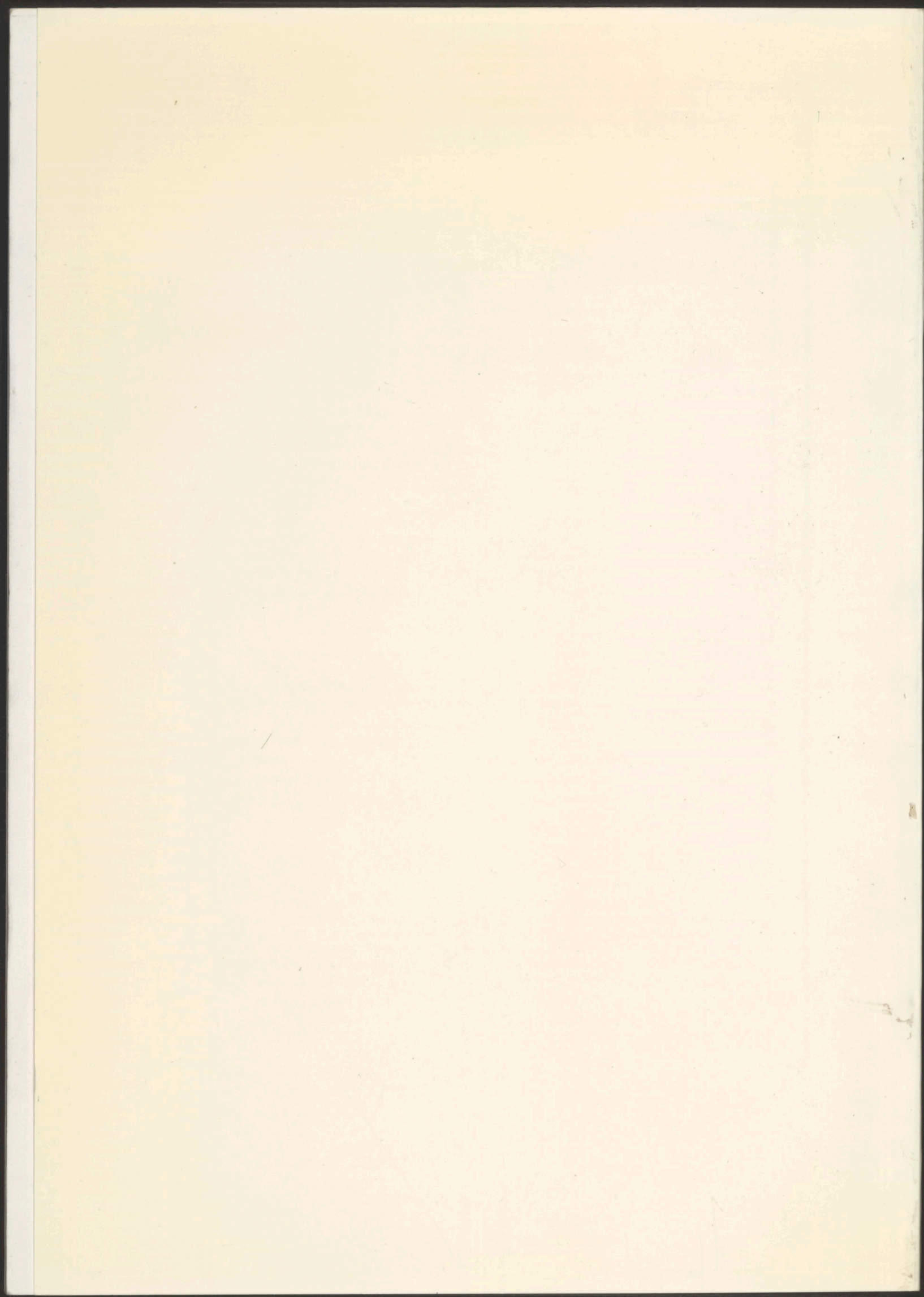




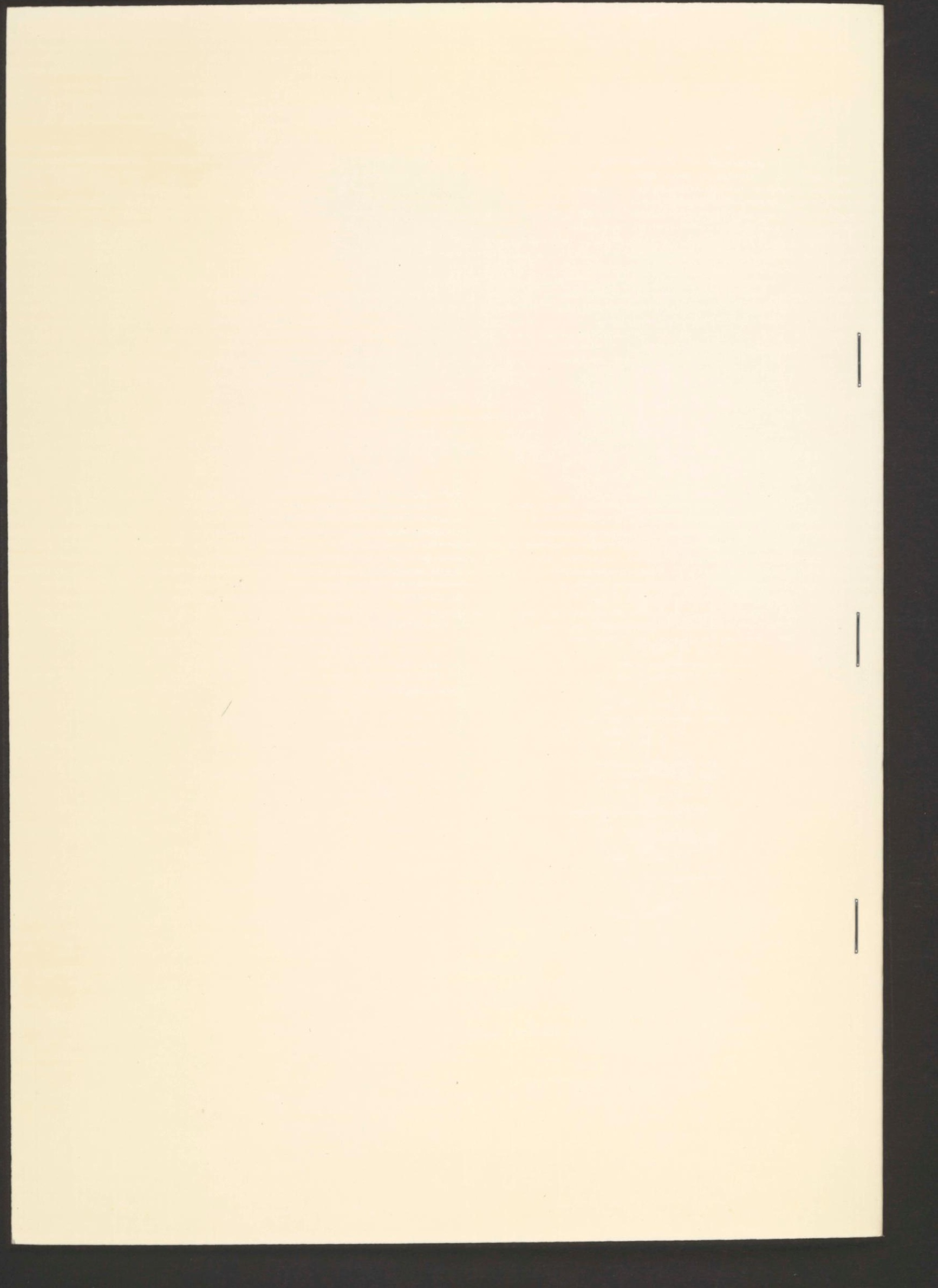

